\title{
Rheumatology 2.0
}

EMPOWERING PATIENTS BY EHEALTH 


\section{RHEUMATOLOGY 2.0 EMPOWERING PATIENTS BY EHEALTH}

Rosalie van der Vaart 
Thesis, University of Twente, 2013

(C) Rosalie van der Vaart

Coverdesign by Niels van Dijk, www.nevandijk.nl

Printed by Gildeprint Drukkerijen, Enschede, the Netherlands

With financial support of Reumafonds (Dutch Arthritis Foundation) and dr. G.J. van Hoytema Stichting.

The studies presented in this thesis were financially supported by the Institute for Behavioral Research (IBR) at the University of Twente; Pfizer Inc and MSD BV.

ISBN: 978-90-365-3533-5

DOI: $10.3990 / 1.9789036535335$ 


\title{
RHEUMATOLOGY 2.0 EMPOWERING PATIENTS BY EHEALTH
}

\author{
PROEFSCHRIFT \\ ter verkrijging van \\ de graad van doctor aan de Universiteit Twente, \\ op gezag van de rector magnificus, \\ Prof. dr. H. Brinksma, \\ volgens besluit van het College van Promoties \\ in het openbaar te verdedigen \\ op vrijdag 31 mei 2013 om 16:45 uur \\ door \\ Rosalie van der Vaart \\ geboren op 26 juni 1986 \\ te Ermelo
}


Dit proefschrift is goedgekeurd door de promotor Prof. dr. M.A.F.J. van de Laar en de assistent-promotoren dr. C.H.C. Drossaert en dr. E. Taal. 


\section{Samenstelling promotiecommissie}

Promotor:

Assistent-promotoren:

Leden:
Prof. dr. M.A.F.J. van de Laar

(Universiteit Twente; Medisch Spectrum Twente)

Dr. C.H.C. Drossaert

(Universiteit Twente)

Dr. E. Taal

(Universiteit Twente)

Prof. dr. K.M.G. Schreurs

(Universiteit Twente; Roessingh Research \&

Development)

Prof. dr. R. Sanderman

(Universiteit Twente; Rijksuniversiteit Groningen)

Dr. J.E.W.C. van Gemert-Pijnen

(Universiteit Twente)

Prof. dr. J. Kremer

(UMC St. Radboud)

Prof. dr. M.J. Sorbi

(Universiteit Utrecht)

Prof. dr. S. Newman

(City University London) 



\section{Contents}

Chapter 1 General introduction

Chapter 2 Experiences and preferences of patients regarding a rheumatology Interactive Health Communication Application: a qualitative study

Chapter 3 Patient preferences for a hospital-based rheumatology Interactive Health Communication Application and factors associated with these preferences

Chapter 4 Giving rheumatology patients online home access to their electronic medical record (EMR): advantages, drawbacks and preconditions according to care providers

Chapter 5 Validation of the Dutch functional, communicative and critical health literacy scales

Chapter 6 Does the eHealth Literacy Scale (eHEALS) measure what it intends to measure? Validation of a Dutch version of the eHEALS in two adult populations

Chapter $7 \quad$ Measuring actual eHealth literacy among patients with rheumatic diseases: a qualitative analysis of problems encountered using Health 1.0 and Health 2.0 applications

Chapter 8 Design and implementation of the rheumatology patient web portal

Chapter 9 Impact of patient-accessible Electronic Medical Records in rheumatology: use, satisfaction and effects on empowerment among patients

Chapter 10 General discussion

Chapter 11 Summary

Samenvatting (Summary in Dutch)

Dankwoord (Acknowledgements)

List of publications 

Chapter 1

General introduction 
Rheumatic diseases are common, chronic auto-immune diseases characterized by symptoms as pain, tender and swollen joints, stiffness, functional limitations and fatigue. Often these diseases have a substantial impact on patients' physical and psychological well-being. Many patients suffering from rheumatic diseases experience impaired functioning and are limited in general activities, such as working, social relationships and leisure [1-3].

Since rheumatic diseases have such an influence on patients' daily lives, it is essential that patients learn how to adapt to their condition and cope with the limitations it causes. Essential self-care behaviors that patients should master are, for example, medication adherence, exercising appropriately, and identifying the limits and boundaries of their capabilities and energy [4]. Therefore, key components in the treatment of rheumatic diseases are education and assistance in coping with the disease, to ensure that patients have the knowledge and skills to self-manage their disease [5]. Increasing the personal responsibility and involvement of patients in health care is not only beneficial for patients themselves, it is encouraged from an economic perspective as well. Since the demands on health care are growing, due to the aging population and the increasing amount of chronic diseases, a shift in the responsibility of health management is essential [6-9]. To be able to manage health care efficiently and keep expenses under control, patients should be empowered and encouraged to become an active participant in their own care process. Information provision and self-care support play an important role in this $[10,11]$.

\section{Rheumatology 2.0}

Utilizing information and communication technology in health care, also called "eHealth", has a large potential to shift the direction in health care to a more patient-centered perspective [12]. The use of Internet can expand the care for patients beyond the walls of health care institutions, by offering patients self-care tools from the comfort of their own home [13-16]. Today, many patients already use the Internet to retrieve health information [17]. Patients see it as a key source of health information [18,19], and the number of health-related websites is increasing rapidly. When typing the word 'arthritis' in a popular online search engine, over 99 million search results are found, of which many are informational websites on symptoms, diagnosis, treatment, and available care and support for patients suffering from rheumatic diseases. Patients can benefit from this information by broadening their knowledge and by finding support on how to cope with their disease $[20,21]$.

In recent years, the Internet has evolved and has become much more than a onesided provider of information. New developments in technology enable online interactivity, such as online communication and web applications that ask for input of users. These so-called Web 2.0 features enable a growing number of opportunities to change the way health care is delivered, and to empower patients by enhancing their involvement in their treatment [22-24]. Therefore, the term Health 2.0 or Medicine 2.0 is often used, which is defined as "applications, services, and tools that are web-based services for healthcare consumers, caregivers, patients, health professionals, and 
biomedical researchers that use Web 2.0 technologies (...) to enable and facilitate social networking, participation, apomediation, collaboration, and openness within and between these user groups" [22]. Well-known examples of Health 2.0 applications related to communication are peer support forums, through which patients can contact each other to share experiences and to find acknowledgement and support among each other [25]. Besides these support forums, more advanced online applications have been developed in rheumatology over the past years. For example, monitoring applications, which provide patients insight in their disease activity, their pain over time or their well-being have become available [26]. Furthermore, online interactive courses have been developed to teach patients how to enhance their self-management skills when coping with their rheumatic disease $[27,28]$.

Health 2.0 applications can be initiated and developed by individuals, by commercial organizations, by governmental organizations, or by health care institutions. Currently, hospitals show an increasing interest to develop online applications embedded in their care process. A growing number of care providers offer, for example, online consultations which facilitate care at a distance [29]. Additionally, to increase patients' participation in their treatment, they can be offer services such as online access to medical records and online decision aids. These services supply patients tailored information on their current treatment and their treatment options, which enable them to be more involved in monitoring and managing their disease, and to participate in treatment decisions [30,31]. When several (hospital-based) online applications are combined into one 'interactive health communication application' or patient web portal, patients can access all their disease-related information, communication and participation tools using one web address [32]. From previous studies it is assumed that providing patients with such a service can improve health care on several levels, by enhancing patient satisfaction, the quality of care, and patient empowerment [33-35].

Although hospital-based patient web portals may generate an extension of health care, current research on the use of health technologies in clinical practice shows that the development and implementation of a valuable application is a complex process $[24,36]$. Often, technologies are implemented simply because they are available [14], without taking the end-users into account $[37,38]$. This approach can frustrate uptake and proper use of online applications [39]. The aim of this thesis was to develop, implement and evaluate a hospital-based patient web portal, based on user-centered studies in rheumatology, in order to empower patients in their treatment.

\section{Connecting to end-users' needs: a bottom-up development}

Up until now, only little was known about how rheumatology patients use the Internet in relation to their health. Also, no studies have been performed on what rheumatic patients' needs and preferences for a web portal would be, in order to offer a combination of services from the hospital [27,28,40,41]. Previous studies on implementation of health technologies have shown, however, that different patients perceive benefit from different sorts of information, communication and participation services, depending on personal characteristics, disease characteristics, or the stage of their illness [42-46]. Therefore, in order to fit an online application to the preferences of 
the end-user, it is essential to take this information into account and to assess patients' needs beforehand, in order to prevent disappointing usage [15,39,47,48].

From the care provider perspective, there are also several reasons why proper implementation of health technologies is hindered [49]. Some care providers doubt the effectiveness of these applications, since grounded proof on their impact and costeffectiveness is still scarce [15,36,49]. Also, care providers show concerns about the benefits of working with eHealth applications for themselves, the potential for added work, changes in work processes, lack of reimbursement, and inappropriate use by patients $[50,51]$. This resistance in clinical practice hampers the implementation of online applications into care programs, or complicates the continuity of eHealth programs into regular care when a pilot program finishes. Since no studies among rheumatology professionals, addressing these matters, have been conducted before, their preferences and barriers related to health technology must be analyzed as well, in order to embed the application in the care process [52].

The aforementioned needs assessments encourage a bottom-up development of online applications, in dialogue with the end-users. To map the different stages that are essential in this development, a roadmap was designed at the Centre for eHealth Research and Disease Management of the University of Twente; the CeHRes Roadmap [53]. This roadmap provides an overview of the steps that need to be attained in the process of eHealth development from beginning to end, taking all possible facilitators and barriers into account. Essential in the roadmap is the involvement of key stakeholders, to create an application which is broadly supported. The roadmap is based on six underlying principles: eHealth technology development is a participatory process, it involves continuous evaluation cycles, it is intertwined with implementation, it changes the organization of health care, it should involve persuasive design techniques, and it needs advanced methods to assess impact. The model consists of five steps which depict the developmental process and accompanying research activities that should be performed to come to a final product, while taking the underlying core principles into account [53]. The first step is contextual inquiry, which entails information gathering from the intended users and the environment in which the technology will be implemented. Using this information, developers can specify how eHealth applications can solve existing problems or fill existing gaps in health care. Second, value specification among the intended users and key stakeholders is necessary to gain an overview of the perceived benefits and barriers of an application and to define its requirements. These two steps are followed by the design phase, in which prototypes are built. These prototypes are tested with the endusers in several rounds in order to match content, format and navigation, and users' needs respectively [53]. When the final design is completed, the operational phase starts in step 4 , in which the application is introduced in practice. In this phase the application needs to be adopted by the end-users, which calls for communication in the clinical setting. Finally, the fifth step is the evaluation of the application. This phase should involve evaluation on the uptake of the application, as well as evaluation of the impact of the application. While this roadmap is rather new and it has not been fully validated yet, it offers a grounded method to develop our application from a user perspective. 


\section{Connecting to patients skills: measuring (e)Health literacy}

Aside from needs and preferences, another key determinant of success in online applications, is patients' capacities to use a service [54]. Therefore, an eHealth technology should fit users' skills to utilize computers and the Internet $[55,56]$. To fully profit from online health information and applications, patients need a certain level of "eHealth literacy" $[54,57,58]$. Being eHealth literate comprises being able to seek, find, understand, and evaluate health information from electronic sources and apply the knowledge gained to addressing or solving a health problem [54]. Previous research already found that many people struggle with searching and evaluating health information on the Internet $[59,60]$. Up until now, however, no research has been done on eHealth literacy among (rheumatology) patients, and we have no insight into their skills to use online information and eHealth applications. While an instrument that aims to measure peoples' skills to retrieve and use online health information exists [54], this instrument has not been validated yet. Moreover, it only measures skills in retrieving information, while recent Health 2.0 applications ask more from patients. When using interactive applications, patients also have to be able to add personal content to the web, mind who the reader of their content will be, and ascertain the privacy of themselves and others $[22,61]$. Currently, websites and interactive applications are often designed by web-technologists who have little knowledge of the exact target group and their skills. Generally they do not take the complexity of the application into account, which reduces the usability for a broad range of people [42,62]. As a result, many tools that are created to help and educate patients are actually inaccessible to them [54], which hinders the effect of the application as well $[55,63]$. Therefore, it is essential to gain more insight into patients' (e)health literacy levels and in ways to measure eHealth literacy properly.

\section{Outline of this thesis}

Taking the above mentioned necessities into account, in this project a multidisciplinary team of researchers, patients, rheumatologists, nurses, designers, decision makers and programmers have been working together to create an interactive patient web portal within rheumatology. The research to sustain the whole process is described in this thesis.

The first chapters of this thesis outline three studies which were conducted to capture contextual inquiry and value specification of the patient web portal, by exploring the needs, preferences and perceived drawbacks of (different groups of) patients and health care professionals. In chapter 2, patients with rheumatic diseases were interviewed to gain an overview of their current Internet use, their vision on seven online information, communication and participation tools which could improve their involvement in treatment, and their motivations and requirements to use those tools. Subsequently, in chapter 3 the results of this explorative study were validated in a quantitative survey study. Using a survey, patients were asked if they intended to use online support tools if they would be provided by their hospital. Moreover, differences in needs between groups of patients were explored, related to socio-demographics, health characteristics and health literacy. To assess the feasibility of patients' needs for online information and support, and the possible impact of a patient web portal on clinical practice, we explored 
perceived facilitators and barriers among rheumatology care professionals. Chapter 4 focuses on care providers' views related to patient home-access to their electronic medical records (EMR). In this study, a 2-step Delphi approach was used, in which rheumatologists and nurses/nurse practitioners were interviewed on possible advantages and drawbacks, and essential preconditions of this service. Subsequently, the same sample of care providers was asked to complete a survey, based on the obtained qualitative data, to quantify the responses. Using these results, we were able to translate the needs of patients into an application that could be integrated in current health care with support of care providers.

To improve the consensus between the usability level of the application and patients' skills, three studies were performed on patients' eHealth literacy. Since eHealth literacy is such a broad concept, which covers a combination of skills, there is no consensus on how to measure this ability in literature. In order to gain insight into the assessment of eHealth literacy, two promising instruments were validated for the Dutch situation. In chapter 5, the validity of a Dutch translation of the Functional, Communicative and Critical health literacy scales by Ishikawa et al [64] is examined. This instrument lays large emphasis on the critical appraisal of health information, which is essential when using online information. The reliability and the structural, convergent and content validity of this instrument were examined in two quantitative survey studies and in one qualitative study, using cognitive interviewing, among patients with rheumatic diseases. Chapter 6 investigates the validity of the eHealth Literacy Scale (eHEALS) [65], the only existing instrument that aims to measure eHealth literacy. In this study the internal consistency and the construct and predictive validity of a Dutch translation of the eHEALS were analyzed. To gain more insight into the problems that patients with rheumatic diseases encounter when using the Internet, an observational study was performed, which is described in chapter 7. This study focuses on both information retrieval skills (Health 1.0) and skills to use interactive applications (Health 2.0), such as e-consultations or accessing electronic medical records.

Using the previous studies as building blocks for the content and usability of the application, we started the design phase of our rheumatology patient web portal. In this phase, patients were involved again, following participatory design principles [66]. Chapter 8 provides an overview of the design and implementation process of the patient web portal, including screen shots of the final product. The last study described in this thesis, chapter 9, focuses on the evaluation of the patient web portal and the actual impact that it has. The use, satisfaction and effects of the application on empowerment were assessed in a pretest-posttest study, among patients suffering from rheumatoid arthritis. Changes (from pretest to posttest) on perceived satisfaction with care, trust in the rheumatologist, self-efficacy in patient-provider communication, illness perception, and medication adherence were assessed to explore the effect of the application. In addition, patients were also asked about their perceived changes on these outcome measures. 
Chapter 10 contains a general discussion of the results and elaborates on the implications of all the steps taken in the developmental process. Furthermore, future research directions are explored. Chapter $\mathbf{1 1}$ offers summaries in English and Dutch of all the research findings described in this thesis, including perspectives for future research and clinical practice. 


\section{References}

1 Abraido-Lanza AF, Revenson TA. Illness intrusion and psychological adjustment to rheumatic diseases: a social identity framework. Arthritis Rheum 2006; 55: 224232.

2 Vriezekolk J. Targeting distress in rheumatic diseases. (Doctoral Dissertation): University of Utrecht, the Netherlands; 2012.

3 Taal E, Hagens P, Braakman-Jansen L, van de Laar MAFJ. Perceived restrictions in participation in life situations among patients with rheumatoid arthritis. Arthritis Rheum 2009; 60(Suppl10): 2080.

$4 \quad$ Katz PP. The stresses of rheumatoid arthritis: Appraisals of perceived impact and coping efficacy. Arthritis Care Res 1998; 11: 9-22.

5 Arvidsson S, Bergman S, Arvidsson B, Fridlund B, Tingström P. Psychometric properties of the Swedish Rheumatic Disease Empowerment Scale, SWE-RES-23. Musculoskelet Care 2012; 10(2): 101-9.

6 Carlin CS, Christianson JB, Keenan P, Finch M. Chronic Illness and Patient Satisfaction. Health Serv Res 2012; 47(6): 2250-72.

7 Newman S, Steed L, Mulligan K. Self-management interventions for chronic illness. Lancet 2004; 364: 1523-37.

8 Wagner EH, Austin BT, Davis C, Hindmarsh M, Schaefer J, Bonomi A. Improving chronic illness care: translating evidence into action. Health Affairs 2001; 20: 64 78.

9 Ball MJ, Lillis J. E-health: transforming the physician/ patient relationship. J Am Med Inform Assoc 2001; 61: 1-10.

10 Raad voor de Volksgezondheid en Zorg. Van zorg en ziekte naar gedrag en gezondheid [Counsil for Public Health and Health Care. From care and disease to behavior and health]: Den Haag, the Netherlands; 2012.

11 Patient empowerment - who empowers whom? Lancet 2012; 379(9827): 1677.

12 Eysenbach G. What is e-health? J Med Internet Res 2001 Apr-Jun; 3(2): E20.

13 Kreps G, Neuhauser L. New directions in eHealth communication: opportunities and challenges. Patient Educ Couns 2010; 78: 329-36.

14 Nijland N, Grounding eHealth: towards a holistic framework for sustainable eHealth technologies. (Doctoral Dissertation): University of Twente, the Netherlands; 2011.

15 Demiris G, Afrin LB, Speedie S, Courtney KL, Sondhi M, Vimarlund V, Lovis C, Goossen W, Lynch C. Patient-centered applications: use of information technology to promote disease management and wellness. A white paper by the AMIA knowledge in motion working group. J Am Med Inform Assoc 2008; 15: 8-13.

16 Powell JA, Darvell M, Gray JAM. The doctor, the patient and the world-wide web: how the Internet is changing healthcare. J R Soc Med 2003; 96: 74-6.

17 Ansani NT, Vogt M, Henderson BA, McKaveney TP, Weber RJ, Smith RB, Burda M, Kwoh CK, Osial TA, Starz T. Quality of arthritis information on the Internet. Am J Health-Syst Pharm 2005 Jun; 62(11): 1184-9.

18 Lemire M, Paré G, Sicotte C, Harvey C. Determinants of Internet use as a preferred source of information on personal health. Int J Med Inform 2008; 77: 723-34. 
19 Fox S. The Engaged E-Patient Population. Washington DC, Pew Internet and American Life Project, 2008.

20 Robinson C, Graham J. Perceived Internet health literacy of HIV-positive people through the provision of a computer and Internet health education intervention. Health Info Libr J 2010; 27(4): 295-303.

21 Rice RE. Influences, usage, and outcomes of Internet health information searching: Multivariate results from the Pew surveys. Int J Med Inform 2006; 75(1): 8-28.

22 Eysenbach G. Medicine 2.0: social networking, collaboration, participation, apomediation, and openness. J Med Internet Res 2008; 10: e22.

23 Stump T, Zilch S, Coustasse A. The Emergence and Potential Impact of Medicine 2.0 in the Healthcare Industry. Hosp Top 2012; 90(2): 33-8.

24 Kreps GL, Neuhauser L. New directions in eHealth communication: opportunities and challenges. Pat Educ Couns 2010; 78: 329-39.

25 Van Uden-Kraan CF, Drossaert CHC, Taal E, Shaw BR, Seydel ER, Van de Laar MAFJ. Empowering processes and outcomes of participation in online support groups for patients with breast cancer, arthritis and fibromyalgia. Qual Health Res 2008; 18(3): 405-17.

26 Stinson JN, Stevens BJ, Feldman BM, Streiner D, McGrath PJ, Dupuis A, Gill N, Pertroz GC. Construct validity of a multidimensional electronic pain diary for adolescents with arthritis. Pain 2008; 136: 281-92.

27 Stinson JN, McGrath PJ, Hodnett ED, Feldman BM, Duffy CM, Huber AM, Tucker LB, Hetherington CR, Tse SML, Spiegel LR, Campillo S, Gill NK, White ME. An Internetbased self-management program with telephone support for adolescents with arthritis: a pilot randomized controlled trial. J Rheumatol 2010; 37: 1944-52.

28 Lorig K, Ritter PL, Laurent DD, Plant K. The Internet-based arthritis selfmanagement program: a one-year randomized trial for patients with arthritis or fibromyalgia. Arthr Care Res 2008; 59: 1009-17.

29 Patt MR, Houston TK, Jenckes MW, Sands DZ, Ford DE. Doctors who are using email with their patients: a qualitative exploration. J Med Internet Res 2003; 5(2): e9.

30 Ammenwerth E, Schnell-Inderst P, Hoerbst A. The impact of electronic patient portals on patient care: a systematic review of controlled trials. J Med Internet Res 2012; 14(6): e162.

31 Collard F, Garibaldi JM. Measuring health care decision aid effectiveness. Proceedings of the International Symposium on Computer-Based Medical Systems 2012; 20-22 June Rome, Italy.

32 Murray E, Burns J, See Tai S, Lai R, Nazareth I. Interactive health communication applications for people with chronic disease. Cochrane Database of Syst Rev 2009; (1).

33 Leonard K, Wiljer D, Casselman M. An innovative information paradigm for consumers with chronic conditions: the value proposition. J Inf Tech Health Care 2008; 6: 274-82.

34 Dorr D, Bonner LM, Cohen AN, Shoai RS, Perrin R, Chaney E, Young AS. Informatics systems to promote improved care for chronic illness: a literature review. J Am Med Inform Assoc 2007; 14: 156-63. 
35 Garcia-Lizana F, Sarria-Santamera A. New technologies for chronic disease management and control: a systematic review. J Telemed Telecare 2007; 13: 62-8.

36 Black AD, Car J, Pagliari C, Anandan C, Cresswell K, Bokun T, McKinstry B, Procter R, Majeed A, Sheikh A. The impact of eHealth on the quality and safety of health care: a systematic overview. PLoS Med 2011; 8(1): e1000387.

37 Silvestre A, Sue VM, Allen JY. If you build it, will they come? The Kaiser permanente model of online health care. Health Aff 2009; 28: 334-44.

38 Flynn D, Gregory P, Makki H, Gabbay M. Expectations and experiences of eHealth in primary care: a qualitative practice-based investigation. Int J Med Inform 2009; 78: 588-604.

39 Or CKL, Karsh B. A systematic review of patient acceptance of consumer health information technology. J Am Med Inform Assoc 2009; 16: 550-60.

40 Richter JG, Becker A, Specker C, Monser R, Schneider M. Disease-oriented internet use in outpatients with inflammatory rheumatic diseases. Z Rheumatol 2004; 63: 216-22.

41 Richter JG, Becker A, Koch T, Willers R, Nixdorf M, Schacher B, Monser R, Specker C, Alten $\mathrm{R}$, Schneider $\mathrm{M}$. Changing attitudes towards online electronic health records and online patients documentation in rheumatology outpatients. Clin Exp Rheumatol 2010; 28: 261-4.

42 Pagliari C. Design and evaluation in eHealth: challenges and implications for an interdisciplinary field. J Med Internet Res 2007; 9: e15.

43 Keselman A, Logan R, Smith CA, Leroy G, Zeng-Treitler Q. Developing informatics tools and strategies for consumer-centered health communication. J Am Med Inform Assoc 2008; 15: 473-83.

44 Nguyen HQ, Carrieri-Kohlman V, Rankin SH, Slaughter R, Stulbarg MS. Internetbased patient education and support interventions: a review of evaluation studies and directions for future research. Comput Bio Med 2004; 34: 95-112.

45 Lapsley $\mathrm{P}$, Groves $\mathrm{T}$. The patient's journey: travelling through life with a chronic illness, authors. Br Med J 2004; 329: 582-3.

46 Kerr C, Murray E, Stevenson F, Gore C, Nazareth I. Internet interventions for longterm conditions: patient and caregiver quality criteria. J Med Internet Res 2006; 8: e13.

47 Wilson EV, Lankton NK. Modeling patients' acceptance of provider-delivered ehealth. J Am Med Inform Assoc 2004; 11: 241-8.

48 Or CKL, Karsh BT, Severtson DJ, Burke LJ, Brown RL, Brennan PF. Factors affecting home care patients' acceptance of a web-based interactive self-management technology. J Am Med Inform Assoc 2011; 18: 51-9.

49 Reti SR, Feldman HJ, Ross SE, Safran C. Improving personal health records for patient-centered care. J Am Med Inform Assoc 2010; 17: 192-5.

50 Leonard KJ, Dalziel S. How and when eHealth is a good investment for patients managing chronic disease. Healthc Manag Forum 2011; 24(3): 122-36.

51 Buntin MB, Burke MF, Hoaglin MC, Blumenthal D. The benefits of health information technology: a review of the recent literature shows predominantly positive results. Health Affair 2011; 30(3): 464-71. 
52 Karsh BT, Weinger MB, Abbott PA, Wears RL. Health information technology: fallacies and sober realities. J Am Med Assoc 2010; 17: 617-23.

53 Van Gemert-Pijnen JEWC, Nijland N, Van Limburg M, Eng B, Ossebaard HC, Kelders SM, Eysenbach G, Seydel ER. A holistic framework to improve the uptake and impact of eHealth technologies. J Med Internet Res 2011; 13(4): e111.

54 Norman CD, Skinner HA. eHealth literacy: essential skills for consumer health in a networked world. J Med Internet Res 2006; 8(2): e9.

55 Dominick GM, Friedman DB, Hoffman-Goetz L. Do we need to understand the technology to get to the science? A systematic review of the concept of computer literacy in preventive health programs. Health Educ J 2009; 68: 296.

56 McCray AT. Promoting Health Literacy. J Am Med Inform Assoc 2005; 12: 152-63.

57 Sarkar U, Karter AJ, Liu JY, Adler NE, Nguyen R, López A, Schillinger D. The literacy divide: Health literacy and the use of an Internet-based patient portal in an integrated health system - results from the diabetes study of Northern California (DISTANCE). J Health Commun 2010; 15: 183-96.

58 Neter E, Brainin E. eHealth literacy: Extending the digital divide to the realm of health Information. J Med Internet Res 2012; 14(1): e19.

59 Eysenbach G, Köhler C. How do consumers search for and appraise health information on the world wide web? Qualitative study using focus groups, usability tests, and in-depth interviews. Br Med J 2002; 324(7337): 573-7.

60 van Deursen A, van Dijk J. Internet skills performance tests: are people ready for eHealth? J Med Internet Res 2011; 13(2): e35.

61 Norman C. eHealth Literacy 2.0: Problems and Opportunities With an Evolving Concept. J Med Internet Res 2011; 13(4): e125.

62 Kelders SM. Understanding adherence to web-based interventions. (Doctoral Dissertation): University of Twente, the Netherlands; 2012.

63 Nguyen BV, Burstein F, Fisher J, Wilson C. Taxonomy of usage problems for improving user-centric online health information provision. AMCIS 2011 Proceedings 2011; 65. Detroit, Michigan, USA.

64 Ishikawa $\mathrm{H}$, Takeuchi T, Yano E. Measuring functional, communicative and critical health literacy among diabetic patients. Diabetes Care 2008; 31: 874-9.

65 Norman CD, Skinner HA. eHEALS: The eHealth Literacy Scale. J Med Internet Res 2006; 8(4): e27.

66 Nielsen J. Usability Engineering. Second Edition; Morgan Kaufmann Publishers, 1994. 


\title{
Chapter 2
}

\section{Experiences and preferences of patients regarding a rheumatology Interactive Health Communication Application: a qualitative study}

\author{
Rosalie van der Vaart \\ Constance H.C. Drossaert \\ Erik Taal \\ Mart A.F.J. van de Laar
}

Proceedings of the Second International Conference on eHealth, Telemedicine, and Social Medicine, eTELEMED'10 Saint Martin; 2010: 64-

Extended version published in: International Journal on Advances in Life Sciences 2010; 2(3\&4): 143-53. 


\begin{abstract}
Objectives: Interactive Health Communication Applications (IHCAs) can make a valuable contribution to rheumatology. The development of online health applications is moving quickly, and positive results have been shown. Yet solid research on use and acceptance of different information, communication and participation tools by patients is still lacking. In this qualitative study, we examined the health-related Internet use of patients with rheumatic diseases, their motives for using or not using certain applications, and their needs and preferences with regard to a rheumatology IHCA.
\end{abstract}

Methods: Semi-structured individual interviews were conducted with eighteen patients, who were selected from a hospital's patient panel. Participants were diagnosed with eight different forms of rheumatism and their mean age was 50.7 years. The interviews were coded by two independent researchers.

Results: The applications most preferred by participants were: information provision on both medical and support topics, online communication with their doctor and insight in their electronic medical records. Patient support groups were less valued as were participation tools such as symptom monitoring and online exercise programs. Furthermore, a large discrepancy was shown between patients' current use and their future preferences with respect to information about care and support, access to electronic medical records and having online contact with their doctor.

Conclusion: Patients see great value in an IHCA provided by their own hospital, since it could increase reliability, and would give them the confidence to use the application. The current study shows a significant discrepancy between current use and future preferences among patients with rheumatic diseases regarding online communication with their doctor, online symptom monitoring and insight in their electronic medical records. Overall, a rheumatology IHCA should contain communication and participation tools which are linked to the hospital, including information about disease, care and practical support. 
The Internet is making an increasing impact on today's health care and the expectations about the effects of Internet applications in health care are high. First, Internet applications have the potential to lead to more cost-effective healthcare. Internet applications could support the growing need for health care resulting from both our aging population and the increasing number of people who suffer from one or more chronic diseases. Second, online applications offer the opportunity to extend patients' selfmanagement in health care [1,2]. Accordingly, such applications could support the transformation of the patient from passive receiver of care into an active participant in the management of one's illness, which is considered highly desirable in chronic health care [3-5].

Over the past decade, the number of Internet applications in health care has grown spectacularly. Presently, patients with various chronic diseases can go online to find tools such as information, self-tests, self-help or to get in contact with peer patients. In addition, health care organizations and health care providers are increasingly developing their own web applications for their patients. These applications sometimes provide besides the above mentioned tools- opportunities for online contact with health professionals and/or access to patients' electronic medical records. Overall, three main categories of online health care applications can be distinguished: information, communication and participation. Information applications mostly concern information about the disease and available care. Communication applications concern facilities for communication with peers or with health professionals. Participation -a broad areaconcerns applications as symptom monitoring, self-management and access to electronic medical records.

Interactive Health Communication Applications (IHCAs) are operational software programs which combine the provision of health information with at least one of the above-mentioned communication or participation applications. Patients with chronic diseases, such as rheumatism, can benefit particularly from IHCAs, while such patients are often considered to be on an 'illness journey' [6]. As patients progress through their journey, they experience different information, self-management and support needs [6-8]. As a result, different patients will have different needs at different points in time. An IHCA has the potential to meet these multiple needs because it provides a wide range of information, communication and participation tools. Furthermore, an IHCA is accessible, independent of time and place, and its content can be patient tailored - which also supports the patients' personal illness journey [2,9]. Moreover, the information can be presented in accessible formats, such as video and audio clips, and graphics [10]. Above all, a recent systematic review suggests that health care IHCAs are effective on improving knowledge, perceived social support, health behavior and clinical results for various kinds of chronic diseases [10].

However, despite these benefits, online applications for rheumatic patients remain scarce. A recent systematic review by Murray included 24 randomized controlled trials on IHCAs, but no rheumatism application [10]. Another systematic review on online selfmanagement systems by Solomon also did not include a rheumatology system in any of the 28 articles reviewed [11]. A literature search revealed only one study about a website for patients with rheumatic diseases that combined information, patient-provider communication and health assessment tools [12]. Other existing online rheumatology 
applications are single applications focusing mainly on participation, such as symptom monitoring, physical exercise, and overall self-management [13-15]. Furthermore, whereas IHCAs seem to be effective, it is still unclear which applications contribute to these successes [16]; nor are all applications equally well used [17]. Therefore, it is essential to carefully match the applications on an IHCA to the needs of the patients for which it is intended [1]. In summary, while user-focused research into online applications has been done for other chronic diseases [7], within rheumatology there remains a gap in this kind of knowledge. The aim of this study was to perform a needs assessment among patients with rheumatic diseases regarding an IHCA. This study focused on several questions: (1) Which (information, communication and participation) support applications do rheumatism patients already use on the Internet? (2) What are their attitudes about available online support applications? (3) What are their preferences and demands for a rheumatology IHCA and, most importantly, what are their reasons for preferring or not preferring certain applications?

\section{Methods}

A descriptive qualitative design was used, since this study was explorative. We preferred the use of individual semi-structured interviews to get the best understanding of patients' experiences of, needs, motives and preferences for a selection of widely used Internet applications.

\section{Selection of participants}

Participants were selected from an existing patient panel, which was initiated in cooperation between the University of Twente and Twente's largest clinical hospital. Patients registered on this panel are willing to volunteer in rheumatology research. The criteria for patient participation for the present study were: willing to participate in interviews, contactable by e-mail and not older than 60 years. Qualified patients were invited via e-mail. All invited patients were willing to take part in the study, and were contacted to schedule an interview. The interviews took place at the university or at people's homes, at each participant's choice. In total, 18 interviews were conducted, after which data saturation was reached; meaning that no more new information of value was obtained $[18,19]$.

\section{Interview structure}

Each interview started off broadly, by asking participants about their Internet use. Both general Internet use and health and rheumatic related Internet use were asked about. Subsequently, participants were asked to reflect freely about their ideas and preferences for a rheumatology IHCA. The interview continued by discussing seven types of widelyused applications within the three main categories of online health support: information, communication and participation. For each type, a prototype card was made which showed representative examples of existing Internet applications and websites. The participants were asked about their current use of and needs for the applications, their attitudes about these applications, their motives for use or nonuse and their preferences for the usage of the applications. The seven illustrated cards showed: (1) information 
about disease and treatment (general medical information about rheumatic diseases and their treatment); (2) information about care and support (practical information about rheumatology health care in the region and support services); (3) peer support groups (finding support from other patients and exchanging experiences, tips and tricks by message boards or online chat); (4) "ask your doctor" (the opportunity for e-consultations via e-mail or online chat with the rheumatology department of the hospital); (5) symptom monitoring (scoring of variables such as pain, swollen joints, mood and activity through which a graphic overview in time shows); (6) exercise programs (self-regulation of physical activity by tips, tests and online support); and (7) access to electronic medical records (the ability to provide patients access to their own medical files, with information about their diagnosis, treatment plan and latest lab results). The interviews took one to two hours, depending on the patient. The interviews were audiotaped, for which all patients had given permission beforehand.

\section{Data analyses}

The audiotapes of the interviews were transcribed verbatim. Current use and needs were extracted, and citations about attitudes and motives for use, nonuse and preferences were selected and coded into categories by two independent researchers. The final categories were defined by consensus between the two researchers. Next, the first researcher examined the raw data again to ensure the robustness of the analytical process and to confirm that all the data were indeed reflected in the coding scheme [19]. During this process, only the participant numbers were used to protect the anonymity of the participants.

\section{Results}

\section{Characteristics and internet use}

Eighteen participants were interviewed, five male and thirteen female, with a mean age of 50.7 years (S.D. $=9.27$ ). Interviewed participants had been diagnosed with eight different forms of rheumatic diseases. More than half of the participants were diagnosed with rheumatoid arthritis $(n=10)$, two with osteoarthritis. The remaining participants were all diagnosed with a less common rheumatic disease. All participants owned a computer and had home access to the Internet. They used the Internet on a regular basis, generally for several hours a day. The Internet was mainly used for email, obtaining information, purchasing goods and banking. All the participants reported that they had used the Internet for health-related purposes, usually to search for information.

\section{Utilization of, and attitudes toward health related Internet applications}

Overall, participants saw great value in an IHCA provided by their own hospital. They reported it would lower barriers to search for information and would give them the confidence to use the IHCA. When asked an open-ended question about which applications participants would like to find and use on a rheumatology IHCA, participants mentioned various topics. Most frequently mentioned were: information on the latest developments in treatment and medication, insight into hospital procedures, and tips to 
cope with disease-related issues in daily life (e.g. at work, when shopping or doing household chores). Table 1 shows an outline of participants' current use and needs of online applications and their motives to use it or not. Table 2 shows an outline of patients' preferences and pre-conditions to use the seven applications in the future. The applications most preferred by participants were information provision on both medical and support topics, online communication with their doctor and insight in their electronic medical records. Patient support groups were less preferred, and so were the participation tools to monitor symptoms and to follow an online exercise program. What stands out is the significant discrepancy between current use and future preferences on information about care and support, online communication with the doctor and access to electronic medical records.

Table 1: Current use, needs and motives of participants towards online applications ( $n=18$ )

\begin{tabular}{|c|c|c|c|c|}
\hline Application & $U_{s e}{ }^{a}$ & Needs $^{a}$ & Motives pro & Motives con \\
\hline \multicolumn{5}{|l|}{ Information } \\
\hline $\begin{array}{l}\text { Information } \\
\text { about disease } \\
\& \text { treatment }\end{array}$ & high & high & $\begin{array}{l}\text { - easy and fast } \\
\text { - can read what one } \\
\text { wants } \\
\text { - can read it when } \\
\text { one wants }\end{array}$ & $\begin{array}{l}\text { - information overflow } \\
\text { - can be unreliable } \\
\text { - confrontational/can } \\
\text { cause worry } \\
\text { - already has all the } \\
\text { necessary information } \\
\text { - one gets information } \\
\text { otherwise }\end{array}$ \\
\hline $\begin{array}{l}\text { Information } \\
\text { about care \& } \\
\text { support }\end{array}$ & moderate & high & $\begin{array}{l}\text { - structured and } \\
\text { complete overview } \\
\text { - helpful in } \\
\text { decision-making } \\
\text { - good reference } \\
\text { tool }\end{array}$ & $\begin{array}{l}\text { - no additional care } \\
\text { necessary } \\
\text { - current health } \\
\text { professionals } \\
\text { recommend or refer to } \\
\text { supplementary care }\end{array}$ \\
\hline \multicolumn{5}{|l|}{ Communication } \\
\hline $\begin{array}{l}\text { Peer support } \\
\text { groups }\end{array}$ & moderate & moderate & $\begin{array}{l}\text { - } \text { recognition } \\
\text { - support in coping } \\
\text { - giving and } \\
\text { receiving advice } \\
\text { - } \text { anonymous }\end{array}$ & $\begin{array}{l}\text { - } \text { unreliable } \\
\text { information/advice } \\
\text { - complaining people } \\
\text { - confronting } \\
\text { - impersonal }\end{array}$ \\
\hline E-consultation & low & high & $\begin{array}{l}\text { - accessible and easy } \\
\text { - reliable } \\
\text { - enables time to } \\
\text { write down a } \\
\text { question and } \\
\text { (re)read the } \\
\text { answer } \\
\text { - could save visit to } \\
\text { the doctor }\end{array}$ & $\begin{array}{l}\text { - non synchronous } \\
\text { communication } \\
\text { - waiting time for a } \\
\text { response }\end{array}$ \\
\hline \multicolumn{5}{|l|}{ Participation } \\
\hline $\begin{array}{l}\text { Symptom } \\
\text { monitoring }\end{array}$ & low & moderate & $\begin{array}{l}\text { - better disease } \\
\text { insight for oneself } \\
\text { and the doctor }\end{array}$ & $\begin{array}{l}\text { - confronting } \\
\text { - time consuming } \\
\text { - gets one too focused on }\end{array}$ \\
\hline
\end{tabular}




\begin{tabular}{|c|c|c|c|c|}
\hline & & & $\begin{array}{l}\text { - new and fun to try } \\
\text { - shows patterns } \\
\text { over time }\end{array}$ & pain and signs \\
\hline $\begin{array}{l}\text { Exercise } \\
\text { programs }\end{array}$ & moderate & moderate & $\begin{array}{l}\text { - help maintain } \\
\text { self-respect } \\
\text { - comfortable to } \\
\text { exercise and } \\
\text { receive support at } \\
\text { home }\end{array}$ & $\begin{array}{l}\text { - requests self-discipline } \\
\text { - one already exercises } \\
\text { independently/with a } \\
\text { therapist } \\
\text { - doubtful accuracy and } \\
\text { safety }\end{array}$ \\
\hline $\begin{array}{l}\text { Access to } \\
\text { electronic } \\
\text { medical } \\
\text { records }\end{array}$ & low & high & $\begin{array}{l}\text { - more involvement } \\
\text { in treatment } \\
\text { - overview of } \\
\text { appointments } \\
\text { - overview of } \\
\text { lab/blood results }\end{array}$ & $\begin{array}{l}\text { - too difficult to } \\
\text { understand }\end{array}$ \\
\hline
\end{tabular}

a. Low: < 6 participants reacted positively; Moderate: 6 - 12 participants reacted positively; High: > 12 participants reacted positively

Table 2: Preferences and pre-conditions of participants for online applications ( $n=18)$

\begin{tabular}{|c|c|}
\hline Application & Preferences and pre-conditions \\
\hline \multicolumn{2}{|l|}{ Information } \\
\hline $\begin{array}{l}\text { Information about disease \& } \\
\text { treatment }\end{array}$ & $\begin{array}{l}\text { Information on three topics: } \\
-\quad \text { disease (diagnosis, symptoms, heredity) } \\
-\quad \text { treatment (medication, therapies, protocols) } \\
\text { - } \quad \text { coping (psychological, social) }\end{array}$ \\
\hline $\begin{array}{l}\text { Information about care \& } \\
\text { support }\end{array}$ & $\begin{array}{l}\text { Information on two topics: } \\
\text { - } \quad \text { medical care (specializations, hospital procedures) } \\
\text { - } \quad \text { practical support (facilities, insurances) }\end{array}$ \\
\hline \multicolumn{2}{|l|}{ Communication } \\
\hline Peer support groups & $\begin{array}{ll}\text { - } & \text { positive topics; tips \& tricks } \\
\text { - } & \text { diverse target groups } \\
\text { - } & \text { good control and protection on posts and privacy }\end{array}$ \\
\hline E-consultation & $\begin{array}{ll}\text { - } & \text { extension to current care but no replacement } \\
\text { - } & \text { contact with own health professional } \\
\text { - } & \text { use for non-urgent questions } \\
\text { - } & \text { quick handling of messages }\end{array}$ \\
\hline \multicolumn{2}{|l|}{ Participation } \\
\hline Symptom monitoring & $\begin{array}{ll}- & \text { tele-monitoring by doctor } \\
\text { - } & \text { use in consult and treatment } \\
\text { - } & \text { overview in graphs }\end{array}$ \\
\hline Exercise programs & $\begin{array}{ll}- & \text { solution to self-discipline barrier } \\
\text { - } & \text { safe exercises } \\
\text { - } & \text { online coach }\end{array}$ \\
\hline $\begin{array}{l}\text { Access to electronic medical } \\
\text { records }\end{array}$ & $\begin{array}{ll}\text { - } & \text { clear information and instructions } \\
\text { - } & \text { high security }\end{array}$ \\
\hline
\end{tabular}




\section{Information about disease and treatment}

Every participant reported to have searched for online information on rheumatic diseases before. Most of the topics patients had searched for were related to medication, such as instructions for use, side-effects and the development of new medications. Participants also went online when they felt pain, when they had doubts about their symptoms or when they noticed new symptoms. Furthermore, the Internet was used to gather information after participants had been given their diagnosis and when they heard or read something interesting. A final reason to search the Internet was when a person had forgotten to ask their doctor something during their consultation. According to the participants, the largest benefits of online information were that it is easy, fast and one can decide for oneself what to read and when to read it. Whereas most participants had used the Internet to obtain information, some participants did not have (or did no longer have) the urge to use the Internet for information because they believed it was too confrontational or led to unnecessary worries about their disease. "I don't need al that information, I can think of so many other things to search for and giving myself a hard time about. I live my life now and I don't want to think about it daily [Female, 40, RA]". Also, many participants already felt that they knew everything they wanted to know. Furthermore, some participants reported that they felt there is an overflow of information on the Internet, which can make it hard to find relevant information, judge the reliability of information and to interpret information correctly. Other participants reported obtaining their information in alternative ways, such as through their doctor or from patient organization magazines. However, information provision via a rheumatology IHCA provoked enthusiasm, since it could overcome the problem of information unreliability.

The information participants preferred the most could be classified into three categories. The first category is disease information, which contains topics such as the diagnosis, heredity and related symptoms, such as fatigue. Second, treatment information was preferred, such as information on medication, therapies and protocols. The final category concerns information about how to cope with rheumatic diseases, which involves topics such as dealing with the psychological and social consequences relating to family, friends and work, how to keep exercising, and tips and tricks to overcome the difficulties in daily life that rheumatic diseases can cause.

\section{Information about care and support}

Participants were asked to what extend they used or were interested in a "care guide", which is an overview of all the rheumatology care and support available in the region. Half of the participants reported knowing of and using existing care guides. Participants thought that these guides provided structured and complete overviews of health care and support services, and that they were helpful in making informed choices concerning health professionals. The most important reason participants mentioned not to use a care guide was that they did not need any additional care and if necessary current health professionals usually made recommendations. However, a care guide from a rheumatology IHCA would be appreciated by most participants since it is seen as a potentially good reference tool in healthcare and support. "I used one (care guide, ed.) to 
find a physiotherapist in Haaksbergen (small town, ed.) who was specialized in rheumatic diseases. Through this website I found the therapist I have now [Female, 53 years, RA]".

An effective care guide includes two kinds of information, according to the participants. The first type is aimed at medical care; the second type at support services and local resources. Regarding the medical care information, participants expect job descriptions and specializations of all health care facilities, including psychological and familial help. Each facility should show a complete overview of all its health care professionals. Also, information about accessibility, waiting lists, and hyperlinks to the web page of each health professional is valued. A few participants would additionally like to read about experiences and opinions of other patients about particular professionals. Participants wanted information about hospital procedures, reciprocal expectations between the hospital and the patients, any changes in the rheumatology department and announcements of activities and meetings involving rheumatic diseases. The preferred information on support services and local resources varied from household services to work reintegration authorities and health resorts for vacations. Participants also mentioned missing clear information about the options and financial help for home adjustments, support tools, health insurances and tips for disabled-friendly shopping, dining and entertainment in the region.

\section{Communication with peers}

One-third of the participants reported using online peer support groups or looking at support message boards occasionally. Participants identified advantages in online support groups since they can supply recognition, advice and support in coping with the disease. Furthermore, such groups are anonymous, which reduces the reluctance to discuss personal topics. Reasons not to use online support groups were that the information can be unreliable and some participants felt that people who post on online support groups tend to complain a great deal or would only talk about their own problems. Also, some participants reported that they did not fit into the target group represented by the online support group and that the messages could be confrontational. "I searched a lot in the beginning, when I was just diagnosed with arthritis, and then I stumbled upon an arthritis peer support forum. That's when I thought that if this is where I'll end up, then I'm never looking again. I was really shocked by it [Female, 40 years, RA]". Some participants added that they didn't want to hear strangers' stories or advice and that they didn't want to spend too much time reflecting on their disease. However, because of the large amount and large diversity of pros and cons for peer support groups most people found it difficult to give a clear opinion or preference about the desirability of such an application within a rheumatology IHCA. "Personally, I don't want to be occupied with my disease too much. But on the other hand, I don't want to miss valuable advice either [Female, 57 years, Forestier's Disease]".

Participants report that there should be a clear value for them in the online support groups: messages should be positive and the exchange of tips and tricks should be the main function of the group. Other important preconditions were that there should be accurate control of posts as well as on privacy, and participants thought it was important to have a variety of topics and target groups on a forum. 


\section{Communication with the health professional}

The majority of participants had never used an e-consultation to contact their doctor. However, there was a significant discrepancy between actual and preferred use. Nearly all participants felt that this facility would be a valuable addition to their current care, since it is accessible, reliable and convenient. Moreover, participants mentioned that econsultations would allow them to take time to formulate a question and to carefully read or reread a doctor's answer. Also, it could possibly even save a visit to the hospital. Despite their positive views, disadvantages were also mentioned: one disadvantage mentioned is the lack of synchronism in the communication, which inhibits both doctors and patients from immediately asking a follow-up question for clarification. Also, patients would have to wait a while for a reply message, while face-to-face or phone contact is both direct and in real time. Therefore, participants would use e-consultations mainly for minor, non-urgent questions. "Sometimes I just have a short question and it's not necessary to make an appointment. Something I just want to check. I don't have to make a telephone call for it either, there's no rush. Sending an e-mail would suffice [Male, 58 years, SLE]".

Participants thought this application could be a valuable extension to their current healthcare. The most essential criteria for this tool are that the online contact occurs with the rheumatology department of their own hospital and that it should not replace the regular contacts with their doctor. Moreover, participants expected a quick response on messages in a secured environment.

\section{Participation by symptom monitoring}

Half of the participants did not have experience with symptom monitoring. The other half had some experience in various ways, for example using a diary or monitoring certain variables during a treatment. Reasons mentioned for using a symptom monitoring tool were that it could provide both the participant and the doctor a better insight into the disease, which could benefit communication and treatment. Also, it was considered good to be open-minded about new approaches and methods, and it could be fun to use the tool and see patterns emerge over time. "You get a much better idea of what your bottlenecks are, and then you can explain it to the rheumatologist a lot better [Female, 40 years, Osteoarthritis]".

Some participants were not able to grasp the use and the extra value of regular monitoring. Other reasons for not using symptom monitoring were that it could be confrontational, participants did not want to spend too much time thinking about their disease and some patients feared it could be counterproductive if one becomes too focused on pain and symptoms. "I just don't want to know. Ignorance is bliss; if I'm feeling good on a day, then I live it to the fullest. If I feel miserable the next day, then that's the way it is. I don't think about it too much [Female, 57 years, RA]".

Participants particularly appreciated the value of symptom monitoring when their doctor would receive the data via tele-monitoring and would use it to tailor the treatment. Symptoms that participants would like to monitor were pain, inflamed and swollen joints, overall health, and physical exercise. Stress, fatigue, medication and nutrition were also mentioned. Furthermore, the participants thought it could be important to view the 
correlation between these various factors in graphs. Symptom monitoring would mainly be used semi-regularly in times of high disease activity, and before a consult.

\section{Participation by exercise programs}

Most participants did not have any experience with online exercise programs. They mentioned not having enough self-discipline to persist and they mostly preferred visiting the physiotherapist. Some participants reported that using an online exercise program might help to maintain a sense of self-respect: doing things on your own. Furthermore, being able to exercise at home and get tips and support via the Internet would be comfortable. Almost half of the participants did not see any value of an exercise program on a rheumatology IHCA. They did not think the tool could address the need for selfdiscipline. They were afraid of the accuracy and the safety of the exercises, and of doing them without a supervisor. "It all depends on proper supervision. I can and I want to exercise, but if I do things the wrong way I get injured easily. When a healthy person does something incorrectly, he gets muscle aches, but if I do something incorrectly I can't walk for a week. To prevent this, I want a physiotherapist next to me. I want to keep on exercising, but in a healthy way [Female, 43 years, Ankvlosing Spondylitis]". For some participants, this seemed like a good idea to overcome these barriers with an online coach, someone who can watch the patient via a webcam, so that the coach can provide tips and advice.

\section{Participation by insight in electronic medical records}

The most enthusiastically received example of an online application by participants was access to their electronic medical records. Fifteen out of eighteen participants were positive about this; they would like to have access to their complete electronic medical records, including previous and current blood and lab results, their treatment plans and an overview of all the upcoming appointments. The most important reason why they wanted this was to feel more involved with, and in control of, their disease and treatment. Also, it would provide a good overview of their entire treatment, which participants often miss. "It would mean more involvement in myself. It concerns information about me, so I would like that very much (insight in electronic medical records, ed.) [Male, 59 years, RA]".

One reason not to want access to their electronic medical records would be that participants feel it is too difficult to understand all the information. Participants argued that it is the doctor's information and they would not know how to interpret it. Therefore, an important precondition is that the medical records should contain enough clear information and instructions to allow the patient to correctly interpret all the results and information. Furthermore, it is essential that the records would be safely secured.

\section{Discussion}

To the best of our knowledge, this is the first study to identify a broad overview of use, needs, motives and preferences of patients with rheumatic diseases on a full spectrum of online support applications. Results reveal that the provision of an IHCA by ones' own hospital causes enthusiasm. Overall, participants were most interested in receiving information on both medical and support topics, online contact with their doctor and 
access to their electronic medical records. Patient support groups were less preferred, as well as participation tools such as online symptom monitoring and online exercise programs. Furthermore, a significant discrepancy between current use and future preferences was seen in information about care and support, online communication with the doctor and insight in electronic medical records.

\section{Information}

Participants used the Internet predominantly to search for information. Previous research among patients with rheumatic diseases, as well as among those suffering from other diseases, has shown similar findings [20-22]. In this study the emphasis was on the kind of information and the reasons for which patients searched the Internet. We found that the participants were predominantly interested in disease information, treatment information and information on care, which was also reported by Gordon [23] and Hay [24]. Still, many participants reported searching for other information than the aforementioned subjects, which is not reflected in earlier studies. First, many participants emphasized information about coping: how to deal with psychological and social consequences relating to stress, family, friends and work, how to keep exercising, and tips and tricks to overcome the difficulties in daily life that rheumatism can cause. Second, information on support services and local resources was valued, such as on household services and financial support for home adjustments. Overall, participants seem to want information about rheumatology in a broader spectrum. Many participants mentioned that they often experience an information overload. This is widely described in the literature: the available health information is often unreliable or biased $[25,26]$. Information provision via a hospital IHCA, would overcome the problem of information overload.

\section{Communication}

The reported overall use of communication tools by participants is limited. Much is written about the possible positive results peer support groups can provide $[27,28]$. Still, actual usage of online support groups seems to be moderate [22,29-32]. The current study showed that most participants do not immediately reject the concept of online peer support groups, but they will only use it under certain conditions. Participants would like to read positive messages and practical tips from other patients. Communication with health professionals shows a large discrepancy between current use and needs for the future. This is also shown by Van Lankveld in a study on current and expected use of online health applications by chronically ill patients [22]. This discrepancy is largely due to a lack of opportunity. Most participants have never communicated with their doctor online [29], because such applications were not available. Still, when offered, online contact through e-consultations appears to be a popular facility $[12,17,30,31,33]$. Participants report it would be an accessible, reliable and easy way to improve their current care. However, patients do not want online communication to replace face-tofacce consultations. Moreover, practical implementation might be difficult as online communication might cause legal, budgetary and motivational barriers [34]. 


\section{Participation}

The current use of self-management or exercise programs is reported as moderate by patients. Many of our participants did not see the purpose of these applications, or they believed it would demand too great a time investment without clear benefits. Previous trial studies concerning self-management and physical activity in rheumatology showed good results using computer-based technologies [14,27,35]. However, despite of promising results, the predicted use of suchlike tools on an IHCA is still moderate whereas participants reported barriers in both self-discipline and accuracy and safety of the exercises. On symptom monitoring patients stated that their motivation to use the application would definitely increase if their doctor would use the information for treatment purposes. Therefore, the greatest promise of these tools would be when integration in the treatment can be realized. Finally, a participation tool with large potential is access to online electronic medical records. Previous studies have shown that this application is well received by patients $[17,33,34,36]$ and the participants in this study also reported enthusiasm. This application would provide patients the sense of being involved with, and in charge of, their own disease and treatment. Motivations such as this are essential because they demonstrate the value an IHCA can have in involving patients in their care process. Again, it should be noticed that many patients have not yet had the opportunity to use these kinds of participation applications, so preferences are not based on experience, but on expected usefulness.

\section{Study limitations}

There are limitations to this study. This qualitative study may not be representative for all patients. The participants were volunteers who, being more actively involved in research than usual patients, may not represent typical patients. Furthermore, the participants had mostly suffered from a rheumatic disease for a longer time. This can influence their needs and preferences; they are in a later stage of their illness journey than recently diagnosed patients. In a quantitative follow-up study these limitations will have to be averted.

\section{Conclusion}

Patients see great value in an IHCA provided by their own hospital, since it could increase reliability, and would give them the confidence to use the application. The current study shows a significant discrepancy between current use and future preferences that patients have regarding online communication with their doctor, online symptom monitoring and insight in their electronic medical records. Overall a rheumatology IHCA should contain communication and participation tools, both linked to the hospital, including information about disease, care and practical support.

\section{Acknowledgements}

We would kindly like to thank all the patients that participated in this research for their time and effort. This work was supported by an unrestricted educational grant from Wyeth Pharmaceuticals. This funding source had no involvement in data collection, analysis, or the preparation of this manuscript. 


\section{References}

1 Demiris G, Afrin LB, Speedie S, Courtney KL, Sondhi M, Vimarlund V, Lovis C, Goossen W, Lynch C. Patient-centered applications: use of information technology to promote disease management and wellness. A white paper by the AMIA knowledge in motion working group. J Am Med Inform Assoc 2008; 15: 8-13.

2 Keselman A, Logan R, Smith CA, Leroy G, Zeng- Treitler Q. Developing informatics tools and strategies for consumer-centered health communication. J Am Med Inform Assoc 2008; 15: 473-83.

3 Powell JA, Darvell M, Gray JAM. The doctor, the patient and the world-wide web: how the Internet is changing healthcare. Journal of the Royal Society of Medicine 2003; 96.

4 Ball MJ, Lillis J. E-health: transforming the physician/patient relationship. Int J Med Inform 2001; 61: 1-10.

5 Gustafson DH, Hawkins R, Boberg E, Pingree S, Serlin RE, Graziano F, Chan CL. Impact of a patientcentered, computer-based health information/support system background: Consumer health information systems potentially improve a patient's quality of life and activate patient selfcare. Am J Prev Med 1999; 16(1): 1-9.

6 Lapsley P, Groves T. The patient's journey: travelling through life with a chronic illness, authors. BMJ 2004; 329: 582-3.

7 Kerr C, Murray E, Stevenson F, Gore C, Nazareth I. Internet interventions for longterm conditions: patient and caregiver quality criteria. J Med Internet Res 2006; 8(3).

8 Winkelman WJ, Choo CW. Provider-sponsored virtual communities for chronic patients: improving health outcomes through organizational patient-centered knowledge management. Health Expect 2003; 6: 352-8.

9 Nguyen HQ, Carrieri-Kohlman V, Rankin SH, Slaughter R, Tulbarg, MS. Internetbased patient education and support interventions: a review of evaluation studies and directions for future research. Comput Biol Med 2004; 34: 95-112.

10 Murray E, Burns J, See Tai S, Lai R, Nazareth I. Interactive health communication applications for people with chronic disease (Review). Cochrane Database of Syst Rev 2009, 1.

11 Solomon MR. Information technology to support self-management in chronic care: a systematic review. Dis Manag Health Out 2008; 16(6): 391-401.

12 Ansani NT, Fedutes-Henderson BA, Weber RJ, Smith R, Dean J, Vogt M, Gold K, Kwoh CK, Osial T, Starz TW The Drug information center arthritis project: providing patients with interactive and reliable arthritis Internet education. Drug Inform J 2006; 40(1): 39-49.

13 Stinson JN, Stevens BJ, Feldman BM, Streiner D, McGrath PJ, Dupuis A, Gill N, Pertroz GC. Construct validity of a multidimensional electronic pain diary for adolescents with arthritis. Pain 2008; 136: 281-92.

14 Van den Berg MH, Ronday HK, Peeters AJ, Le Cessie S, Van der Giesen FJ, Breedveld FC, Vliet Vlieland TPM. Using Internet technology to deliver a home-based physical 
activity intervention for patients with rheumatoid arthritis: a randomized controlled trial. Arthritis Rheum 2006; 55: 935-45.

15 Lorig KR, Ritter PL, Laurent DD, Pland K. The Internet-based arthritis selfmanagement program: a one year randomized trial for patients with arthritis or fibromyalgia. Arthritis Rheum 2008; 59: 1009-17.

16 Eysenbach G, Fartasch D, Diepgen TL. Evidence-based patient education on the web: methods and studies for determining consumers' needs. J Med Internet Res 1999, Supplement 1.

17 Silvestre A, Sue VM, Allen JY. If you build it, will they come? The Kaiser permanent model of online health care. Health Affair 2009; 28(2): 334-44.

18 Guest G, Bunce A, Johnson L. How many interviews are enough?: an experiment with data saturation and variability. Field Method 2006; 18(1): 59-82.

19 Patton MQ. Qualitative evaluation and research methods (2nd ed.). Newbury Park 1990, CA: Sage.

20 Eysenbach $\mathrm{G}$, Köhler $\mathrm{C}$. What is the prevalence of health-related searches on the World Wide Web? Qualitative and quantitative analyses of search engine queries on the Internet. AMIA 2003 Symposium Proceedings 2003; 225.

21 Richter JG, Becker A, Specker C, Monser R, Schneider M. Disease-oriented Internet use in outpatients with inflammatory rheumatic diseases. Z Rheumatol 2004; 63: 216-222.

22 Van Lankveld WGJM, Derks AM, Van den Hoogen FHJ. Disease related use of the Internet in chronically ill adults: current and expected use. Ann Rheum Diseases 2005; 65: 121-123.

23 Gordon MM, Capell HA. The use of the Internet as a resource for health information among patients attending a rheumatology clinic. Rheumatology 2002; 41: 1402-5.

24 Hay CM, Cadigan RJ, Khanna D, Strathmann C, Lieber E, Altman R, McMahon M, Kokhab M, Furst DE. Prepared patients: Internet information seeking by new rheumatology patients. Arthrit Care Res 2008; 59(4): 575-82.

25 Wilson EV, Lankton NK. Modeling patients' acceptance of provider-delivered ehealth. J Am Med Inform Assoc 2004; 11(4): 241-8.

26 Glenton C, Paulsen EJ, Oxman AD. Portals to wonderland: health portals lead to confusing information about the effects of health care. Med Inform Decis Mak 2005; 5(7).

27 Shigaki CL, Smarr KL, Gong Y, Donovan-Hanson K, Siva C. Social interactions in an online selfmanagement program for rheumatoid arthritis. Chronic Illness 2008; 4: 239-46.

28 Eysenbach G, Powell J, Englesakis M, Rizo C, Stern A. Health related virtual communities and electronic support groups: systematic review of the effects of online peer to peer interactions. BMJ 2004; 328.

29 Anderson JG. Consumers of e-health: patterns of use and barriers. Soc Sci Comput Rev 2004; 22: 242.

30 Siva C, Smarr KL, Donovan Hanson K, Parikh M, Lawlor K, Ge B. Internet use and email communications between patients and providers: a survey of rheumatology outpatients. J Clin Rheumatol 2008; 14: 318-23. 
31 Atkinson NL, Saperstein SL, Pleis J. Using the Internet for health-related activities: findings from a national probability sample. J Med Internet Res 2009; 11(1).

32 Van Uden-Kraan CF, Drossaert CHC, Taal E, Lebrun CEI, Drossaers-Bakker KW, Smit WM, Seydel ER, Van de Laar MAFJ. Coping with somatic illnesses in online support groups: do the feared disadvantages actually occur? Comput Hum Behav 2008; 24 : 309-24.

33 Weingart SN, Rind D, Tofias Z, Sands DZ. Who uses the patient Internet portal? The PatientSite experience. J Am Med Inform Assoc 2006; 13(1): 91-5.

34 Hassol A, Walker JM, Kidder D, Rokita K, Young D, Pierdon S, Deitz D, Kuck S, Ortiz,E. Patient experiences and attitudes about access to a patient electronic health care record and linked web messaging. J Am Med Inform Assoc 2004; 11(6).

35 Lorig KR, Ritter PL, Laurent DD, Plant K. Internet-based chronic disease selfmanagement: a randomized trial. Med Care 2006; 44: 964-71.

36 Dorr D, Bonner LM, Cohen AN, Shoai RS, Perrin R, Chaney E, Young AS. Informatics systems to promote improved care for chronic illness: a literature review. J Am Med Inform Assoc 2007; 14: 156-63. 


\section{Chapter 3}

\section{Patient preferences for a hospital-based rheumatology Interactive Health Communication Application and factors associated with these preferences}

Rosalie van der Vaart Constance H.C. Drossaert Erik Taal Mart A.F.J. van de Laar 


\begin{abstract}
Objectives: To examine current disease-related Internet use and intentions to use various online support services on a hospital-based Interactive Health Communication Application (IHCA) of patients with rheumatic diseases. Furthermore, to examine which variables are associated with the intentions to use different online services.
\end{abstract}

Methods: Questionnaires were sent to a random sample of 484 patients of a large hospital's rheumatology clinic, response was $47 \%(n=227)$. Questions included sociodemographics, health characteristics, health literacy, patients' current disease-related Internet use and their intentions to use eight different online support services: (i) information about disease and treatment; (ii) information about care and support; (iii) peer communication; (iv) e-consultations; (v) autonomous symptom monitoring; (vi) symptom monitoring with tele-monitoring; (vii) self-management support; and (viii) access to personal electronic medical records.

Results: Although most patients with Internet access had used it in relation to their disease $(82 \%)$, Internet use was mainly limited to searching information. Many patients (45-68\%), however, intended to use seven out of eight possible online services, if offered on a hospital-based rheumatology IHCA. An exception was peer communication; only $11 \%$ intended to use a peer support group service. Of all the services, access to electronic medical records was mostly preferred, followed by information provision. Demographics, health characteristics and health literacy did not show clear significant relationships with the reported intentions.

Conclusion: Results show that patients with rheumatic diseases are interested in online support from the hospital and that they intend to use an IHCA, if it is available. Clear associating variables with reported intentions to use the different services were not found. 
Over the past decade the number of health applications on the Internet has grown spectacularly [1]. Patients can nowadays turn to the Internet for information about disorders, medication and treatments or for interactive health services such as self-tests and online contact with care providers or fellow sufferers. Health-care organizations and health-care providers are increasingly developing their own online health applications for their patients, as an addition to their usual care [2]. These developments provide opportunities such as e-consultations, tele-monitoring and online access to medical records [3-5].

Interactive Health Communication Applications (IHCAs) are applications, or web portals, which combine the provision of health information with at least one complementary service that supports communication or participation of the patient in their treatment. Communication applications concern facilities for communication with peers or with health professionals, whereas participation applications concern services that enhance the involvement of the patient in one's own care process, such as symptom monitoring, self-management support and access to electronic medical records. It is assumed that IHCAs can be a valuable addition to the care for chronically ill patients [6]. Chronic illnesses influence many aspects of life, and patients have varying information, support and self-management needs. The provision of a wide range of services has the potential to meet these multiple needs [7-9]. Furthermore, the needs of a patient may change over time while their illness proceeds [10]. A reliable portal that combines various services may improve a patient's empowerment and involvement in treatment [11-14]. A systematic review by Murray et al. [6] revealed that IHCAs can indeed be effective in improving knowledge, perceived social support, health behavior and clinical results for patients suffering from chronic conditions such as diabetes, asthma and cancer. In rheumatology, there are some examples of IHCAs, for both adults and adolescents (e.g. www.hopkins-arthritis.org; www.jong-en-reuma.nl). Preliminary evaluations of IHCAs that provide online self-management interventions and peer support for both adults and adolescents have been reported [15-18]. Evaluations of rheumatology IHCAs provided by the hospital that supply other services have not been reported in the literature until now.

Although IHCAs are thus increasingly being developed and may be beneficial to patients, previous research has shown that not all online health applications are accepted and used well [19]. It has been argued that it is often not known whether the services offered on the Internet are the services that patients actually desire [20,21]. Online services are often developed without involvement of the main user: the patient [22]. Among adolescents with rheumatic diseases, there is evidence of a need for support services. For example, Stinson et al. [23] showed that adolescents are interested in self-management support and that web-based applications would be attractive to them. In follow-up studies, several online self-management tools for this subgroup were developed $[15,16,24]$, which appeared to be feasible and highly relevant to this target group. However, thus far only little is known about wishes and needs that adult patients with rheumatic diseases have regarding online services $[25,26]$. To ensure that our IHCA will be used by as many patients as possible, and to avoid spending means on developing online services that will not be used [27], this study focuses on the preferences and needs of patients regarding online information and support on a hospital-based rheumatology IHCA. 
It should be noted that different patient groups may have different intentions and needs when it comes to online support services. Knowledge of the factors that are associated with intentions to use certain online health applications is important as it enables targeting of services and/or the development of group-specific services [28]. However, although previous research has investigated the influence of (predominantly socio-demographic) variables on usage of health technology applications of patients with various (chronic) conditions, the results thus far are inconclusive [19]. An explanation might be that different kinds of online support services might have different predictors. For example, younger patients might be more interested in online peer communication, for this is a well-accepted form of communication for them, while this may not be appealing for older patients. Also, more highly educated patients might be more interested in accessing their electronic medical records than patients with lower educational levels. Furthermore, more seriously ill people might desire a participation service as symptom monitoring to get a better insight into their disease, for they have many complaints and changing symptoms, whereas patients with a low disease activity might not be interested in regular scoring of symptoms.

One possible factor in explaining interest in online health services that has received little attention up until now is the level of health literacy [29,30]. Health literacy is an important issue in today's health care [31] and can be defined as the ability people have to retrieve and interpret information, and to use this information to one's own benefit [32]. It is likely that health literacy levels influence the uptake of health services on a hospitalbased IHCA. It can be argued that patients with low health literacy levels would feel more comfortable by using online information if they knew that the information was preselected and judged by their physician, whereas patients with high health literacy levels may find their way on the web themselves. From this perspective one could argue that patients with low health literacy levels would have higher intentions to use an IHCA for information purposes. On the other hand, it could also be argued that some advanced services, such as online access to electronic medical records and laboratory results, might be too difficult for people with low health literacy levels. Therefore, it is interesting to investigate if people with different levels of health literacy have different needs for online information and support, to optimize the development of services for various target groups.

In conclusion, this study aims to examine intentions of patients suffering from rheumatic diseases to use various online support services in the domains of information, communication and participation, if offered by their own hospital. In addition, we examine the influence of socio-demographics, health characteristics and health literacy on these reported intentions, to gain an overview of different needs that different patient groups have. Both of these goals are essential in the development of a valuable online support application within rheumatology care.

\section{Methods}

\section{Patients}

A survey was set up for data collection. We selected a random sample of 530 patients from the patient population in the electronic database of the rheumatology clinic of 
Medisch Spectrum Twente, in Enschede, the Netherlands. The pre-set inclusion criteria were: having a rheumatic diagnosis, having visited a rheumatologist in the past 6 months and an age $<70$ years. Treating rheumatologists $(n=6)$ were asked to exclude those patients who were deemed unsuitable for participation. Reasons mentioned for exclusion included age (too young to independently fill out the questionnaire), no proper mastery of the Dutch language, significant cognitive impairment, co-morbidity or change of hospital.

In total, 496 patients were sent a personal invitation letter and a paper-and-pencil questionnaire by their rheumatologists. A reminder was sent to those who did not respond within two weeks. Of the 496 patients approached, twelve invitations returned as undeliverable. The invitation letter explained the purpose of the study, the use of data, the voluntary nature and the anonymity of the participant, therefore returned questionnaires could be presumed as consent. According to local regulations in the Netherlands [Medical Research (Human Subjects) Act], the study did not need approval of the ethical review board, only (non-intervention) studies with high burden for patients have to be reviewed.

\section{Questionnaire}

The questionnaire comprised four parts: (i) socio-demographics and health characteristics; (ii) health literacy; (iii) general and health-related Internet usage; and (iv) intention to use different services on a rheumatology IHCA. The instrument was pre-tested with six participants. Minor revisions were made in formulation and layout according to the received remarks and recommendations.

The socio-demographic characteristics that were assessed included: age, gender, country of birth, marital status, education, employment and income. Patients were also asked what their diagnosis was, when they had received this diagnosis and how often they had visited their rheumatologist in the past twelve months. Health-related quality of life was assessed with the Short Form-12 (SF-12) [33]. Standardized scores for this scale were calculated for perceived physical and mental health varying from 0 (poor) to 100 (excellent), with a mean (S.D.) of 50 (10) in the general population of the USA, since scores for the Netherlands were not available [33].

Health literacy was measured using a scale by Ishikawa [34], which is a 14-item scale consisting of three sub-scales: functional health literacy (five items); communicative health literacy (five items); and critical health literacy (four items). Items of the original scale were translated into Dutch according to World Health Organization (WHO) guidelines [35]. Cronbach's alphas found in our translated scales were $0.86,0.86$ and 0.78 , respectively, and corresponded to $\alpha$-scores of the original version of the sub-scales [34].

Internet use was measured by asking patients if they had home Internet access, and, if so, how much they used the Internet on a five-point scale ranging from one (daily) to five ((almost) never). Health-related Internet use was measured by 18 items on use of different existing online applications for information (e.g. searching for different kinds of rheumatology information), communication (e.g. reading along and posting on a patient support group, asking questions to a physician or making an appointment) and participation (e.g. filling out self-tests and monitoring symptoms) (see Table 3 for all items). 
To measure intentions to use several services on a rheumatology IHCA in the future, examples of eight widely used online health services were given. The selection of these services derived from a former qualitative interview study on patient preferences for a rheumatology IHCA [8]. For each service, a short description of its purpose, possibilities and utilization was given. After that, the patient's intention to use it on a hospital-based IHCA was measured using a five-point Likert scale ranging from 1 (definitely not intend to use) to 5 (definitely intend to use). The eight services were: (i) provision of information about disease and treatment; (ii) provision of information about care and support; (iii) peer communication by support groups; (iv) patient-provider communication by e-consultation; ( $v$ ) autonomous symptom monitoring (scoring of variables such as pain, swollen joints, mood and activity that is visualized in graphs); (vi) symptom monitoring with tele-monitoring of the care provider (the care provider uses monitoring results in consults and treatment); (vii) self-management support (self-regulation of physical, psychological and social consequences by tips, tests and online support); and (viii) access to personal electronic medical records (providing information about their diagnosis, treatment plan and latest laboratory results). To conclude the questionnaire, the overall intention to use the IHCA was measured by asking patients how often they would visit the IHCA if it was available, using a five-point Likert scale ranging from 1 (never) to 5 (daily).

\section{Data analyses}

Data were analyzed using the Statistical Package for the Social Sciences (SPSS 17.0 for Windows, Chicago, IL, USA). Quantities, percentages and mean scores were calculated for patients' socio-demographics, health characteristics, health-related Internet use and intentions to use IHCA services. Kendall's tau was calculated to reveal correlations between intention to use the eight support services and the respondents' characteristics. $P<0.05$ was considered to be statistically significant.

\section{Results}

\section{Patient characteristics}

In total, $47 \%$ of the patients (227 out of 484 ) completed and sent back the questionnaire. The study sample consisted of a representative group of patients in our rheumatology clinic, as is shown in Table 1. Responders and non-responders did not differ on gender, but non-responders were on average 5 years younger, with a mean age of 47 years $(P=0.01)$. Also, patients who were diagnosed with RA showed a remarkable high response rate of $66 \%$. Mean scores on physical and mental health were comparable with those found by Ware et al. [33] in a sample of US RA patients (Table 2). The majority of the respondents $(87 \%)$ had Internet access and used it daily (53\%) or weekly (22\%). 
Table 1: Participants' self-reported socio-demographic characteristics and health literacy skills ( $\mathrm{n}=$ 227)

\begin{tabular}{|c|c|c|c|}
\hline Participant characteristics & & $\mathrm{n}$ & $\%$ \\
\hline \multirow[t]{2}{*}{ Gender } & Female & 143 & 63 \\
\hline & Male & 84 & 37 \\
\hline Age in years & Mean (S.D.) & 52 & (11.0) \\
\hline \multirow[t]{3}{*}{ Marital status } & Single & 42 & 18 \\
\hline & Living with partner & 183 & 81 \\
\hline & Unknown & 2 & 1 \\
\hline \multirow[t]{2}{*}{ Country of birth } & the Netherlands & 216 & 95 \\
\hline & Other & 11 & 5 \\
\hline \multirow[t]{4}{*}{ Education } & Low & 61 & 27 \\
\hline & Middle & 116 & 51 \\
\hline & High & 46 & 20 \\
\hline & Unknown & 4 & 2 \\
\hline \multirow[t]{2}{*}{ Employment } & Employed & 119 & 52 \\
\hline & Unemployed & 106 & 47 \\
\hline \multirow[t]{4}{*}{ Income } & Low & 55 & 24 \\
\hline & Average & 51 & 23 \\
\hline & High & 61 & 27 \\
\hline & Unknown & 60 & 26 \\
\hline Number of respondents with Internet access & & 198 & 87 \\
\hline \multirow[t]{6}{*}{ Amount of Internet usage } & (almost) Every day & 119 & 53 \\
\hline & Several days a week & 35 & 15 \\
\hline & About 1 day a week & 16 & 7 \\
\hline & Less & 10 & 4 \\
\hline & (almost) Never & 14 & 6 \\
\hline & Unknown & 33 & 15 \\
\hline Functional health literacy ${ }^{a}$ & Mean (S.D.) & 3.4 & (0.55) \\
\hline Communicative health literacy ${ }^{\mathrm{a}}$ & Mean (S.D.) & 2.8 & (0.64) \\
\hline Critical health literacy & Mean (S.D.) & 2.0 & $(0.67)$ \\
\hline
\end{tabular}

a Scores range from 1 (low skills) to 4 (high skills)

Table 2: Participants' self-reported health characteristics $(n=227)$

\begin{tabular}{llrr}
\hline Health characteristics & & $\mathrm{n}$ & $\%$ \\
\hline Diagnosis & Rheumatoid Arthritis & 93 & 44 \\
& Other rheumatic diseases & \\
& Unknown & 120 & 50 \\
Disease duration & No diagnosis yet & 14 & 6 \\
& $<1$ year & 9 & 4 \\
& $1-5$ years & 52 & 23 \\
& $>5$ years & 68 & 30 \\
Number of visits to the clinic in previous & Unknown & 97 & 43 \\
12 months & 1 & 1 & - \\
& $2-4$ & 32 & 14 \\
Physical health (SF12) & 4 or more & 158 & 70 \\
Mental health (SF12) & Mean (S.D.) & 37 & 16 \\
& Mean (S.D.) & 40.1 & $(10.2)$ \\
\hline
\end{tabular}

a 29 different diagnoses (e.g. Sjögren's Syndrome, Gout, Fibromyalgia). 


\section{Health-related Internet use}

Most participants with Internet access had searched for health-related information on rheumatic illnesses at some point in time (82\%) (Table 3), which is $71 \%$ of our total respondent population. Information searches on other rheumatology-related topics, as lifestyle, medication and treatment, and care and support were relatively high as well among patients with Internet access (49-63\%). However, searches on information about care providers, patient organizations and specific law regulations were fewer (32-35\%).

One in four participants with Internet access had ever read messages posted on a patient support forum, only $4 \%$ had ever posted a message themselves. Online communication with the physician or making an online appointment was not used very often. Use of services for participation in the care process was reported slightly higher. Symptom monitoring, ordering online medication and filling out a self-test were used by about onequarter of the participants. Online exercise programs were hardly used (3\%).

Table 3: Disease-related Internet use among patients with Internet access $(n=198)$

\begin{tabular}{llrr}
\hline Disease-related Internet use & & $\mathrm{n}$ & $\%$ \\
\hline Number of respondents who have ever & & 162 & 82 \\
searched for information on & the disease & 124 & 63 \\
& lifestyle & 122 & 62 \\
& medication & 96 & 49 \\
& treatments & 69 & 35 \\
& care providers & 67 & 34 \\
& patient organizations & 64 & 32 \\
Number of respondents who have ever & law regulations & & \\
used a peer support group forum to & read along with others & 45 & 23 \\
& post a message themselves & 8 & 4 \\
Number of respondents who have ever & chat with peer patients & 5 & 3 \\
communicated online to & & & \\
& ask a question to an online care & & \\
& provider & 28 & 14 \\
Number of respondents who have ever & ask a question to own provider & 23 & 12 \\
participated in their treatment by & schedule an appointment & 20 & 10 \\
& ordering online medication & 45 & 23 \\
& filling out a self-test & 46 & 23 \\
& monitoring symptoms & 49 & 25 \\
& an online exercise program & 5 & 3 \\
\hline
\end{tabular}

\section{Intentions to use IHCA support services}

Half of the participants would use the rheumatology IHCA several times a year; most other patients would use it several times a month (data not shown). Intention to use the eight different IHCA support services in the future is reported in Table 4. The two informationrelated services were very desirable: almost two-thirds of the respondents reported probably or definitely intending to use information on care and support and information on disease and treatment, when offered. Participation services were desirable as well: 
two-thirds of the participants would probably to definitely use the service to access their electronic medical records and the service to monitor symptoms with tele-monitoring by the care provider. Half of the respondents reported that they would probably or definitely use the participation services autonomous symptom monitoring and self-management support. Communication services were a little less popular: half of the participants would use an e-consultation service, but only one out of ten respondents had the intention to use online peer communication. More than half of the respondents reported to have no intention to use this service at all, while only a small part of the sample had probably to definitely no intention to use the other information, communication and participation services. Furthermore, $21-37 \%$ of patients reported that they were unsure if they would use various services if they were available (Table 4).

Table 4: Intention to use eight IHCA support services $(n=227)$

\begin{tabular}{|c|c|c|c|c|c|c|c|c|}
\hline \multirow[b]{2}{*}{ Support service } & \multicolumn{2}{|c|}{$\begin{array}{l}\text { Probably/Definitely } \\
\text { not }(1+2)\end{array}$} & \multicolumn{6}{|c|}{$\begin{array}{l}\text { Probably/Definitely yes } \\
\qquad(4+5)\end{array}$} \\
\hline & Count & $\%$ & Count & $\%$ & Count & $\%$ & M & S.D. \\
\hline \multicolumn{9}{|l|}{ Information } \\
\hline $\begin{array}{l}\text { Information about } \\
\text { disease and treatment }\end{array}$ & 18 & (9\%) & 51 & $(26 \%)$ & 127 & $(65 \%)$ & 3.7 & .86 \\
\hline $\begin{array}{l}\text { Information about care } \\
\text { and support }\end{array}$ & 19 & $(10 \%)$ & 53 & $(27 \%)$ & 121 & $(63 \%)$ & 3.7 & .85 \\
\hline \multicolumn{9}{|l|}{ Communication } \\
\hline E-consultations & 36 & $(19 \%)$ & 70 & $(36 \%)$ & 87 & $(45 \%)$ & 3.3 & 1.00 \\
\hline Peer support groups & 111 & (59\%) & 55 & $(30 \%)$ & 21 & $(11 \%)$ & 2.4 & .94 \\
\hline \multicolumn{9}{|l|}{ Participation } \\
\hline $\begin{array}{l}\text { Access to electronic } \\
\text { medical records }\end{array}$ & 21 & $(11 \%)$ & 41 & $(21 \%)$ & 131 & $(68 \%)$ & 3.9 & 1.00 \\
\hline $\begin{array}{l}\text { Symptom monitoring } \\
\text { with care provider }\end{array}$ & 12 & $(6 \%)$ & 58 & $(31 \%)$ & 120 & $(63 \%)$ & 3.7 & .87 \\
\hline $\begin{array}{l}\text { Autonomous symptom } \\
\text { monitoring }\end{array}$ & 31 & $(16 \%)$ & 62 & $(33 \%)$ & 95 & (51\%) & 3.4 & 1.00 \\
\hline $\begin{array}{l}\text { Self-management } \\
\text { support }\end{array}$ & 28 & $(14 \%)$ & 70 & $(37 \%)$ & 94 & $(49 \%)$ & 3.4 & .88 \\
\hline
\end{tabular}

\section{Associated factors}

The overall intention to use a rheumatology IHCA did not correlate with any of the sociodemographics, nor with any of the health literacy scales. Only mental health showed a significant, though weak correlation with intention $(\tau=-0.15)$, indicating that patients with a higher self-reported mental health had slightly lower intentions to visit the IHCA, if it would be available. Correlations between intention to use each of the eight single support services and respondent characteristics showed no clear associated factors as well (Table 5). Of the socio-demographic factors, age and gender showed small correlations with the services information provision and e-consultations $(\tau \leq 0.18)$. Older people were somewhat less interested in provider communication through e-consultation than younger 
people. Women were more inclined to seek information and to use e-consultations than men. Of the health characteristics, physical and mental health showed small correlations with access to an electronic medical record, self-management support and e-consultations $(\tau \leq-0.21)$. It seemed that patients who reported better physical health were less interested in accessing their electronic medical record. Patients who reported to function better mentally were less inclined to use self-management services and e-consultations. Health literacy showed small correlations between both communicative and critical health literacy and the services information about disease and treatment, e-consultations, peer support groups and access to their electronic medical records $(t \leq 0.18)$. Patients who scored higher on communicative health literacy reported a higher intention to use disease and treatment information and peer support groups. Patients who scored higher on critical health literacy were more inclined to use e-consultations, peer support communication and access to their electronic medical records. 


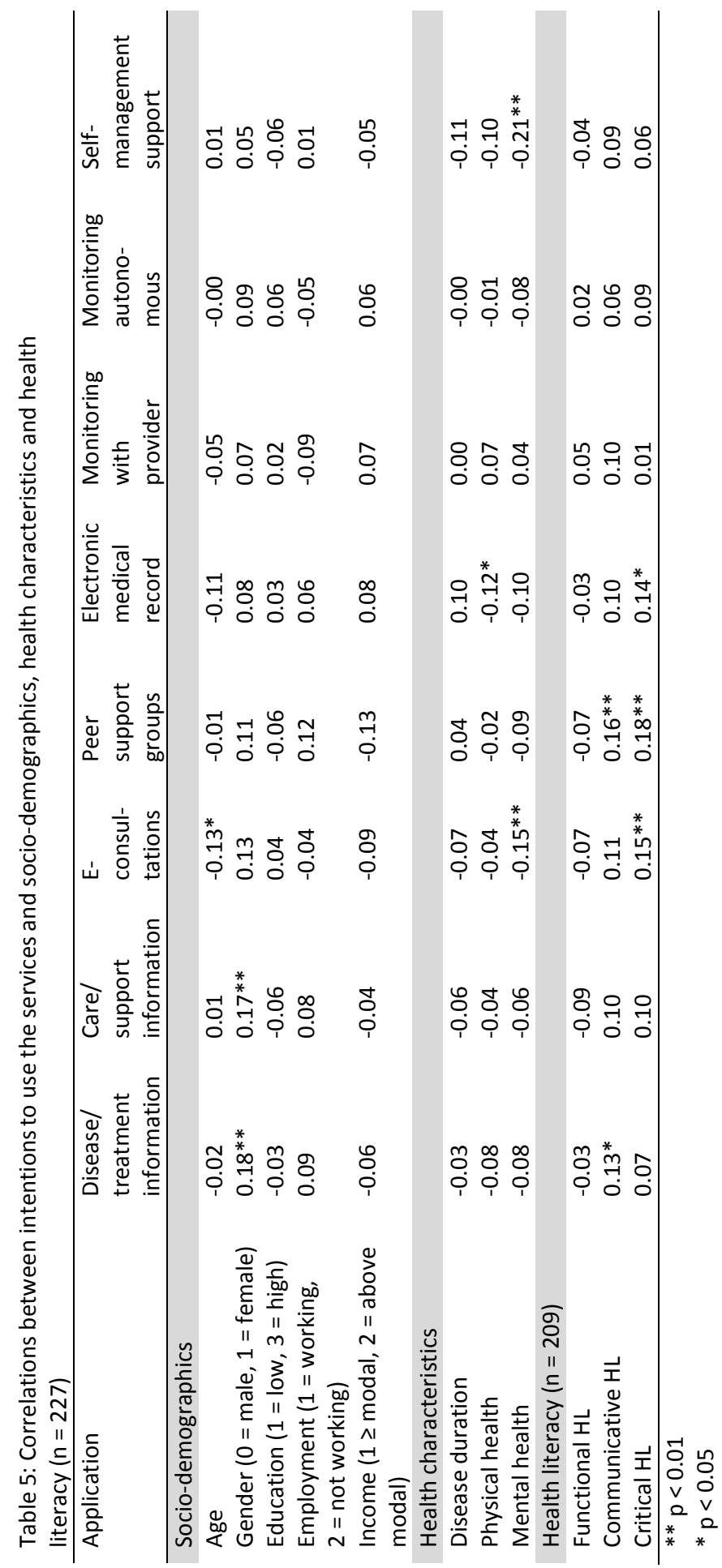




\section{Discussion}

Our study shows that current Internet use among patients with rheumatic diseases is high. Of the respondents, $87 \%$ had access to the Internet and $53 \%$ used it on a daily basis. These percentages are somewhat lower than those reported in National Surveys, i.e. $94 \%$ for Internet access and $76 \%$ for daily use in 2010 [36], which could be explained by the high proportion of elderly patients in our sample ( $55 \%$ were $\leq 55$ years old). Health-related Internet use among patients with Internet access was $82 \%$ in our study, and $71 \%$ in the total respondent population. When we compare these results with those from earlier studies among this patient group, it can be concluded that the use of online information by patients with rheumatic diseases has risen from $27 \%$ in 2002 [37] and 56\% in 2004 [38], to $71 \%$ in our study. Although this rise in Internet use might partly reflect a broader societal adaptation of Internet in general, these results do indicate that patients suffering from rheumatic diseases increasingly use the Internet to find health-related information. However, despite this increase, we found that health-related Internet use often remains limited to searching information; our study shows that patients hardly use any other support services, such as online facilities for communication (such as e-consultations and patient support forums) or participation (such as online self-tests and self-management programs). These findings agree with previous studies $[21,22,39,40]$.

Despite this low reported current use of online support services, we found that patients are interested in various online support services when provided on an IHCA of their hospital. Our study shows that both the overall intentions of the participants and their intentions to use several different support services on a rheumatology IHCA are fairly high. Besides information provision, patients were most interested in participation services, especially access to their electronic medical records, followed by symptom monitoring - if tele-monitored and used by the care provider. Previous studies, among other patient groups, have also showed this desire for online health support $[41,42]$ as well as a high interest in online access to personal medical data $[8,43,44]$. The discrepancy in current use and desires for future use indicates a need for supply of such services, in a way that patients can be certain of the safety and reliability of the information.

Previous studies on associations between socio-demographic factors, healthrelated factors and (intention to) health technology use did not find conclusive results. Our study did not find any clear related factors, nor for intention to use the IHCA as a whole, nor for the intention to use the various services on it. Regarding the influence of socio-demographics, it is often assumed that both older people and people with a lower educational level use the Internet less for health-related purposes [19]. However, our results did not show any substantial correlations between reported intentions and age or education. An explanation for the lack of correlation between age and intention to use an IHCA could be that participants in our study were fairly old in general, and thus there was little distribution of age. Still, other studies have also shown positive results for the usage of health technology by older people $[45,46]$, and some suggest that older adults use the Internet for health information equally to adolescents [47]. Possibly, the gap in Internet usage between younger and older people is decreasing, as the Internet is getting more common in our society. We were somewhat surprised about the lack of a relationship between educational level and intention to use the IHCA, because in previous studies it has generally been found that lower education is related to less health technology use [48]. It 
seems that, although it might be more difficult for people with lower educational levels to find their way on the Internet by themselves, they nevertheless intend to use information and support when it is offered on the Internet by their physician. While this lack of a relationship has been found earlier as well $[49,50]$ only the future will determine whether patients with a lower educational level will indeed use the rheumatology IHCA to the same degree as more highly educated patients.

To our knowledge, our study is the first to examine patients' health literacy levels in relation to their intentions to use various health technology services. It was anticipated that patients with low health literacy levels would prefer other services than patients with high health literacy levels. However, we found only small correlations between health literacy and intentions to use the IHCA, and all relations proved to be positive, indicating that high health literacy was associated with stronger intentions to use the particular service. There were no indications that patients with low health literacy levels had preferences for certain services. Apparently, patients' competency in finding and using health-related information and support does not correlate with their future intention to use a rheumatology IHCA. From this we might conclude that the development of an IHCA, provided by the hospital, would be a valuable addition to care for everyone, independent of patients' skills to find their own way on the Internet. Perhaps the question should not be whether patients with different health literacy levels desire different services, but whether patients with different health literacy levels desire different presentation of services. An IHCA would be optimally suitable for tailoring services since its technology can use animated pictures, videos and sounds to support differentiated supply of information and support [51]. Judicious use of these supporting tools could enhance the use and acceptability of online services among patients with different health literacy levels, as well as among patients in different age groups and with a different educational level.

Due to some limitations of the study, some caution is necessary when interpreting our results. Firstly, due to non-response, our results on patients' reported intentions might be somewhat overly optimistic. We saw a significant difference in age between responders and non-responders, with the non-responders being younger than the responders. Possibly older people have more severe and life-interfering symptoms, which makes them more interested in (responding to questionnaires about) information and support in general. This was also reflected in the difference in diagnosis between responders and non-responders, with a higher response rate among patients with RA, which has a large impact on people's daily lives. Secondly, we asked participants to indicate their intentions to use services that are currently not (yet) available or that they did not use before. To report such intentions one must have a fairly good idea of what the service withholds. For example, the relatively limited interest in e-consultations might be related to inexperience and/or lack of access to this service, since our hospital does not yet provide such a service. Furthermore, we should be aware that we measured patients' intentions, which is not the same as actual use [52]. Although research in the information technology domain on acceptation of applications has shown that behavioral intentions are a good predictor of acceptance and actual use of technological applications [53], further research after the development is necessary to measure actual use of the application. Furthermore, to create optimal acceptance and use of our IHCA, research on attitudes, possibilities and barriers according to the involved health professionals should 
also be included in the user-centered development [54].

In conclusion, our results show that patients' current health-related Internet use is mainly limited to searching information, but they do intend to use various online communication and participation services in the future, when offered by the hospital. Clear related factors for these reported intentions, to use the IHCA in general and to use the separate services, were not found.

\section{Acknowledgements}

We would kindly like to thank the participants of the survey, and the rheumatologists and rheumatology secretariat of Medisch Spectrum Twente, Enschede, for their participation and contribution to this study. This work was supported by an unrestricted educational grant from Wyeth Pharmaceuticals, part of Pfizer Inc. This funding source had no involvement in data collection, analysis or the preparation of this manuscript. 


\section{References}

1 Powell JA, Darvell M, Gray JAM. The doctor, the patient and the world-wide web: how the Internet is changing healthcare. J R Soc Med 2003; 96: 74-6.

2 Solomon MR. Information technology to support self-management in chronic care: a systematic review. Dis Manag Health Outcomes 2008; 16: 391-401.

3 Eysenbach G. Medicine 2.0: social networking, collaboration, participation, apomediation, and openness. J Med Internet Res 2008; 10: e22.

4 Dorr D, Bonner LM, Cohen AN, Shoai RS, Perrin R, Chaney E, Young AS. Informatics systems to promote improved care for chronic illness: a literature review. J Am Med Inform Assoc 2007; 14: 156-63.

5 Garcia-Lizana F, Sarria-Santamera A. New technologies for chronic disease management and control: a systematic review. J Telemed Telecare 2007; 13: 62-8.

6 Murray E, Burns J, See Tai S, Lai R, Nazareth I. Interactive health communication applications for people with chronic disease. Cochrane Database of Syst Rev 2009;(1) Article number: CD004274.

7 Kjeken I, Dagfinrud H, Mowinckel P, Uhlig T, Kvien TK, Finset A. Rheumatology care: involvement in medical decisions, received information, satisfaction with care, and unmet health care needs in patients with rheumatoid arthritis and ankylosing spondylitis. Arthritis Care Res 2006; 55: 394-401.

8 Van der Vaart R, Drossaert CHC, Taal E, Van de Laar MAFJ. Experiences and preferences of patients with rheumatic diseases regarding an interactive health communication application. In: eTELEMED'10 Second International Conference on eHealth, Telemedicine, and Social Medicine, Saint Martin, 2010:64-71. doi: 10.1109/eTELEMED.2010.16.

9 Kreps G, Neuhauser L. New directions in eHealth communication: opportunities and challenges. Patient Educ Couns 2010; 78: 329-36.

10 Lapsley $\mathrm{P}$, Groves $\mathrm{T}$. The patient's journey: travelling through life with a chronic illness, authors. Br Med J 2004; 329: 582-3.

11 Demiris G, Afrin LB, Speedie S, Courtney KL, Sondhi M, Vimarlund V, Lovis C, Goossen W, Lynch C. Patient-centered applications: use of information technology to promote disease management and wellness. A white paper by the AMIA knowledge in motion working group. J Am Med Inform Assoc 2008; 15: 8-13.

12 Keselman A, Logan R, Smith CA, Leroy G, Zeng-Treitler Q. Developing informatics tools and strategies for consumer-centered health communication. J Am Med Inform Assoc 2008; 15: 473-83.

13 Ball MJ, Lillis J. E-health: transforming the physician/ patient relationship. Int J Med Inform 2001; 61: 1-10.

14 Gustafson DH, Hawkins R, Boberg E, Pingree S, Serlin RE, Graziano F. Impact of a patient-centered, computer-based health information/support system background: Consumer health information systems potentially improve a patient's quality of life and activate patient self-care. Am J Prev Med 1999; 16: 1-9.

15 Stinson JN, McGrath PJ, Hodnett ED, Feldman B, Duffy C, Huber A, Tucker L, Hetherington R, Tse S, Spiegel L, Campillo S, Gill N, White M. Usability testing of an 
online self-management program for adolescents with juvenile idiopathic arthritis. J Med Internet Res 2010; 12: e30.

16 Stinson JN, McGrath PJ, Hodnett ED, Feldman BM, Duffy CM, Huber AM, Tucker LB, Hetherington CR, Tse SML, Spiegel LR, Campillo S, Gill NK, White ME. An Internetbased self-management program with telephone support for adolescents with arthritis: a pilot randomized controlled trial. J Rheumatol 2010; 37: 1944-52.

17 Lorig K, Ritter PL, Laurent DD, Plant K. The Internet-based arthritis selfmanagement program: a one-year randomized trial for patients with arthritis or fibromyalgia. Arthr Care Res 2008; 59: 1009-17.

18 Shigaki CL, Smarr KL, Gong Y. Social interactions in an online self-management program for rheumatoid arthritis. Chronic Illness 2008; 4: 239-46.

19 Or CKL, Karsh B. A systematic review of patients acceptance of consumer health information technology. J Am Med Inform Assoc 2009; 16: 550-60.

20 Wilson EV, Lankton NK. Modeling patients' acceptance of provider-delivered ehealth. J Am Med Inform Assoc 2004; 11: 241-8.

21 Van Uden-Kraan CF. Online peer support for patients with somatic diseases. (Doctoral Dissertation): University of Twente, Enschede, the Netherlands; 2008.

22 Pagliari C. Design and evaluation in eHealth: challenges and implications for an interdisciplinary field. J Med Internet Res 2007; 9: e15.

23 Stinson JN, Toomey PC, Stevens BJ, Kagan S, Duffy CM, Huber A, Malleson P, McGrath PJ, Yeung RSM, Feldman BM. Asking the experts: exploring the selfmanagement needs of adolescents with arthritis. Arthritis Rheum 2008; 59: 65-72.

24 Stinson JN, Stevens BJ, Feldman BM, Streiner D, McGrath PJ, Dupuis A, Gill N, Petroz GC. Construct validity of a multidimensional electronic pain diary for adolescents with arthritis. Pain 2008; 136: 281-92.

25 Ansani NT, Fedutes-Henderson BA, Weber RJ, Smith R, Dean J, Vogt M, Gold K, Kwoh CK, Osiol T, Starz TW. The drug information center arthritis project: providing patients with interactive and reliable arthritis Internet education. Drug Inf J 2006; 40: 39-49.

26 Van Lankveld WGJM, Derks AM, van den Hoogen FHJ. Disease related use of the Internet in chronically ill adults: current and expected use. Ann Rheum Dis 2005; 65: 121-3.

27 Nguyen HQ, Carrieri-Kohlman V, Rankin SH, Slaughter R, Stulbarg MS. Internetbased patient education and support interventions: a review of evaluation studies and directions for future research. Comput Bio Med 2004; 34: 95-112.

28 Wilson AS, Kitas GD, Llewellyn P, Carruthers DM, Cheseldine DC, Harris S, Huissoon AP, Bacon PA, Young, SP. Provision of Internet-based rheumatology education. Rheumatology 2001; 40: 645-51.

29 Dominick GM, Friedman DB, Hoffman-Goetz L. Do we need to understand the technology to get to the science? A systematic review of the concept of computer literacy in preventive health programs. Health Educ J 2009; 68: 296.

30 Protheroe J, Nutbeam D, Rowlands J. Health literacy: a necessity for increasing participation in health care. Brit J Gen Pract 2009; 59: 721-3.

31 Ad Hoc Committee on Health Literacy for the Council on Scientific Affairs, American Medical Association. Health Literacy: Report of the Council on Scientific Affairs. J 
Am Med Assoc 1999; 281: 552-7.

32 Baker DW. The meaning and the measure of health literacy. Gen Intern Med 2006; 21: 878-83.

33 Ware JE, Kosinski MA, Turner-Bowker DM, Gandek B. User's manual for the SF-12v2 health survey. Lincoln, RI: QualityMetric Incorporated, 2002.

34 Ishikawa $\mathrm{H}$, Takeuchi $\mathrm{T}$, Yano $\mathrm{E}$. Measuring functional, communicative, and critical health literacy among diabetic patients. Diabetes Care 2008; 31: 874-9.

35 World Health Organisation. Process of translation and adaptation of instruments. http://www.who.int/substance_ abuse/research_tools/translation/en/index.html (19 March 2010, date last accessed).

36 Central Bureau for Statistics Statline -ICT use of people according to person characteristics [Centraal Bureau voor de Statistiek Statline -ICT gebruik van personen naar persoonskenmerken]. http://statline.cbs.nl/StatWeb/ publication/?DM=SLNL\&PA=71098ned\&D1=3-14,23,27133\&D2=0-2,46\&D3=a\&HDR=G1\&STB=T,G2\&VW=T (16 February 2011, date last accessed).

37 Gordon MM, Capell HA. The use of the Internet as a resource for health information among patients attending a rheumatology clinic. Rheumatology 2002; 41: 1402-5.

38 Richter JG, Becker A, Specker C, Monser R, Schneider M. Disease-oriented Internet use in outpatients with inflammatory rheumatic diseases. Z Rheumatol 2004; 63: 216-22.

39 Richter JG, Becker A, Koch T, Nixdorf M, Schacher B, Monser R, Specker C, Alten R, Schneider $M$. Internet use in rheumatology outpatients in 2006: gender less important. Clin Exp Rheumatol 2006; 27: 15-21.

40 Richter JG, Becker A, Koch T, Willers R, Nixdorf M, Schacher B, Monser R, Specker C, Alten $\mathrm{R}$, Schneider $\mathrm{M}$. Changing attitudes towards online electronic health records and online patients documentation in rheumatology outpatients. Clin Exp Rheumatol 2010; 28: 261-4.

41 Anderson JG. Consumers of e-health: patterns of use and barriers. Soc Sci Comput Rev 2004; 22: 242-8.

42 Atkinson NL, Saperstein SL, Pleis J. Using the Internet for health-related activities: findings from a national probability sample. J Med Internet Res 2009; 11: e4.

43 Silvestre A, Sue VM, Allen JY. If you build it, will they come? The Kaiser permanent model of online health care. Health Aff 2009; 28: 334-44.

44 Hassol A, Walker JM, Kidder D, Rokita K, Young D, Pierdon S, Deitz D, Kuck S, Ortiz,E. Patient experiences and attitudes about access to a patient electronic health care record and linked web messaging. J Am Med Inform Assoc 2004; 11(6).

45 Singh H, Fox SA, Petersen NJ, Shethia A, Strreet RL. Older patients' enthusiasm to use electronic mail to communicate with their physicians: cross-sectional survey. J Med Internet Res 2009; 11: e18.

46 Carrell D, Ralston JD. Variation in adoption rates of a patient web portal with a shared medical record by age, gender, and morbidity level. American Medical Association Symposium Proceedings. Washington DC, USA, 2006:871.

47 Ybarra $M$, Suman $M$. Reasons, assessments and actions taken: sex and age differences in uses of Internet health information. Health Educ Res 2008; 23: 512 - 
21.

48 Hay MC, Cadigan J, Khanna D, Strathmann C, Lieber E, Altman R, McMahon M, Kokhab M, Furst DE. Prepared patients: Internet information seeking by new rheumatology patients. Arthrit Care Res 2008 Apr; 59(4): 575-82.

49 Boberg EW, Gustafson DH, Hawkins RP, Chan C, Bricker E, Pingree S, Berhe H. Development, acceptance, and use patterns of a computer-based education and social support system for people living with AIDS/HIV infection. Comput Hum Behav 1995; 11: 289-311.

50 Siva C, Smarr KL, Donovan Hanson K, Parikh M, Lawlor K, Ge B. Internet use and email communications between patients and providers: a survey of rheumatology outpatients. J Clin Rheumatol 2006; 14: 318-23.

51 Bodie GD, Dutta MJ. Understanding health literacy for strategic health marketing: eHealth literacy, health disparities, and the digital divide. Health Marketing Q 2008; 25: 175-203.

52 Flynn D, Gregory P, Makki H, Gabbay M. Expectations and experiences of eHealth in primary care: a qualitative practice-based investigation. Int J Med Inform 2009; 78: 588-604.

53 Davis FD. User acceptance of information technology: system characteristics, user perceptions and behavioral impacts. Int J Man Mach Stud 1993; 38: 475-87.

54 Kerr C, Murray E, Stevenson F, Gore C, Nazareth I. Internet interventions for longterm conditions: patient and caregiver quality criteria. J Med Internet Res 2006; 8: e13 
Chapter 4

\title{
Giving rheumatology patients online home access to their electronic medical record \\ (EMR): advantages, drawbacks and preconditions according to care providers
}

\author{
Rosalie van der Vaart \\ Constance H.C. Drossaert \\ Erik Taal \\ Mart A.F.J. van de Laar
}

Rheumatology International 2012, ePub ahead of print 


\section{Abstract}

Objectives: Technology enables patients home access to their electronic medical records (EMR), via a patient web portal. This study aims to analyze (dis)advantages, preconditions and suitable content for this service, according to rheumatology health professionals.

Methods: A two-phase policy Delphi study was conducted. First, interviews were performed with nurses/nurse practitioners $(n=9)$ and rheumatologists $(n=13)$. Subsequently, collected responses were quantified, using a questionnaire among the interviewees.

Results: The following advantages of patient home access to the EMR were reported: (1) enhancement of patient participation in treatment, (2) increased knowledge and selfmanagement, (3) improved patient-provider interaction, (4) increased patient safety, and (5) better communication with others. Foreseen disadvantages of the service included: (1) problems with interpretation of data, (2) extra workload, (3) a change in consultation content, and (4) disturbance of the patient-provider interaction. Also, the following preconditions emerged from the data: (1) optimal security, (2) no extra record, but a patient-accessible section, (3) no access to clinical notes, and (4) a lag time on the release of lab data. Most respondents reported that data on diagnosis, medication, treatment plan and consultations could be released to patients. On releasing more complex data, such as bodily examination results, lab results and radiological images the opinions differed considerably.

Conclusion: Providing patients home access to their medical records might be a valuable next step into patient empowerment and in service towards the patient, provided that security is optimal and content and presentation of data are carefully considered. 
Providing patients online home access to their electronic medical records (EMR) offers a new perspective on patient empowerment [1]. In several studies, including studies in rheumatology, patients are found to be eager to access their EMR, independent of age, race or educational level [2-7]. Patients report that it would enhance involvement in their treatment and that it would give them the feeling of ownership of their own medical information [7]. However, despite potential benefits and patients' positive attitudes, studies among health professionals in several areas show that professionals are more cautious towards providing patients home access to their EMR $[2,8,9]$. While health professionals have acknowledged benefits, such as increased patient knowledge and empowerment, or improved doctor-patient communication, many concerns about confused patients and increased workload still remain $[2,10]$. As a result, the service of providing patients home access to their medical data remains scarcely implemented $[9,11]$.

In the field of rheumatology, patient home access to the EMR seems particularly useful, since patient self-management and patient involvement in their treatment are considered highly important due to the chronic nature of many rheumatic conditions. Moreover, rheumatology care providers often have a long-term treatment relationship with their patients, in which cooperation plays an important role [12]. Yet, no previous studies on providing rheumatology patients online access to their EMR have been published. Knowledge on how rheumatology care providers feel about offering their patients home access to their EMR is, therefore, lacking. The aim of this study was to analyze rheumatology care providers' foreseen advantages and disadvantages towards this service, and to examine how this service could be used in clinical practice.

\section{Methods}

A policy Delphi method was used [13], in which care providers' opinions on patient home access to the EMR were explored, using qualitative interviews, and in which areas of (dis)agreement were identified in a quantitative survey containing questions based on the interview data $[14,15]$.

\section{Recruitment of participants}

Twenty-two rheumatologists and thirteen nurses/nurse practitioners, from twelve hospitals spread over The Netherlands, were randomly selected from the most recent versions of the Dutch Rheumatology Association's member lists [16,17]. Thirteen rheumatologists (59\%) and nine nurses/nurse practitioners (69\%) from nine different hospitals agreed to participate in an interview. The interviews were scheduled the care providers' hospital and took approximately 45 minutes. Data saturation was reached, meaning that no new information of added value was obtained in the final three interviews [18].

\section{Phase 1: interviews}

Each interview started off by asking care providers about their work-related Internet use, and their views on using a patient web portal in rheumatologic care. The interviews continued by showing care providers a paper prototype of an online patient-accessible 
EMR, offering patients home access to their diagnosis, medication, treatment plan and latest lab results, and access to care providers' clinical notes. The interview scheme contained the following fixed questions: "What would be the advantages/disadvantages of this service?" "Would the advantages/disadvantages differ for patients and care providers?" and "What preconditions or guidelines would you set for this service on a hospital based patient web portal?"

The audiotapes of the interviews were transcribed verbatim. Using content analysis, two independent researchers (RvdV and CHCD) selected quotes on advantages, disadvantages and preconditions, and coded them into categories. Subsequently, these categories were discussed between the two researchers, until consensus about the final categories was reached.

\section{Phase 2: questionnaire}

In phase two, the categories of responses from phase 1 were translated into a questionnaire with pre-formulated answer categories. Each item could be answered on a 5-point Likert scale, ranging from "definitely yes" to "definitely no". Tables 1 and 2 provide an overview of the categories and items on advantages and disadvantages, respectively. Table 3 shows three additional items which reflect preconditions mentioned by the care providers in the interviews. Additionally, items were designed to examine suitable content for a patient home-accessible EMR (see Table 4). Results from the questionnaire were analyzed by quantifying scores on each item and calculating percentages of care providers who agreed, were neutral or disagreed on the items.

\section{Results}

\section{Participants}

Twenty-two care providers were interviewed in phase 1 . All the nurses/nurse practitioners $(n=9)$ were female, with a mean age of 40 years (range 26-52). Among the interviewed rheumatologists $(n=13)$ Five were male and eight were female, with a mean age of 46 years (range 38-64). All interviewees used the Internet regularly, also for work-related purposes. In phase 2 , response on the questionnaire was $77 \%$, in total, eight nurses/nurse practitioners and nine rheumatologists completed the questionnaire, with a mean age of 44 years (range 28-64).

\section{Phase 1: interviews}

\section{Perceived advantages to patient home EMR access}

Five main categories of advantages could be distinguished. First, a large majority of the interviewees felt that the service could improve patient participation and involvement in the treatment process. "I can imagine that as a patient, you'd like to look through your data before a consultation. That way, you'd be more prepared." [Nurse practitioner, Female, 50 years old]. Second, several care providers mentioned that the service could enhance patients' knowledge and make them better informed about their disease and treatment. This might enhance treatment adherence, since patients could have a better 
understanding of how and why their treatment works. Third, the service might affect the patient-provider interaction, due to the shared information and the openness of the records: "People can have strange ideas on what doctors write about them. Sometimes there is a feeling of mistrust, which can be taken away by this." [Rheumatologist, Female, 47 years old]. Furthermore, a few care providers reported that the service could positively influence patient safety, since the reading along of patients might reduce mistakes. "I think it forces us to write things down very precisely." [Rheumatologist, Female, 43 years old]. Finally, improved communication with others was mentioned. Because patients would have their own data available, it could help them to recall what was said in the consult, which could enhance communication with relatives or other doctors. Also, patients would have their data available on vacation or abroad, which was perceived as useful in emergency situations.

\section{Perceived disadvantages to patient home EMR access}

Disadvantages of patient home access to the EMR could be divided into four categories (Table 2). Many care providers assumed a lack of knowledge and understanding of EMRdata among a large amount of patients, which could cause fear and stress among patients due to misinterpretation. Second, the service could require extra work or a change in administration, because physicians might have to explain and clarify a lot more, both in consult and in the records itself. Third, some care providers feared that the EMR access would change the emphasis of the consultation and would absorb valuable consult time. "Then you get all sorts of questions if this or that is increased or decreased. Subsequently, you need 10 minutes to explain all these little things." [Rheumatologist, Male, 61 years old]. Finally, the service could have a reverse effect on the patient-provider relationship, since a few care providers expected offended or worried patients due to physicians' personal notes concerning a patient. "Sometimes you impetuously write your own conclusion of a consultation, for example, a comment about treatment adherence. You have to write that in the record somewhere, but it can be a sensitive topic." [Rheumatologist, Female, 40 years old].

\section{Preconditions for patient home EMR access}

Conserning preconditions, it is essential that the technology is solid and safe, to protect and ensure patients' privacy. Furthermore, a number of care providers mentioned that the home-accessible EMR should be an extraction of the existing EMR, and not a separate record, to overcome extra work and mistakes. "It should not generate extra work, for example that you become obliged to type something about the lab results. Because then I'm just typing as a service towards the patient. And that is not what I need for myself, to pursue a good policy." [Rheumatologist, Female, 44 years old]. The third precondition was a filter on the personal and clinical notes of the care provider. Most care providers felt it would be unpleasant and undesirable if patients read their clinical notes, which often contain jargon, personal considerations, and diagnostic considerations. "Sometimes you make a differential diagnosis, for we often have to think of cancer. While 99\% of the time it isn't cancer, I do have to write it down. So, I wouldn't let them read along in my clinical notes, it can be alarming. I'm not there to explain it" [Rheumatologist, Female, 49 years 
old]. Finally, opinions vary on the medical data that could be released to patients, including how and when this data should be presented. According to several care providers, information on lab results should not be available to patients until after the consult, in order to explain matters to patients, and to put the results into context. The results of phase 2 of our Delphi study present a complete overview of what medical data would be suitable to release to patients.

\section{Phase 2: questionnaire}

Table 1 shows the answering frequencies of the items related to advantages of patient home access to the EMR. According to the respondents, the service could particularly have a positive influence on patients' participation in treatment (65-88\%), their knowledge and self-management (77-82\%), and their communication with others (76\%). The most frequently agreed upon disadvantage, regarded patients' skills to interpret their medical information (88\%) (Table 2). As for preconditions, according to $94 \%$ of the respondents, the home-accessible record should be an extraction of the existing EMR, and not a separate record (Table 3). Furthermore, $82 \%$ would prefer an inaccessible section in the record, to write down personal notes. A lag time on the release of lab data was an important precondition for $65 \%$ of the respondents. Table 4 provides an overview of suitable content for a patient home-accessible EMR. Large parts of the disease and treatment data could be released to patients, according to most respondents. However, on more complicated outcomes, such as results of physical examinations, several lab results and radiological images, a differentiation is shown between the care providers. Moreover, most respondents (71\%) did not want patients to have access to their clinical notes. 
Table 1: Advantages of patient home access to the EMR (arranged in categories obtained in phase 1 ) $(\mathrm{n}=17)$

\begin{tabular}{|c|c|c|c|}
\hline Questionnaire item & $\begin{array}{l}\text { Definitely/ } \\
\text { Probably } \\
\% *(n)\end{array}$ & $\begin{array}{l}\text { Neutral } \\
\% *(n)\end{array}$ & $\begin{array}{l}\text { Definitely not/ } \\
\text { Probably not } \\
\%^{*}(\mathrm{n})\end{array}$ \\
\hline \multicolumn{4}{|l|}{ Patient participation } \\
\hline $\begin{array}{l}\text { It could help the patient prepare for consult. } \\
\text { It could enhance the patients' feeling of grip/control }\end{array}$ & $88(15)$ & $12(2)$ & $0(0)$ \\
\hline on the treatment. & $82(14)$ & $18(3)$ & $0(0)$ \\
\hline The patient could get more involved in the treatment. & $82(14)$ & $18(3)$ & $0(0)$ \\
\hline $\begin{array}{l}\text { It could enhance shared decision making. } \\
\text { It could enhance autonomy/emancipation of the }\end{array}$ & $82(14)$ & $18(3)$ & $0(0)$ \\
\hline patient. & $65(11)$ & $29(5)$ & $6(1)$ \\
\hline \multicolumn{4}{|l|}{ Knowledge \& self-management } \\
\hline It could enhance insight/understanding in the disease. & $82(14)$ & $18(3)$ & $0(0)$ \\
\hline The patient could be better informed $(n=16)$ & $81(13)$ & $19(3)$ & $0(0)$ \\
\hline It could enhance therapy adherence. & $77(13)$ & $18(3)$ & $6(1)$ \\
\hline \multicolumn{4}{|l|}{ Patient - provider interaction } \\
\hline $\begin{array}{l}\text { It could improve the trust that patients have in their } \\
\text { care provider. }\end{array}$ & $53(9)$ & $29(5)$ & $18(3)$ \\
\hline It could equalize patient-provider communication. & $47(8)$ & $41(7)$ & $12(2)$ \\
\hline It could enhance the patient-provider relationship. & $47(8)$ & $29(5)$ & $24(4)$ \\
\hline \multicolumn{4}{|l|}{ Patient safety } \\
\hline $\begin{array}{l}\text { It could enhance safety of care, for patients can read } \\
\text { along and detect mistakes. }\end{array}$ & $59(10)$ & $24(4)$ & $18(3)$ \\
\hline \multicolumn{4}{|l|}{ Communication with others } \\
\hline $\begin{array}{l}\text { It could support patients in communicating with } \\
\text { friends and family about their disease and treatment, } \\
\text { because they can look at the record together. } \\
\text { It is practical that the patient can take the record } \\
\text { along to another hospital/GP/on vacation. }\end{array}$ & $76(13)$ & $18(3)$ & $6(1)$ \\
\hline
\end{tabular}

*Percentages do not always end up to $100 \%$ because of rounding 
Table 2: Disadvantages of patient home access to the EMR (arranged in categories obtained in phase 1) $(n=17)$

\begin{tabular}{|c|c|c|c|}
\hline Questionnaire item & $\begin{array}{l}\text { Definitely/ } \\
\text { Probably } \\
\% *(n)\end{array}$ & $\begin{array}{l}\text { Neutral } \\
\% *(n)\end{array}$ & $\begin{array}{l}\text { Definitely not/ } \\
\text { Probably not } \\
\% *(n)\end{array}$ \\
\hline \multicolumn{4}{|l|}{ Interpretation of data } \\
\hline $\begin{array}{l}\text { Patients might lack knowledge/insight for a good } \\
\text { interpretation of the whole record. } \\
\text { It could cause fear, stress or agitation. }\end{array}$ & $\begin{array}{l}88(15) \\
65(11)\end{array}$ & $\begin{array}{l}12(2) \\
29(5)\end{array}$ & $\begin{array}{l}0(0) \\
6(1)\end{array}$ \\
\hline \multicolumn{4}{|l|}{ Requires extra work/change in administration } \\
\hline $\begin{array}{l}\text { As a care provider I will have to explain a lot more } \\
\text { to patients. } \\
\text { It will be difficult to (have to) write things } \\
\text { differently (in layman's terms). }\end{array}$ & $65(11)$ & $18(3)$ & $18(3)$ \\
\hline \multicolumn{4}{|l|}{ Change in consult } \\
\hline $\begin{array}{l}\text { It could prevent me from being complete in my } \\
\text { clinical notes (e.g. less personal interpretation). } \\
\text { The emphasis of the consult could lie too strongly } \\
\text { on the EMR. }\end{array}$ & $\begin{array}{l}53(9) \\
29(5)\end{array}$ & $\begin{array}{l}24(4) \\
53(9)\end{array}$ & $\begin{array}{l}24(4) \\
18(3)\end{array}$ \\
\hline \multicolumn{4}{|l|}{ Patient - provider interaction } \\
\hline $\begin{array}{l}\text { It could cause friction or a feeling of insult among } \\
\text { patients (e.g. when they read care providers' } \\
\text { clinical notes). }\end{array}$ & $53(9)$ & $41(7)$ & $6(1)$ \\
\hline
\end{tabular}

*Percentages do not always end up to $100 \%$ because of rounding

Table 3: Preconditions of patient home access to the EMR $(n=17)$

\begin{tabular}{llll}
\hline Questionnaire item & $\begin{array}{l}\text { Definitely/ } \\
\text { Probably } \\
\%(n)\end{array}$ & $\begin{array}{c}\text { Neutral } \\
\%(n)\end{array}$ & $\begin{array}{l}\text { Definitely not/ } \\
\text { Probably not } \\
\%(n)\end{array}$ \\
\hline $\begin{array}{l}\text { There should be a separate section in the EMR } \\
\text { which is not visible for patients. }\end{array}$ & $82 \%(14)$ & $6 \%(1)$ & $12 \%(2)$ \\
$\begin{array}{l}\text { There should be a lag time on the release of lab } \\
\text { results until after the consult. }\end{array}$ & $65 \%(11)$ & $18 \%(3)$ & $18 \%(3)$ \\
$\begin{array}{l}\text { A patient-accessible EMR should be a copy of the } \\
\text { existing EMR, and not an extra record. }\end{array}$ & $94 \%(16)$ & $6 \%(1)$ & $0(0)$ \\
\hline
\end{tabular}


Table 4: Content of the EMR that should be available for patients, according to care providers $(n=17)$

\begin{tabular}{llll}
\hline Content & $\begin{array}{l}\text { Positive } \\
\%^{*}(\mathrm{n})\end{array}$ & $\begin{array}{l}\text { Neutral } \\
\%^{*}(\mathrm{n})\end{array}$ & $\begin{array}{l}\text { Negative } \\
\%^{*}(\mathrm{n})\end{array}$ \\
\hline Basic information & & & \\
Diagnosis & $100(17)$ & $0(0)$ & $0(0)$ \\
Allergies & $100(17)$ & $0(0)$ & $0(0)$ \\
Medical history & $100(17)$ & $0(0)$ & $0(0)$ \\
Medication & & & \\
Prescribed medication & $100(17)$ & $0(0)$ & $0(0)$ \\
(side)Effects medication & $88(15)$ & $12(2)$ & $0(0)$ \\
Medication history & $82(14)$ & $18(3)$ & $0(0)$ \\
Contra-indications medication & $59(10)$ & $35(6)$ & $6(1)$ \\
Consult information & & & \\
Reason consult & $88(15)$ & $6(1)$ & $6(1)$ \\
Conclusion consult ( $\mathrm{n}=16)$ & $88(14)$ & $0(0)$ & $13(2)$ \\
Results anamnesis & $53(9)$ & $29(5)$ & $18(3)$ \\
Results physical examination & $53(9)$ & $29(5)$ & $18(3)$ \\
Clinical notes & $18(3)$ & $12(2)$ & $71(12)$ \\
Planned interventions & $88(15)$ & $12(2)$ & $0(0)$ \\
Treatment plan ( $=16)$ & $100(16)$ & $0(0)$ & $0(0)$ \\
Correspondence with GP & $65(11)$ & $29(5)$ & $6(1)$ \\
Lab results & & & \\
ESR value & $82(14)$ & $18(3)$ & $0(0)$ \\
CRP value & $82(14)$ & $12(2)$ & $6(1)$ \\
Liver function & $65(11)$ & $24(4)$ & $12(2)$ \\
Kidney function & $59(10)$ & $29(5)$ & $12(2)$ \\
Hb value & $65(11)$ & $24(4)$ & $12(2)$ \\
Full overview lab results & $35(6)$ & $24(4)$ & $41(7)$ \\
Other results & & & \\
DAS28 & $94(16)$ & $6(1)$ & $0(0)$ \\
Radiological images & $35(6)$ & $18(3)$ & $47(8)$ \\
Interpretation Radiological images & $38(6)$ & $31(5)$ & $31(5)$ \\
\hline & & & \\
\hline & & & \\
\hline
\end{tabular}

\section{Discussion}

Investigating rheumatology care providers' opinions on patient home access to the EMR led to varying reactions. Expected positive consequences among participants were an increase in patient participation in treatment, an increase in patient knowledge, selfmanagement and patient safety, a more equal relationship between the patient and the care provider, and practical benefits in communication with others. Nevertheless, according to the participants, patients might experience difficulties in interpreting medical data, which could cause (unnecessary) interpretation and communication problems, and an increase in workload. Overall, these findings agree with what is found in previous studies on care providers' stands on this subject $[5,13,19]$. While the use of homeaccessible EMRs in rheumatology practice is not described in literature yet, there are some examples from general clinical practice in which this service is adopted already. Gen- 
erally, the key message confirms a number of positive outcomes and very few negative ones [20-22]. It seems that the anticipated problem of worried or offended patients hardly occurs [3]. Several evaluations reveal that patients are generally enthusiastic about the access; they find it informative, they use it to prepare consults and they state that it enhances the understanding of their treatment [20,21,23,24]. Positive outcomes concerning enhancement of trust in the care provider and more secure documentation are shown as well [3,24,25]. Earnest [10], furthermore, concluded that physicians in cardiology did not report any change in workload and no adverse consequences in their practicing procedures. Still, these former studies did reveal some necessary improvements. Patients regularly could not understand all the information in their records $[8,20]$ and they reported that they felt the need for aids to interpret (laboratory) tests or technical terms [10].

Our results on care providers' views related to preconditions and suitable content to display to patients anticipates on these kinds of difficulties. The results showed that most care providers do not want patients to view an overload of detailed information, in order to increase information provision without increasing confusion. Complex results as full blood test results and radiological images should not be available to patients, nor should providers' clinical notes. Also, lab results should not be available to patients until after consult, in order to explain the information to the patient first. Thus, involving care providers in the first phases of the developmental process of patient services is essential.

This study is limited because of the small amount of respondents. However, we feel that the combination of interviews and a questionnaire, among care providers from different hospitals, has covered all main arguments. Further research on the implementation of a patient home-accessible EMR should focus on how care providers' preconditions can be translated in the development of this service. A pilot study in clinical practice in which patients have access to their EMR is currently being set up, in order to study its' advantages and disadvantages for all parties.

In conclusion, care providers are positive about providing patients home access to their medical records, because it might be a valuable next step into patient participation, patient empowerment, and in service towards the patient. In order to use this service in clinical practice, security must be optimal, and careful consideration of the content and presentation of the data is necessary. Participatory design, in which both patients and care providers are involved in the development of the service is eminent to make this service useful in clinical practice.

\section{Acknowledgments}

We thank all the health care providers for their participation in this study. This work was supported by an unrestricted educational grant from Wyeth Pharmaceuticals, part of Pfizer Inc. This funding source had no involvement in data collection, analysis, the preparation of this manuscript or the decision to submit the article for publication. 


\section{References}

1 Demiris G, Afrin LB, Speedie S, Courtney KL, Sondhi M, Vimarlund V, Lovis C, Goossen W, Lynch C. Patient-centered applications: use of information technology to promote disease management and wellness. A white paper by the AMIA knowledge in motion working group. J Am Med Inform Assoc 2008; 15: 8-13.

2 Ross SE, Todd J, Moore LA, Beaty BL, Wittevrongel L, Lin CT. Expectations of patients and physicians regarding patient-accessible medical records. J Med Internet Res 2005 May; 7: e13.

3 Ferreira A, Correia A, Silva A, Corte A, Pinto A, Saavedra A, Pereira AL, Pereira AF, Cruz-Correia R, Antunes LF. Why facilitate patient access to medical records. Med Care Compunetics 2007; 4: 77-90.

4 Honeyman A, Cox B, Fisher B. Potential impacts of patient access to their electronic health records. Inform Prim Care 2005; 13: 55-60.

5 Van der Vaart R, Drossaert CHC, Taal E, Van de Laar MAFJ. Patient preferences for a hospital based rheumatology Interactive Health Communication Application, and factors associated with these preferences. Rheumatology 2011; 50: 1618-26.

6 Van der Vaart R, Drossaert CHC, Taal E, Van de Laar MAFJ Experiences and preferences of patients with rheumatic diseases regarding an interactive health communication application. In: Proceedings of the 2nd eTELEMED international conference on ehealth, telemedicine, and social medicine; 2010 Feb, Saint Martin 64-71.

7 Richter JG, Becker A, Koch T, Willers R, Nixdorf M, Schacher B, Monser R, Specker C, Alten $\mathrm{R}$, Schneider M. Changing attitudes towards online electronic health records and online patients documentation in rheumatology outpatients. Clin Exp Rheumatol 2010; 28: 261-4.

8 Masys D, Baker D, Butros A, Cowles KE. Giving patients access to their medical records via the internet: the PCASSO experience. J Am Med Informs Assoc 2002; 9: 181-91.

9 Reti SR, Feldman HJ, Ross SE, Safran C. Improving personal health records for patient-centered care. J Am Med Inform Assoc 2010; 17: 192-5.

10 Earnest M, Ross SE, Wittevrongel L, Moore LA, Lin, CT. Use of a patient accessible electronic medical record in a practice for congestive heart failure: patient and physician experiences. J Am Med Inform Assoc 2004; 11: 410-7.

11 Winkelman WJ, Leonard KJ. Overcoming structural constraints to patient utilization of electronic medical records: a critical review and proposal for an evaluation framework. J Am Med Inform Assoc 2004; 11:151-61.

12 Leonard K, Wiljer D, Casselman M. An innovative information paradigm for consumers with chronic conditions: the value proposition. J Inf Tech Health Care 2008; 6: 274-82.

13 Dunn WN. Public policy analysis. Prentice-Hall, Englewood CliVs, New Jersey, 1981.

14 Adler M, Ziglio E. Gazing into the oracle: the Delphi method and its application to social policy and public health. Jessica Kingsley Publishers, London, 1996.

15 Linstone HA, TuroV M. The Delphi method: techniques and applications. Addison- 
Wesley Educational Publishers Inc., London, 1975.

16 Members list of the Dutch Association for Rheumatology | [Ledenlijst Nederlandse Vereniging voor Reumatologie] (2010) Haarlem, DCHG Partner in medische communicatie.

17 Members list of the Dutch Health Professionals in Rheumatology | [Ledenlijst Nederlandse Health Professionals in de Reumatologie] (2010) Haarlem, DCHG Partner in medische communicatie.

18 Patton MQ. Qualitative evaluation and research methods. Sage Publications, Newbury Park, 1990.

19 Siteman E, Businger A, Gandhi T, Grant R, Poon E, Schnipper J, Volk LA, Wald JS, Middleton $B$. Clinicians recognize value of patient review of their electronic health record data. In: Proceedings of the AMIA symposium 2006, Washington, DC, 1101.

20 Bhavnani V, Fisher B, WinWeld M, Seed P. How patients use access to their electronic GP record: a quantitative study. Fam Pract 2010; 0: 1-7.

21 Ross SE, Lin C. The eVects of promoting patient access to medical records: a review. J Am Med Assoc 2003; 10: 129-38.

22 Cardoso AB, Lima AF, Pereira AF, Silva AF, Corte AF, Correia Al, Machado Al, Pinto Al, Pereira AL, Saavedra AM. The access to medical records: a systematic review. University of Porto, Faculty of Medicine [Internet]; 2005. Available from: http://medicina.med.up.pt/im/trabalhos05_06/sites/Turma2/files/final.pdf

23 Ralston JD, Carrell D, Reid R, Anderson M, Moran M, Hereford J. Patient web services integrated with a shared medical record: patient use and satisfaction. J Am Med Inform Assoc 2007; 14: 798-806.

24 Fisher B, Bhavnani V, WinWeld M. How patients use access to their full health records: a qualitative study of patients in general practice. J R Soc Med 2009; 102: 538-44.

25 Weissman JS, Schneider EC, Weingart SN, Epstein AM, David-Kasdan J, Feibelmann S, Annas CL, Ridley N, Kirle L, Gatsonis C. Comparing patient-reported hospital adverse events with medical record review: do patients know something that hospitals do not? Ann Intern Med 2008; 149: 100-8. 


\title{
Chapter 5
}

\section{Validation of the Dutch functional, communicative and critical health literacy scales}

\author{
Rosalie van der Vaart \\ Constance H.C. Drossaert \\ Erik Taal \\ Peter M. ten Klooster \\ Rianne T.E. Hilderink-Koertshuis \\ Joost M. Klaase \\ Mart A.F.J. van de Laar
}

Patient Education and Counseling 2012; 89(1): 82-8. 


\section{Abstract}

Objectives: While most existing health literacy (HL) instruments focus primarily on reading comprehension, the functional, communicative and critical $\mathrm{HL}$ scales from Ishikawa et al. [2008] aim to measure a broader HL spectrum. The objective of this study was to evaluate the validity of the Dutch translation of this instrument.

Methods: Two survey studies $(n=79$ and $n=209)$ and one cognitive interview study $(n=$ 18) were performed among samples of breast cancer patients and patients with rheumatic diseases.

Results: Analyses showed the scales measured three distinct factors and convergent validity was satisfactory for communicative and critical HL. Nevertheless, the comprehension of the items and the suitability of the response options raised some problems.

Conclusion: The HL scales seem promising to measure a broad definition of HL. By revising some of the items and response options as proposed in this article, the scale will become more understandable for people with low HL skills, which might increase the content validity and the distributional properties of the scale.

Practice implications: The scale should be revised and revalidated. An improved version should be used in practice to gain insight into HL levels of patients. This will help to develop suitable education programs for people with low HL skills. 
Today, clinical practice encourages patients to be more emancipated and involved in their treatment. Reliable health information is, therefore, essential and currently easily available to most patients. Nonetheless, while health information has the potential to increase patients' knowledge and equalize the communication between the patient and the care provider, availability of information does not automatically lead to informed and involved patients $[1,2]$. To this aim, patients must have the ability to obtain, process, and understand basic health information and services [3,4]. These information skills are referred to as health literacy $(\mathrm{HL})$, a concept that is receiving increasing attention worldwide [5,6]. According to the International Adult Literacy Survey, $11 \%$ of the Dutch population has low general literacy levels [7], and it is assumed that the number of people that have limited levels of $\mathrm{HL}$ is even higher [8]. In other developed countries, this problem is comparable or worse [9-12]. Patients' inability to use health information for their own benefit causes a gap between the expectations laid on them to participate in their own health care, and their actual HL skills [13]. This gap should be narrowed by adapting the reading level of the provided health information on the one hand, and by increasing patients' HL level through education on the other.

To gain insight into patients' level of $\mathrm{HL}$, it is essential to properly measure HL skills $[14,15]$. Yet so far there has not been consensus on how to accomplish this and current instruments show several problems [16-18]. First, most often instruments need to be assessed by a health professional, which is time consuming and unfeasible in clinical practice. Second, underlying constructs and content of the existing instruments vary, and only few instruments are actually based on the proposed definitions and underlying models of health literacy $[16,17]$. Third, most existing HL measures focus primarily on reading comprehension, while health literacy comprises more than just functional literacy, namely the skills to use information in a constructive manner $[16,18]$. A widely accepted theoretical model, introduced by Nutbeam [20] distinguishes three levels of health literacy: (1) functional health literacy, which is the basic level of reading and writing needed to function effectively in everyday situations, (2) communicative or interactive health literacy, which allows a person to extract information and derive meaning from different forms of communication, and (3) critical health literacy, more advanced skills for critically analyzing information and using information to exert control over life events and situations.

A recently developed self-assessment $\mathrm{HL}$ instrument by Ishikawa et al. [19] relies on this model, and aims to measure all three levels of HL skills, unlike any other existing $\mathrm{HL}$ instrument. Ishikawa and colleagues have examined the 3-factor structure of the instrument, and its relationship with associated variables, such as age, education and disease knowledge, in a sample of patients with diabetes [19]. The instrument showed a good internal consistency ( $\alpha=0.84,0.77$ and 0.65 respectively), and its three level structure seemed promising for the measurement of the full spectrum of HL. However, the scales are not further validated in different languages yet, nor for different patient populations, or in comparison with different $\mathrm{HL}$ measures. In addition, although Ishikawa and colleagues have tested the ease of use and comprehensibility of the items [19], a recent study in the Netherlands on applicability of health literacy instruments [21] showed that the items of the HL scales by Ishikawa were perceived as rather complex by patients. By using data from three different studies, both quantitative and qualitative, the goal of 
this paper is to draw conclusions on the reliability and the validity of the Dutch translation of the $\mathrm{HL}$ instrument by Ishikawa et al. [19]. Accordingly, improvements are proposed and practical implications are provided on the use of this instrument in scientific research and in clinical practice.

\section{Methods}

Two quantitative studies (study 1 and study 2) and a qualitative study (study 3) were conducted. The quantitative studies were used to evaluate the reliability, structural validity, distributional properties and convergent validity of the HL instrument among two different patient groups that differ in the nature of their disease (chronic vs. acute). The aim of the qualitative study, in which the method of cognitive interviewing [22] was applied, was to evaluate the content validity of the instrument.

\section{Quantitative studies}

\section{Subjects}

Data from study 1 and 2 were both collected in prior research $[23,24]$. In study 1 , a random sample of patients with rheumatic diseases was selected from the patient database of the rheumatology clinic of a regional hospital. In total, 484 patients were sent an invitation letter and a paper-and-pencil questionnaire by their treating rheumatologists. Patients expected to experience difficulty in completing the survey (because one was too young, had significant cognitive impairment or no proper mastery of the Dutch language) were excluded a priori by their treating rheumatologists. The invitation letter explained the purpose of the study, the use of data, the voluntary nature, and the anonymity of the participant, therefore returned questionnaires could be presumed as consent. Of the 484 questionnaires sent, 209 patients returned the questionnaire with completed $\mathrm{HL}$ scales (43\%).

In study 2 consecutive sampling was used during a one year period in which newly diagnosed breast cancer patients from two hospitals were asked to participate in the study. In total, 86 patients received a questionnaire, including an accompanying letter and an informed consent form. The questionnaire was filled out after the diagnostic consult and returned during the succeeding consult. Of the 86 patients, 79 completed the $\mathrm{HL}$ scales (92\%).

\section{Instruments}

The survey studies assessed: (1) gender, age and education level, (2) a Dutch translation of the functional, communicative and critical HL scales [19], and (3) a Dutch translation of the Single Item Literacy Scale (SILS) [25]. The three HL subscales by Ishikawa contain 14 items in total, which inform how often patients have had trouble with, or have performed certain actions in relation to health information. It is a self-report measure, and all items can be answered on a 4-point Likert scale ranging from "never" (1) to "often" (4). Scores on the functional $\mathrm{HL}$ scale were recoded, and mean scores were calculated for each scale ranging from 1 (low health literacy) to 4 (high health literacy). The SILS is a single item 
instrument intended to identify adults in need of help with printed health material. The SILS asks, "How often do you need to have someone help you when you read instructions, pamphlets, or other written material from your doctor or pharmacy?" Possible responses ranged from "never" (1) to "always" (5) [25]. Scores were recoded so that 1 represented low literacy and 5 represented high health literacy. This instrument was chosen as it could be used in a paper-and-pencil questionnaire, unlike most commonly used health literacy instruments. The original items of both $\mathrm{HL}$ measures were translated into Dutch with forward and backward translation, according to WHO guidelines [26]. The instrument of Ishikawa was adapted to participants' current situation by changing the name of the disease.

\section{Data analysis}

Descriptive, reliability and correlational analyses were performed with PASW Statistics 18.0 (SPSS Inc., Chicago, IL), structural validity was examined using confirmatory factor analysis (CFA) with LISREL 8.70 (Scientific Software International, Lincolnwood, IL). Cronbach's alpha served as a measure of internal consistency, reflecting the (weighted) average correlation of items within the scale $[27,28]$. Distributional properties of the instrument were further inspected to examine the normality of the scores on each subscale and to identify floor and ceiling effects. Floor or ceiling effects were considered to be present if $>15 \%$ of the patients scored the worst or the best possible score [29].

To test whether the HL scales measure a three dimensional construct, a correlated 3-factor model was fit to the data. Given the relatively small sample sizes and nonnormality of the data, robust maximum likelihood estimation with Satorra-Bentler (SB) scaled statistics was used [30,31]. Besides the SB chi-square statistic $\left(\mathrm{SB} \chi^{2}\right)$, where smaller values indicate better fit, the non-normed fit index (NNH), the comparative fit index (CFI), the standardized root mean square residual (SRMR), and the root mean square error of approximation (RMSEA) were used to examine the model fit. NNH and CFI values $\geq 0.95$ and SRMR and RMSEA values $\leq 0.08$ and 0.06 , respectively, were considered indicative of good model fit [32]. Factor loadings in excess of .71 were considered excellent, .63 very good, and .55 good [33].

Evidence for convergent validity was determined by studying Spearman correlations between Ishikawa's (sub)scales and education level, and Ishikawa's (sub)scales and the SILS. Based on previous reviews we hypothesized moderate positive correlations (Rho between 0.3 and 0.6 ) between $\mathrm{HL}$ and education level [2,34]. Between the SILS and the functional HL scales we hypothesized moderate positive correlations (Rho between 0.3 and 0.6 ), and small correlations with the communicative and critical $\mathrm{HL}$ scales, since the SILS only addresses the ability to read health information independently, which represents functional health literacy. Overall, two-tailed P values less than .05 were considered significant. 


\section{Qualitative study}

\section{Subjects}

Study 3, a qualitative study was conducted among 18 patients suffering from rheumatoid arthritis, and comprised a short questionnaire and a cognitive interview [22]. Patients were recruited at the rheumatology clinic of a small regional hospital, using an information letter which explained the purpose and the procedure of the study, and the patients' rights during the study. When patients consented to participate, an appointment was made at the hospital. Interviews were conducted until data saturation was reached; meaning that no more new information of value was obtained [35].

\section{Procedures and instruments}

Participants first filled out the HL scales, in which the "thinking-aloud method" was used [22]. According to this method subjects were explicitly instructed to think aloud as they answered the survey questions, which allowed the interviewer to gain a better understanding of the cognitive processes the participant used to answer the questions. Subsequently, participants were interviewed about their understanding of the items, using the cognitive interviewing technique "probing" [36]. This technique enables the interviewer to gain additional specific information about participants' cognitive processes, while answering the instrument's questions, on 4 categories: (1) the comprehension of the items (e.g. "What does the term 'credibility' mean to you?"), (2) the retrieval from memory of relevant information (e.g. "Could you give an example of how you used health information in your daily life in the past?"), (3) the decision process (e.g. "How did you arrive at that answer?") and (4) the response process (e.g. "Are the response options adequate to answer this question?") [36-38]. An interview framework was developed prior to the interviews with pre-formulated probes for each item. Additionally, the interviewer was free to ask spontaneous probes when this was felt necessary to gain all the valuable information. Participants beforehand received the explicit clarification that the interview was intended to test the instrument, not the participant. The potential problem of socially desirable answers was circumvented as much as possible by making clear to participants that the researcher was not the designer of the scales and that the interviews were aimed to improve the scales as much as possible, wherefore it was good to express difficult parts of the questionnaire. The interviews took approximately 50 minutes.

\section{Data analysis}

The audiotapes of the interviews were transcribed verbatim and coded by two independent researchers, based on the four predetermined categories [37,38]. Differences in the distribution of quotes among the categories were discussed between the researchers, until consensus was reached. In each category the most prominent problems were determined based on the coded quotes. 


\section{Results}

\section{Subjects}

Participant characteristics and health literacy scores are shown in Table 1.

Table 1: Participant characteristics and HL scores in three conducted studies

\begin{tabular}{llrrr}
\hline & & Study 1 & Study 2 & Study 3 \\
& & Rheumatism \\
$\mathrm{n}=209$ & $\begin{array}{r}\text { Breast cancer } \\
\mathrm{n}=79\end{array}$ & $\begin{array}{r}\text { RA } \\
\mathrm{n}=18\end{array}$ \\
\hline Gender, n (\%) & Male & $75(36)$ & $0(0)$ & $2(11)$ \\
& Female & $134(64)$ & $79(100)$ & $16(89)$ \\
Age, mean (S.D.) & & $52.3(10.6)$ & $60.0(10.0)$ & $58.8(6.0)$ \\
Education, $\mathrm{n}$ (\%) & Low & $55(26)$ & $30(38)$ & $0(0)$ \\
& Middle & $108(52)$ & $33(42)$ & $13(72)$ \\
& High & $43(21)$ & $16(20)$ & $5(28)$ \\
Functional HL, mean (S.D.)* & Unknown & $3(1)$ & $0(0)$ & $0(0)$ \\
Communicative HL, mean (S.D.)* & & $3.4(0.59)$ & $3.4(0.55)$ & $3.1(0.56)$ \\
Critical HL, mean (S.D.)* & & $2.8(0.66)$ & $2.9(0.84)$ & $3.0(0.45)$ \\
Total HL, mean (S.D.)* & & $2.0(0.68)$ & $1.9(0.70)$ & $2.1(0.60)$ \\
SILS, mean (S.D.) **a & & $2.8(0.45)$ & $2.8(0.50)$ & $2.7(0.28)$ \\
\hline
\end{tabular}

* Range 1-4

**Range $1-5$

a $n(\%)$ of patients who scored 5 is $142(68 \%)$ in study 1 and $49(62 \%)$ in study 2.

\section{Distributional properties}

The communicative and critical HL scales showed no skewness or kurtosis in the distribution of scores in both studies. Scores on the functional HL scale were not normally distributed in study 1 . In both studies, ceiling effects were found for the functional HL scale, with respectively $21 \%(n=44)$ and $27 \%(n=21)$ of participants scoring the best possible score (4). Floor effects were found in both studies for the critical HL scale with respectively $15 \%(n=31)$ and $18 \%(n=14)$ of participants scoring the worst possible score (1).

\section{Structural validity and reliability}

CFA showed good fit indices for a 3-factor model of the HL scales in both study 1 and 2, and in the two studies combined (Table 2). In study 2 the fit was slightly less adequate, possibly due to the smaller sample size. Standardized factor loadings of the two studies combined ranged between 0.58 and 0.95 (Figure 1). Internal consistencies of the three HL scales were adequate, $\alpha=.87, .87$ and .78 in study $1, \alpha=.83, .94$ and .80 in study 2 .

Table 2: Summary of fit indices of the 3-factor confirmatory factor analysis model

\begin{tabular}{lllllll}
\hline & SB $\chi^{2}$ & df & NNFI & CFI & SRMR & RMSEA (90\% CI) \\
\hline Study 1 & 109.11 & 74 & 0.99 & 0.99 & 0.07 & $0.05(0.03-0.07)$ \\
Study 2 & 104.12 & 74 & 0.97 & 0.97 & 0.09 & $0.07(0.03-0.10)$ \\
Study 1 \& 2 combined & 150.55 & 74 & 0.98 & 0.99 & 0.07 & $0.06(0.05-0.07)$ \\
\hline
\end{tabular}




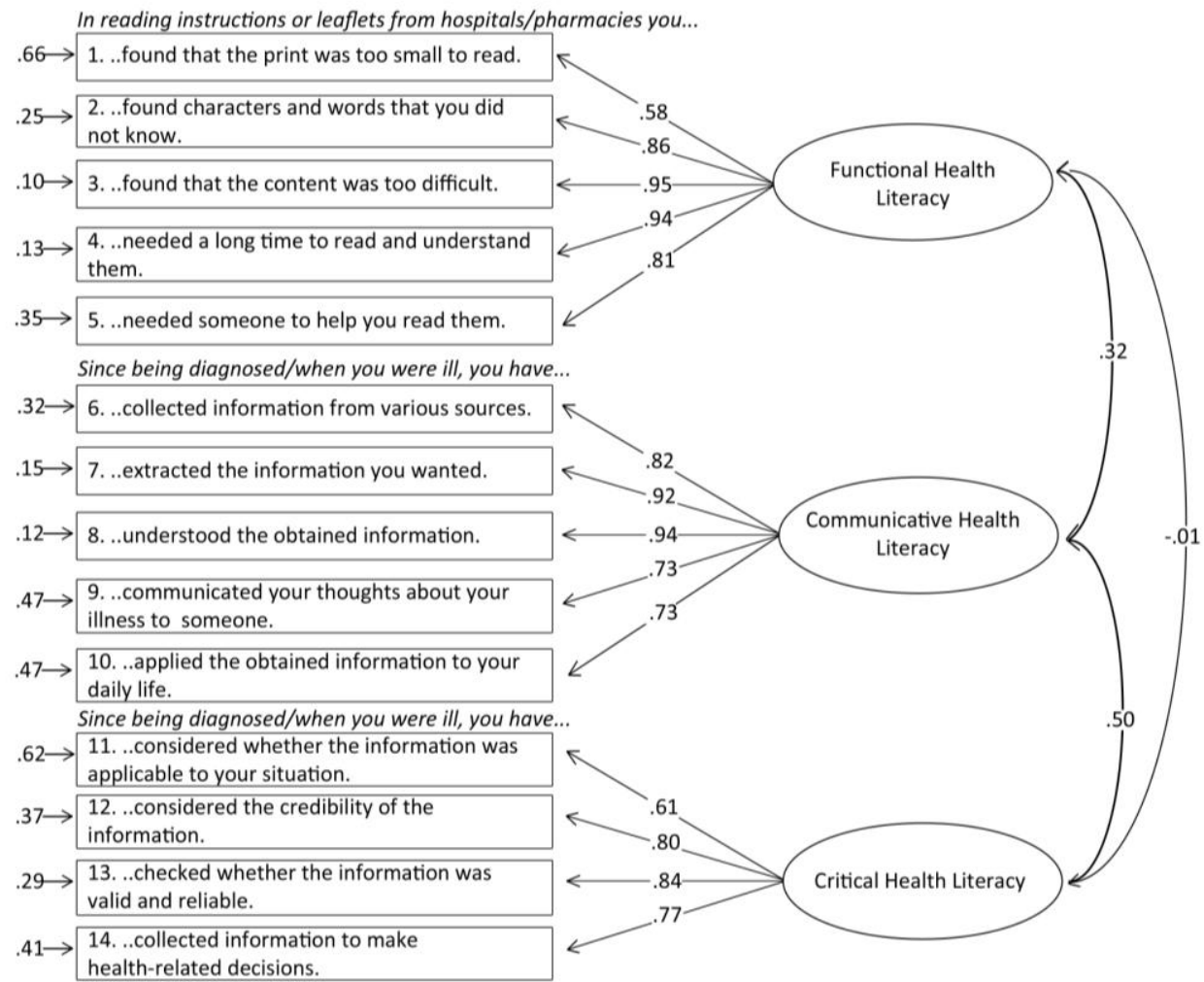

Figure 1: standardized parameter estimates for the for the correlated 3-factor model of the HL scalesin the total sample $(n=188)$. Rectangels represent the observerd variables (items) and ellipses represent the hypothesized latent contructs. Values on the single-headed arrows leading grom the factors to the items are standardized factor loadings. Values to the left of the items represent error variances. Values on the curved double-headed arrows are correlatins between factors terms.

\section{Convergent validity}

Table 3 shows the correlations between the scores on the HL scales and education and the SILS respectively, measured in both survey studies. Correlations between education and the total scores on the $\mathrm{HL}$ scales were moderately positive, as expected. Correlations between education and communicative $\mathrm{HL}$ were moderately positive as well. Correlations between education and critical $\mathrm{HL}$, however, were weak and correlations between education and functional HL were weak to moderate.

As expected, a moderate positive correlation was found between the functional $\mathrm{HL}$ scale and the SILS, and non-significant small correlations were found between the communicative and critical HL scales and the SILS. 
Table 3: Spearman correlations between scores on the HL scales, education, and the SILS ${ }^{a}$

\begin{tabular}{lllll}
\hline & $\begin{array}{c}\text { Education } \\
\text { Rho }\end{array}$ & $P$ & SILS \\
& & & & \\
\hline Study 1 Rheumatic diseases $(\mathrm{n}=209)$ & .12 & .099 & $.38^{* *}$ & $<.001$ \\
$\quad$ Functional Health Literacy & $.31^{* *}$ & $<.001$ & .06 & .39 \\
Communicative Health Literacy & $.15^{*}$ & .04 & -.12 & .09 \\
Critical Health Literacy & $.33^{* *}$ & $<.001$ & .05 & .50 \\
$\quad$ Total Health Literacy & & & & \\
Study 2 Breast cancer ( $\mathrm{n}=79)$ & $.35^{* *}$ & .001 & $.50^{* *}$ & $<.001$ \\
$\quad$ Functional Health Literacy & $.45^{* *}$ & $<.001$ & .06 & .63 \\
Communicative Health Literacy & .16 & .17 & -.21 & .07 \\
Critical Health Literacy & $.47^{* *}$ & $<.001$ & .14 & .24 \\
\hline Total Health Literacy & & & & \\
\hline
\end{tabular}

a Single Item Literacy Scale

\section{Content validity}

Results below show the outcomes of the cognitive interviews (study 3), arranged by four categories. Since various problems were encountered by a small part of the participants, only the items which caused difficulties by at least half of the sample (nine participants) are discussed. Table 4 presents an overview of these problems. The last column shows proposed adaptations to improve the items.

\section{Comprehension of the items}

The interviews showed that not all the items were interpreted similar by all participants. First, several words used in the items were understood differently among participants, which caused different answers based on the understanding of the question (Item 1, 4, 5, 6 and 9; Table 4). Second, a few items referred to concepts which were difficult to understand for participants (Item 14; Table 4). A third problem in the comprehension of items, concerned the reference to different sorts of information in the three subscales. The functional $\mathrm{HL}$ scale refers to information from hospitals and pharmacies, the communicative $\mathrm{HL}$ scale refers to self-collected information from various sources. Subsequently, the critical HL scale references to "the" information, while for many participants it was unclear what information was intended. Most people answered these questions with the self-collected information in mind, but others expressed to have the received doctor's/pharmacist's information in mind (Item 11, Table 4).

\section{Retrieval from memory of relevant information}

Retrieval of relevant information to answer the items was a common problem among participants, especially in the communicative and critical subscales (Table 4). Often, participants had been suffering from their disease for several years, in which their needs and searches for information had changed, which made the items hard to answer.

\section{Decision process}

When answering the items, participants sometimes had trouble to come to a decision, because they felt the item could be answered in several ways. However, this only occurred 
a few times among patients who were very critical. For example, this participant on item 4 ("How often you needed a long time to read and understand health instructions or leaflets?"): "I had to think about that answer, because I would say never. But, it has happened before that I had to read a leaflet a few times to fully understand it, sometimes you read some parts again. You just want to read the information very carefully, to let it sink in." [Female, 60 years old].

\section{Response process}

Concerning the response process, the response range from "never" to "often" caused confusion among many patients. The quantities "rarely", "sometimes" and "often" emerged to be quite subjective, which often caused trouble in choosing the right answer. Also, it seemed that the occurrence rate from "never" to "often" did not always fit the question (Item 10; Table 4).

\section{Discussion}

This study showed that the functional, communicative and critical health literacy scales by Ishikawa et al. [19] might be useful for the measurement of a broad spectrum of HL skills. The internal consistency of the HL scales was high and all CFA fit indices suggested adequate to good fit of a correlated 3-factor model, which supports the existence of the three HL domains. Concerning the distributional properties of the scales, the functional HL scale showed a ceiling effect, and the critical HL scale showed a floor effect. This shows a distribution problem which might lower the ability of the scale to distinguish between people with very low and very high levels of health literacy. Our results on the distribution of scores agree with previous findings on this scale [21], and have been found in many other HL measurement instruments as well [39].

Regarding the convergent validity of the instrument, correlations with education and both total $\mathrm{HL}$ and communicative $\mathrm{HL}$ were moderate, as expected. The strength of the relationship between education and critical $\mathrm{HL}$, however, was rather weak in both studies. Moreover, functional HL only correlated with education in study 2. These results could be due to the floor and ceiling effects of the scales, which influences the distribution of scores. Correlations with the SILS were as expected. Nevertheless, since the score distribution of the SILS is highly skewed (with a mean score of 4.6 on a 5-point scale) the validity of the SILS might be questionable itself. Another explanation for the skewed distribution of scores in both $\mathrm{HL}$ instruments might be the use of a mailed survey in study 1. Due to the voluntary response on this survey, the scores we found might represent an overestimation of the true HL level of the population. Namely, patients with sufficient functional health literacy skills to complete the questionnaire might be more likely to return the questionnaire. Nevertheless, when compared to scores on the functional and communicative subscales, scores on the critical $\mathrm{HL}$ subscale were still strikingly low with 2.0 and 1.9 on a 4-point scale, in study 1 and 2 respectively. Irrespective of the problems with the validity of this scale, this shows that many patients have problems when it comes to the critical appraisal of health information, and with using this information for their own good. This indicates that education on the assessment of credibility and reliability of health information are key issues to enhance patients' health literacy. 
Concerning the content validity of the scales, it appeared from our qualitative study that the respondents perceived several difficulties in filling out the questions. First, the formulation of some items left room for differences in interpretation, and some concepts addressed in the items were rather complicated for patients, which caused problems in answering the questions. To overcome this, some items should be complemented with examples, to provide patients a better notion of the concept. Second, the references to different types of health information (received by a doctor, and self-obtained) caused confusion among parti-cipants. These references should be stated clearly in the question, as is already done in the functional HL scale. Third, recalling the right information from memory appeared difficult for most participants, because many patients had been diagnosed many years ago. This could be resolved by providing a more current time frame in the items and by posing the questions in the present tense. Lastly, the most important issue that was raised out of the interviews was the appropriateness of the response options. Currently the range is based on occurrence of behavior ("never" to "often"). From our data we can conclude that it might be better to measure perceived skills or experienced difficulty on health literacy behavior. Noticeable, that is what Ishikawa and colleagues have done themselves in a later study, by asking participants the amount of agreement with statements on their ability to perform health literacy behaviors [40].

In this combination of studies we have evaluated the construct validity of the scales, and we have performed qualitative analyses to study the content validity of the scales [41]. Still, content validity concerns more than the understandability of the items. What is lacking to give a full judgment on the validity of the instrument are experimental analyses to study if patients' self-reported answers actually correlate to their health literacy behavior in real life $[38,42]$.

\section{Practice implications}

In our opinion, the scales should be revised according to the recommendations mentioned above, in order to make this instrument feasible in (clinical) practice. Further research is necessary to investigate if these adaptations indeed enhance the validity of the instrument. While the larger part of the adaptations is amendable in both the Dutch and the English translation, the adaptations might be universal and presumably could be applied in different languages as well. When proper validity is reached, the measurement of health literacy with this instrument will gain better insight into the full spectrum of skills of patients. This insight will be a first step in offering patients health information in accordance with their competences, and on a larger scale in the development of suitable education programs for people with low health literacy. These steps are key to improve patient self-management and their participation in medical decision making. 


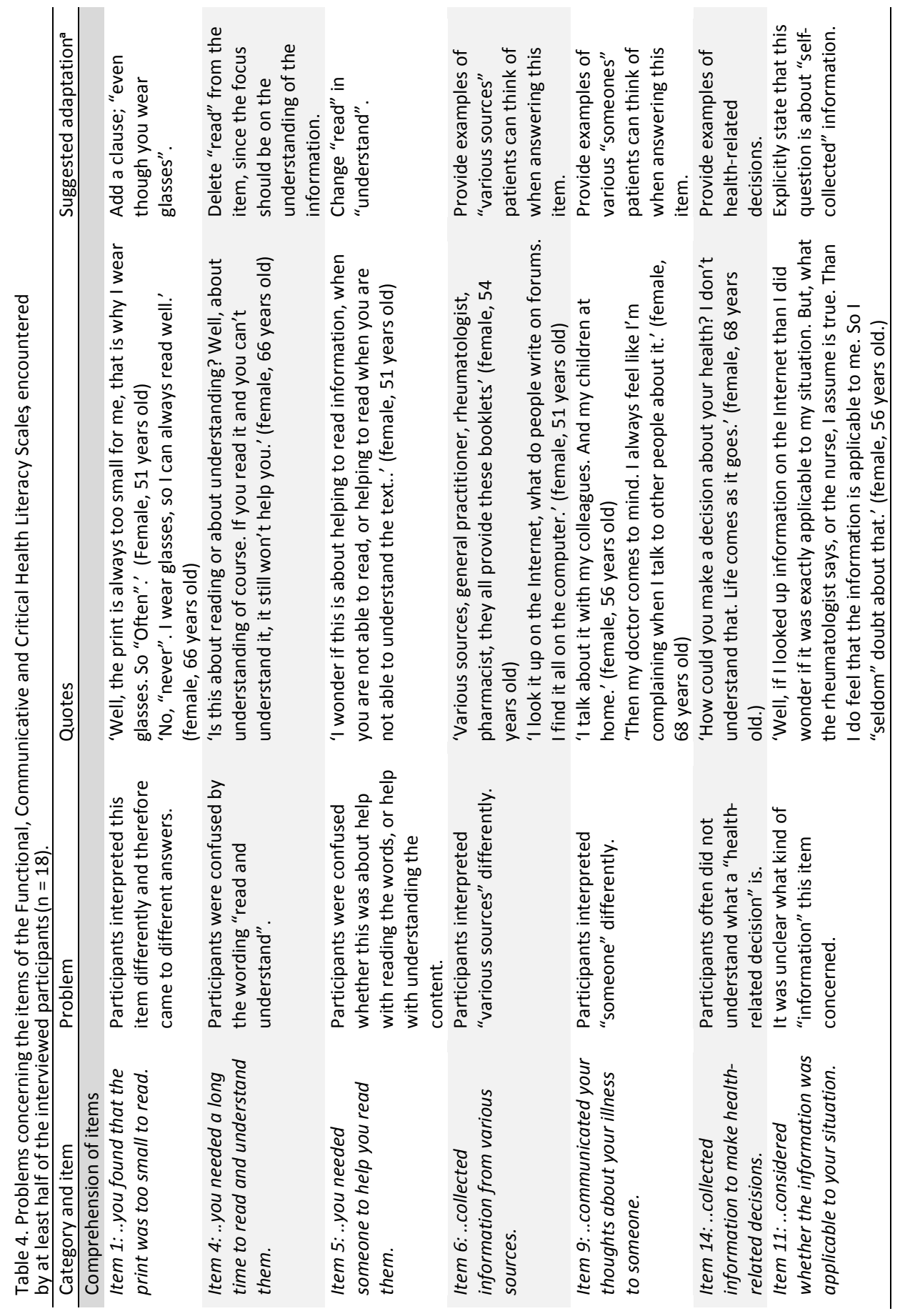




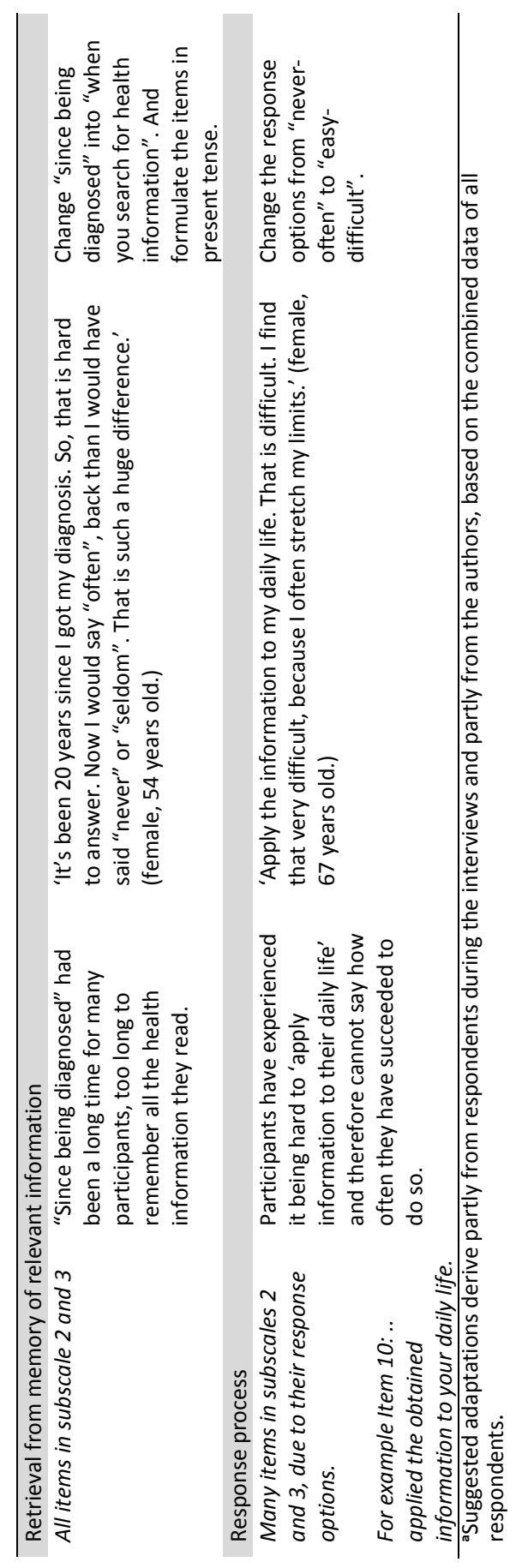




\section{Conclusion}

While most existing HL measurements focus primarily on reading comprehension, the three HL scales from Ishikawa measure more than just functional health literacy. The reliability of all scales was high and the convergent validity was satisfactory for functional and communicative health literacy. Nevertheless, the instrument did show floor and ceiling effects, and the comprehension of the items and the suitability of the response options must be improved. Adaptations are proposed to this end, which also make the instrument more easily adaptable to other populations.

\section{Acknowledgements}

The authors would like to thank G.A.M. ten Velde, L.T. Bruggink, A. van der Kolk and J.H.H. Eijhuisen for their participation in data collection. Part of this work was supported by an unrestricted educational grant from Wyeth Pharmaceuticals, part of Pfizer Inc. This funding source had no involvement in data collection, analysis, or the preparation of this manuscript. 


\section{References}

$1 \quad$ McCray AT. Promoting health literacy. J Am Med Inform Assoc 2005; 12: 152-63.

2 Paasche-Orlow MK, Parker RM, Gazmararian JA, Nielsen-Bohlman LT, Rudd RR. The prevalence of limited health literacy. J Gen Intern Med 2005; 20: 175-84.

3 Baker DW. The meaning and the measure of health literacy. J Gen Intern Med 2006; 21: 878-83.

4 Peerson A, Saunders M. Health literacy revisited: what do we mean and why does it matter? Health Promot Int 2009; 24: 285-96.

5 Ad Hoc Committee on Health Literacy for the Council on Scientific Affairs. Health Literacy: Report of the Council on Scientific Affairs. J Am Med Assoc 1999; 281: 552-7.

6 Nielsen-Bohlman L, Panzer AM, Kindig DA. Health literacy: a prescription to end confusion. Washington, DC: The National Academies Press National; 2004

7 Literacy in the information age: final report of the international adult literacy survey. Organisation for Economic Co-operation and Development statistics Canada. URL: http://www.oecd.org/dataoecd/48/4/41529765.pdf [accessed 15.01.12] (archived by WebCite ${ }^{\circledR}$ at http://www.webcitation. org/5xOuCqCNO ).

8 Twickler TB, Hoogstraaten E, Reuwer AQ, Singels L, Stronks K, Essink-Bot M. Low literacy and limited health skills to answer questions in health care [Laaggeletterdheid en beperkte gezondheidsvaardigheden vragen om een antwoord in de zorg] Ned Tijdschr Geneeskd 2009; 153: A250.

$9 \quad$ Hay L. In practice. Perspect Public Health 2010; 130: 105.

10 Nutbeam D. The evolving concept of health literacy. Soc Sci Med 2008; 67: 2072-8.

11 Protheroe J. Health literacy: a necessity for increasing participation in health care. Br J Gen Pract 2009; 59: 721-3.

12 Beacom AM, Newman SJ. Communicating health information to disadvantaged populations. Fam Community Health 2010; 33: 152-62.

13 Jordan JE, Buchbinder $\mathrm{R}$, Osborne $\mathrm{RH}$. Conceptualising health literacy from the patient perspective. Patient Educ Couns 2010; 79: 36-42.

14 Shaw A, Ibrahim S, Reid F, Ussher M, Rowlands G. Patients' perspectives of the doctor-patient relationship and information giving across a range of literacy levels. Patient Educ Couns 2009; 75: 114-20.

15 Chang BL, Bakken S, Brown S, Houston TK, Kreps GL, Kukafka R, et al. Bridging the digital divide: reaching vulnerable populations. J Am Med Inform Assoc 2004; 11: 448-57.

16 Jordan JE, Osborne $\mathrm{RH}$, Buchbinder R. Critical appraisal of health literacy indices revealed variable underlying constructs, narrow content and psychometric weaknesses. J Clin Epidemiol 2011; 64: 366-79.

17 Pleasant A, McKinney J. Coming to consensus on health literacy measurement: an online discussion and consensus-gauging process. Nurs Outlook 2011; 59: 95-106.

18 Mancuso JM. Assessment and measurement of health literacy: an integrative review of the literature. Nurs Health Sci 2009; 11: 77-89.

19 Ishikawa $\mathrm{H}$, Takeuchi T, Yano E. Measuring functional, communicative and critical 
health literacy among diabetic patients. Diabetes Care 2008; 31: 874-9.

20 Nutbeam D, Kickbusch I. Advancing health literacy, a global challenge for the 21st century. Health Promot Int 2000; 15: 183-4.

21 Fransen MP, Van Schaik TM, Twickler TB, Essink-Bot ML. Applicability of internationally available health literacy measures in the Netherlands. J Health Comm 2011; 16: 134-49.

22 Ericsson KA, Simon HA. Verbal reports as data. Psychol Rev 1980; 87: 215-51.

23 Van der Vaart R, Drossaert CHe, Taal E, Van de Laar MAFJ. Patient preferences for a hospital-based rheumatology Interactive Health Communication Application and factors associated with these preferences. Rheumatology 2011; 50: 1618-26.

24 Van der Kolk A. An animation film as a breast surgery preparing tool. [Een animatiefilm als hulpmiddel ter voorbereiding op een borstoperatie]. (Master Thesis): University of Twente, the Netherlands; 2011.

25 Morris NS, MacLean CD, Chew LD, Littenberg B. The Single Item Literacy Screener: evaluation of a brief instrument to identify limited reading ability. BMC Fam Pract 2006; 7: 21.

26 Process of translation and adaptation of instruments. World Health Organisation. URL: http://www.who.int/substance abuse/research tools/translation/ en/index.html [accessed: 23.03.11] (archived by WebCite ${ }^{\circledR}$ at http://www. webcitation.org/5xOujOr4a).

27 Cronbach L. Coefficient alpha and the internal structure of tests. Psychometrika 1951; 16: 297-334.

28 Streiner DL, Norman GR Health measurement scales: a practical guide to their development and use, 3rd ed., New York: Oxford University Press; 2003.

29 Terwee CB, Bot SD, de Boer MR, van der Windt DA, Knol DL, Dekker J, et al. Quality criteria were proposed for measurement properties of health status questionnaires. J Clin Epidemiol 2007; 60: 34-42.

30 Joreskog KG, Sorbom D, Du Toit S, Du Toit M. LISREL8: new statistical features. Lincolnwood, IL: Scientific Software International; 2001.

31 Curran PJ, West SG, Finch JF. The robustness of test statistics to nonnormality and specification error in confirmatory factor analysis. Psychol Methods 1996; 1: 16-29.

$32 \mathrm{Hu}$ LT, Bentler PM. Cutoff criteria for fit indexes in covariance structure analysis: conventional criteria versus new alternatives. Struct Equat Model 1999; 6: 1-55.

33 Comrey AL, Lee HB. A first course in factor analysis, 2nd ed., Hillsdale, NJ: Lawrence Erlbaum Associates; 1992.

34 Martin LT, Ruder T, Escarce JJ, Ghosh-Dastidar B, Sherman D, Elliott M, et al. Developing predictive models of health literacy. J Gen Intern Med 2009; 24: 1211-6.

35 Patton MQ Qualitative evaluation and research methods, 2nd ed., Newbury Park, CA: Sage; 1990.

36 Willis GB. Cognitive interviewing. London: Sage; 2005.

37 Tourangeau R Cognitive sciences and survey methods. In: Jabine T, Straf M, Tanur J, Tourangeau R, editors. Cognitive aspects of survey methodology: building a bridge between disciplines. Washington, DC: National Academy Press; 1984.

38 Collins D. Pretesting survey instruments: an overview of cognitive methods. Qual Life Res 2003; 12: 229-38. 
39 Pleasant A, McKinney J, Rikard RV. Health literacy measurement: a proposed research agenda. J Health Comm 2011; 16: 11-21.

40 Ishikawa $\mathrm{H}$, Nomura K, Sato M, Yano E. Developing a measure of communicative and critical health literacy: a pilot study of Japanese office workers. Health Promot Int 2008; 23: 269-74.

41 Chinn D. Critical health literacy: a review and critical analysis. Soc Sci Med 2011; 73: 60-7.

42 Van der Vaart R, Van Deursen AJAM, Drossaert CHC, Taal E, van Dijk JAMG, Van de Laar MAFJ. Does the eHealth Literacy Scale (eHFALS) measure what it intends to measure? Validation of a Dutch version ofthe eHEALS in two adult populations. J Med Int Res 2011; 13: e86. 


\title{
Chapter 6
}

\section{Does the eHealth Literacy Scale (eHEALS) measure what it intends to measure? Validation of a Dutch version of the eHEALS in two adult populations}

\author{
Rosalie van der Vaart \\ Alexander J.A.M. van Deursen \\ Constance H.C. Drossaert \\ Erik Taal \\ Jan A.M.G. van Dijk \\ Mart A.F.J. van de Laar
}

Journal of Medical Internet Research 2011; 13(4): e86. 


\begin{abstract}
Background: The Internet increases the availability of health information, which consequently expands the amount of skills that health care consumers must have to obtain and evaluate health information. Norman and Skinner [2006] developed an 8-item self-report eHealth literacy scale to measure these skills: the eHealth Literacy Scale (eHEALS). Up until now, this instrument has been available in English only, and there are no data on its validity.
\end{abstract}

Objectives: To assess the internal consistency, and the construct and predictive validity of a Dutch translation of the eHEALS in two populations.

Methods: We examined the translated scale in a sample of patients with rheumatic diseases $(n=189$; study 1$)$ and in a stratified sample of the Dutch population $(n=88$; study 2). We determined Cronbach's alpha coefficients and analyzed the principal components. Convergent validity was determined by studying correlations with age, education, and current (health-related) Internet use. Furthermore, in study 2 we assessed the predictive validity of the instrument by comparing scores on the eHEALS with an actual performance test.

Results: The internal consistency of the scale was sufficient: $\alpha=.93$ in study 1 and $\alpha=.92$ in study 2 . In both studies the eight items loaded on one single component (respectively $67 \%$ and $63 \%$ of variance). Correlations between eHEALS and age and education were not found. Significant, though weak, correlations were found between the eHEALS and quantity of Internet use $(r=.24, P=.001$ and $r=.24, P=.02$, respectively). Contrary to expectations, correlations between the eHEALS and successfully completed tasks on a performance test were weak and not significant: $r=.18(P=.09)$. The t-tests showed no significant differences in scores on the eHEALS between participants who scored below and above median scores of the performance test.

Conclusions: The eHEALS was assessed as unidimensional in a principal component analysis and the internal consistency of the scale was high, which makes the reliability adequate. However, findings suggest that the validity of the eHEALS instrument requires further study, since the relationship with Internet use was weak and expected relationships with age, education, and actual performance were not significant. Further research to develop a self-report instrument with high correlations with people's actual eHealth literacy skills is warranted. 
Although a large supply of health information is available to educate and empower people, many lack the capability to use this information for their own benefit [1]. This capability is set out in the concept health literacy, which refers to the ability to read, understand, and communicate about health information to make proper health decisions [2]. In the Netherlands, $11 \%$ of the population has low literacy levels, according to the International Adult Literacy Survey [3], and it is assumed that the number of people who have limited levels of health literacy is even higher [4]. In other developed countries this problem is present to the same or worse extent $[5,6]$. These low levels of (health) literacy are worrisome, since health care is changing, and patients are increasingly expected to be involved in treatment, in health decisions, and in self-management of their disease [7]. As a result, there is an increasing gap between the needed level of health literacy to participate in their own health care, and the actual health literacy level of many patients. Consequently, low levels of health literacy might negatively influence health outcomes, success of treatment, and medical costs [8-10].

With the increased diffusion of the Internet among households, the accessibility to relevant health information for the public has increased spectacularly. Controversially, this might also further enlarge the existing differences in health knowledge and access to care $[11,12]$. After all, collecting information through the Internet is different from collecting information through books and leaflets, and it requires specific skills [13-15]. For example, consumers should be able to use the computer, to navigate their way through the Internet, and to judge the large amount of information in terms of personal relevance, credibility, and accuracy [16]. Because the Internet and its impact keep growing, computer and Internet literacy are becoming an important addition to traditional health literacy skills [17]. Therefore, to gain a complete overview of people's skills to obtain and use health information, we should measure eHealth literacy $[11,14,18]$. Insight into people's eHealth literacy skills is required to properly deploy guidelines, strategies, and interventions to offer information on different levels and in different formats. This is essential to make health information available and understandable to everyone who needs it [19].

To measure general health literacy levels, the Rapid Estimate of Adult Literacy in Medicine (REALM) [20] and the Test of Functional Health Literacy in Adults (TOFLA) [21] are often used. Both these instruments measure functional health literacy, which implies reading skills and, to some extent, numeracy. Other instruments that tend to measure a broader spectrum of health literacy skills have recently been developed-for example, the Newest Vital Sign [22], the Functional, Communicative, and Critical Health Literacy Scales by Ishikawa et al [23], and the Health Literacy Skills Instrument by McCormack [24]. For the measurement of health-related Internet skills, fewer instruments are available. Recently, Van Deursen and Van Dijk $[25,26]$ proposed an in-depth definition of Internet skills, consisting of operational skills (basic skills to use the Internet), formal skills (navigation and orientation), information skills (finding information), and strategic skills (using the information for personal benefits). This definition derives from the essential combination in eHealth literacy of both technical aspects, related to the use of the Internet, and evaluative aspects, related to the content provided by the Internet. The definition contains gradients of difficulty, while the four skills have a sequential and conditional nature [27]. The combination of these four Internet skills illustrates that the 
application of operational and formal skills alone is not sufficient when using the Internet. On the other hand, using information and strategic skills often depends on the presence of operational and formal skills to obtain information in the first place. All four types of skills can be measured in a series of performance tests in which participants are asked to complete assignments on the Internet [25]. While this is a valuable method to assess (health-related) Internet skills, it is also quite demanding, costly, and time consuming, which makes it a rather inefficient instrument to use for (clinical) practice and research purposes. Therefore, an easy-to-administer self-assessment instrument that combines the measurement of computer skills with health literacy skills is needed. To our knowledge, the only instrument available that claims to measure the health-related Internet skills of the general Internet user is the eHealth Literacy Scale (eHEALS) by Norman and Skinner [28].

The eHEALS is an 8-item scale that tends to measure perceived skills at finding, evaluating, and applying electronic health information to health problems [28]. The instrument proved to be a reliable and easy-to-use self-report tool, and has been used in some previous studies $[29,30]$. The scale is based on a model that distinguishes between six types of literacy skills: traditional literacy, health literacy, information literacy, scientific literacy, computer literacy, and media literacy [31]. Accordingly, the eHEALS aims to measure a broad overview of literacy skills, which might make it a valuable instrument to assess the effects of eHealth literacy-tailored strategies to deliver online information and applications. However, the eHEALS has only been available in English until now and, to our knowledge, there are no data on its validity. Therefore, the aim of the present study was to examine the reliability and the construct and predictive validity of a Dutch version of the eHEALS.

\section{Methods}

Two populations were studied, one containing patients with rheumatic diseases (study 1) and one containing a stratified sample of the general Dutch population (study 2). Because there are no other instruments that measure eHealth literacy, we measured convergent validity using the associated items age, education, and (health-related) Internet use. Predictive validity was measured by comparison with actual performance on various health-related Internet tasks [32]. Study 1 was originally designed to gain insight into patients' needs and wishes regarding a web-based rheumatology patient portal and comprised a survey to measure age, education, general Internet use, health-related Internet use, and the eHEALS [33]. Study 2 was originally meant to gain insight into peoples' Internet skills and comprised a survey to measure age, education, Internet use, and the eHEALS, plus a series of assignments on an Internet-connected personal computer [32].

\section{Study 1}

\section{Population}

A random sample of patients with rheumatic diseases was selected from the patient database of the rheumatology clinic of Medisch Spectrum Twente, Enschede, the 
Netherlands. A total of 496 patients were sent a personal invitation letter and a paperand-pencil questionnaire by their treating rheumatologists. Patients expected to experience difficulty in completing the survey (because one was too young, had significant cognitive impairment or no proper mastery of the Dutch language) were excluded a priori by their treating rheumatologists. The invitation letter explained the purpose of the study, the use of data, the voluntary nature, and the anonymity of the participant; therefore, returned questionnaires could be presumed to provide consent. A reminder was sent to those who did not respond within two weeks. According to local regulations in the Netherlands (Medical Research [Human Subjects] Act) the study did not need approval of the ethical review board; only (nonintervention) studies with a high burden for patients have to be reviewed. For this study, patients who indicated in the questionnaire that they did not have access to the Internet were excluded.

\section{Instruments}

The questionnaire assessed the following: (1) gender, age, and education level, (2) general and health-related Internet use, and (3) the eHEALS. General Internet use was measured by two items: a yes/no item measuring access to the Internet, and an item on quantity of Internet use with answer options on a 5-point scale ranging from "(almost) never" to "(almost) every day". Health-related Internet use was measured with eight items on quantity of use of different kinds of health-related information. Each item could be answered on a 4-point scale ranging from "never" to "regularly" (see Table 1 for a complete overview of topics). The original items of the eHEALS were translated into Dutch with forward and backward translation, according to World Health Organization guidelines [34]. The eHEALS contains eight items, measured with a 5-point Likert scale with response options ranging from "strongly disagree" to "strongly agree". Total scores of the eHEALS are summed to range from 8 to 40 , with higher scores representing higher self-perceived eHealth literacy. The original version of the eHEALS can be found in Table 2. The whole survey instrument was pretested with six participants. Minor revisions were made in formulation and layout according to the received remarks and recommendations.

\section{Study 2}

\section{Population}

A sample of 88 participants was recruited by randomly dialing telephone numbers in cities and villages in the region of Twente. A stratified sampling method was used to gain equal categories in gender, age, and education. When respondents indicated they were willing to participate, their contact and email address were recorded and a time for the research session was scheduled. All research sessions were scheduled at the University of Twente, which was an unfamiliar environment to all participants. Respondents received a followup letter in the mail for confirmation, and the day before the study respondents were reminded of the session by telephone. Respondents were awarded €25 for their participation. 


\section{Instruments}

The sessions lasted approximately 1.5 hours and started off with a short questionnaire that assessed (1) gender, year of birth, and education level, (2) general Internet use, and (3) the eHEALS. General Internet use was measured with three items: a yes/no item measuring access to the Internet, an item measuring amount of Internet use in hours per week, and an item on Internet experience in years.

Subsequently, participants had to complete a performance test, which contained nine health-related assignments, based on the four defined Internet skills. Two assignments (consisting of eight tasks) were used to measure operational Internet skills (e.g. open a health website, save a file, or add a website to the Favorites menu), two assignments (consisting four tasks) were used to measure formal Internet skills (e.g. navigate different health-related menu and website designs, and surf between different websites), three assignments were used to measure information Internet skills (find health-related information on the Internet), and two assignments were used to measure strategic Internet skills (e.g. extract information from different sources, and make decisions based on the information found). The assignments were generated by a team of researchers that made a conscious effort to include only tasks that were accessible and relevant to the general user population (e.g. find the web address of a health clinic, or search for information on vitamins). All assignments were pilot tested with 12 participants to ensure comprehensibility and applicability. Assignments were administered in a sequence of increasing difficulty. During the assignment completion, participants themselves decided when they were finished or wanted to give up on an assignment. Completion of the tasks, successful and unsuccessful, was directly noted during the sessions. Tasks were assumed successful if the right answer was given within an ample time period, determined in the pilot tests. To execute the assignments, participants used a keyboard, a mouse, and a 17-inch monitor. The personal computer was connected to the Internet on a high-speed university network and was programmed with the three most popular Internet browsers (Internet Explorer, Mozilla Firefox, and Google Chrome). This allowed the participants to replicate their regular Internet use. No default page was set on the browsers and all the assignments started with a blank page. To ensure that participants were not influenced by a previous user's actions, the browser was reset after each session by removing temporary files, cookies, and favorites. In addition, downloaded files, history, forms, and passwords were removed and the laptop was rebooted.

\section{Data analysis}

Data were analyzed using Statistical Package for the Social Sciences (SPSS 17.0 for Windows, Chicago, IL, USA) in both studies. Cronbach's alpha served as a measure of internal consistency, reflecting the (weighted) average correlation of items within the scale [35]. In general, Cronbach's alpha of .7 to .8 is regarded as satisfactory for scales to be used as research tools [36]. Principal component analysis was performed to examine the 1-factor structure of the scale. Factor loadings in excess of .71 were considered excellent, .63 very good, and .55 good [37].

Distributional properties of the eHEALS were further inspected to examine the normality of the total scores and to identify floor and ceiling effects. Skewness and 
kurtosis values between \pm 1 were assumed to indicate no or slight non-normality. Floor or ceiling effects were considered to be present if $>15 \%$ of the participants scored the worst or the best possible score on the eHEALS [38].

Evidence for convergent validity was determined by studying Spearman correlations between total mean scores on the eHEALS and age, education level, quantity of Internet use, and sum scores of health-related Internet use. Based on previous studies on regular health literacy, we hypothesized negative correlations with age and positive correlations with education and (health-related) Internet use $[9,11,39]$. A coefficient magnitude of at least .4 was taken as evidence of convergent validity [40]. The predictive validity of the instrument was assessed by comparing the total mean scores on the eHEALS with the scores on the actual performance test in study 2, using Spearman correlations. The scores on the eHEALS were first related to the total number of successfully completed tasks. Second, the scores on the eHEALS were related to the amount of completed tasks per skill (operational, formal, information and strategic). A coefficient magnitude of at least .4 was taken as evidence of predictive validity. We used t-tests on each skill to investigate whether participants who performed below and above the median score of successfully completed assignments significantly differed on the eHEALS. Two-tailed $P$ values less than .05 were considered significant.

\section{Results}

\section{Study 1}

\section{Participants}

Of the 496 invitations sent out, 12 were returned as undeliverable. In total, 227 of 484 questionnaires were returned (47\%); 189 of these 227 participants had Internet access and completed the eHEALS (83\%). Participant characteristics and Internet use are shown in Table 1. Included respondents used the Internet daily or several days a week. Responders and non-responders did not differ on gender, but non-responders were on average 5 years younger, with a mean age of 47 years $(P<.001)$. 
Table 1: Participants' self-reported socio-demographics and (health related) Internet use

\begin{tabular}{|c|c|c|c|}
\hline & & $\begin{array}{r}\text { Study } 1(\mathrm{n}=189) \\
\mathrm{n}(\%)\end{array}$ & $\begin{array}{r}\text { Study } 2(\mathrm{n}=88) \\
\mathrm{n}(\%)\end{array}$ \\
\hline \multirow[t]{2}{*}{ Gender } & Male & $119(63)$ & $45(51)$ \\
\hline & Female & $70(37)$ & $43(49)$ \\
\hline \multicolumn{2}{|l|}{ Age (M (S.D.)) } & $52(11)$ & $43(18)$ \\
\hline \multirow[t]{4}{*}{ Education } & Low & $38(20)$ & $25(28)$ \\
\hline & Middle & $102(54)$ & $32(36)$ \\
\hline & High & $46(24)$ & $31(35)$ \\
\hline & Unknown & $3(2)$ & \\
\hline \multirow[t]{6}{*}{ Amount of Internet usage } & (almost) Every day & $117(62)$ & $-a^{a}$ \\
\hline & Several days a week & $34(18)$ & \\
\hline & About 1 day a week & $15(8)$ & \\
\hline & Less & $9(5)$ & \\
\hline & (almost) Never & $12(6)$ & \\
\hline & Unknown & $2(1)$ & \\
\hline \multicolumn{2}{|c|}{ Amount Internet use in hours per week (M (S.D.)) } & $-{ }^{a}$ & $12.2(13.7)$ \\
\hline \multicolumn{2}{|c|}{ Internet experience in years (M (S.D.)) } & $-{ }^{a}$ & $9.3(4.3)$ \\
\hline \multirow{2}{*}{\multicolumn{2}{|c|}{$\begin{array}{l}\text { Number of respondents who have ever searched } \\
\text { for information on: } \\
\text { diseases }\end{array}$}} & & \\
\hline & & $159(84)$ & $-a^{a}$ \\
\hline \multicolumn{2}{|l|}{ healthy lifestyle } & $121(64)$ & \\
\hline \multicolumn{2}{|l|}{ medication } & $95(50)$ & \\
\hline \multicolumn{2}{|l|}{ treatments } & $122(65)$ & \\
\hline \multicolumn{2}{|l|}{ care providers } & $69(37)$ & \\
\hline \multicolumn{2}{|l|}{ patient organisations } & $67(35)$ & \\
\hline \multicolumn{2}{|c|}{ law regulations related to health conditions } & $61(34)$ & \\
\hline \multicolumn{2}{|c|}{ peer support forums } & $45(24)$ & \\
\hline
\end{tabular}

a Item was not measured in this study

\section{Distributional properties}

Total scores on the eHEALS were approximately normally distributed with a skewness of .63. Floor and ceiling effects were acceptable, with no participants scoring the worst possible score (8), and five participants scoring the best possible score (40).

\section{Reliability and validity}

The internal consistency of the eHEALS was $\alpha=.93$. Unidimensionality of the scale was supported by principal component analysis (eigenvalue $=5.4,67 \%$ of variance explained). The eigenvalue of the first component was 5 times larger than the eigenvalue of the second component (being 1.1). All items loaded high on this component, ranging from .74 to .85 (Table 2). The mean sum score of the scale was 28.2 (S.D. = 5.9).

Table 3 shows the correlations between the scores on the eHEALS and the variables measured in both studies. Correlations with age $(r=-.11, P=.13)$ and education $(r=.09, P$ 
$=.24)$ were not significant. A significant, though weak, positive correlation was found between the eHEALS and quantity of Internet use $(r=.24, P=.001)$. Concerning healthrelated Internet use, the use of online information correlated weak to moderate with the eHEALS with coefficients varying from .26 to $.40(P<.001)$.

Table 2: eHEALS mean items scores, scale reliability and principal component analysis

\begin{tabular}{|c|c|c|c|c|c|c|c|c|}
\hline \multirow[b]{2}{*}{ eHEALS Items } & \multirow{2}{*}{\multicolumn{2}{|c|}{$\begin{array}{c}\text { M S.D. } \\
\text { Study } \\
1\end{array}$}} & \multirow{2}{*}{\multicolumn{2}{|c|}{$\begin{array}{l}\text { M S.D. } \\
\text { Study } \\
2\end{array}$}} & \multirow{2}{*}{\multicolumn{2}{|c|}{$\begin{array}{cc}\text { Factor loading } \\
\\
\text { Study } & \text { Study } \\
1 & 2\end{array}$}} & \multicolumn{2}{|c|}{$\begin{array}{l}\text { Mean item- } \\
\quad \text { total } \\
\text { correlation }^{a}\end{array}$} \\
\hline & & & & & & & $\begin{array}{c}\text { Study } \\
1\end{array}$ & $\begin{array}{l}\text { Study } \\
2\end{array}$ \\
\hline $\begin{array}{l}\text { 1: I know what health } \\
\text { resources are available on the } \\
\text { Internet }\end{array}$ & 3.6 & 0.83 & 3.4 & 0.86 & .82 & .77 & .80 & .70 \\
\hline $\begin{array}{l}\text { 2: I know where to find helpful } \\
\text { health resources on the } \\
\text { Internet }\end{array}$ & 3.6 & 0.87 & 3.3 & 0.88 & .85 & .79 & .84 & .73 \\
\hline $\begin{array}{l}\text { 3: I know how to find helpful } \\
\text { health resources on the } \\
\text { Internet } \\
\text { 4: I know how to use the }\end{array}$ & 3.7 & 0.81 & 3.5 & 0.94 & .85 & .86 & .85 & .72 \\
\hline $\begin{array}{l}\text { Internet to answer my health } \\
\text { questions }\end{array}$ & 3.6 & 0.85 & 3.6 & 0.88 & .83 & .86 & .83 & .70 \\
\hline $\begin{array}{l}\text { 5: I know how to use the health } \\
\text { information I find on the } \\
\text { Internet to help me }\end{array}$ & 3.5 & 0.88 & 3.4 & 0.87 & .84 & .77 & .85 & .67 \\
\hline $\begin{array}{l}\text { 6: I have the skills I need to } \\
\text { evaluate the health resources I } \\
\text { find on the Internet } \\
7: \text { I can tell high quality from }\end{array}$ & 3.6 & 0.89 & 3.6 & 0.90 & .82 & .77 & .84 & .67 \\
\hline $\begin{array}{l}\text { low quality health resources on } \\
\text { the Internet }\end{array}$ & 3.4 & 0.95 & 3.4 & 1.00 & .80 & .75 & .82 & .76 \\
\hline $\begin{array}{l}\text { 8: I feel confident in using } \\
\text { information from the Internet } \\
\text { to make health decisions }\end{array}$ & 3.3 & 0.99 & 3.1 & 1.12 & .74 & .80 & .78 & .82 \\
\hline Mean sum score (S.D.) & 28.2 & & 27.6 & 5.9) & & & & \\
\hline Eigenvalue first component & 5.36 & & 5.06 & & & & & \\
\hline Variance accounted for & $67 \%$ & & $63 \%$ & & & & & \\
\hline Cronbach's alpha & .93 & & .92 & & & & & \\
\hline
\end{tabular}

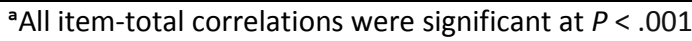


Table 3: Spearman correlations between scores on the eHEALS and age, education, (health related) Internet use and Internet performance skills

\begin{tabular}{|c|c|c|c|c|}
\hline & $\begin{array}{l}\text { Stud } \\
\text { rho }\end{array}$ & $P$ & $\begin{array}{l}\text { Stud } \\
\text { rho }\end{array}$ & $P$ \\
\hline \multicolumn{5}{|l|}{ Socio-demographics } \\
\hline Age & -.11 & .13 & -.08 & .49 \\
\hline Education (1 = low, 2 = middle, $3=$ high) & .09 & .24 & .13 & .25 \\
\hline \multicolumn{5}{|l|}{ Internet use } \\
\hline Amount of Internet usage & .24 & .001 & .24 & .02 \\
\hline \multicolumn{5}{|l|}{ Health related Internet use } \\
\hline Information on: & & & $-{ }^{a}$ & \\
\hline diseases & .40 & $<.001$ & & \\
\hline healthy lifestyle & .28 & $<.001$ & & \\
\hline medication & .29 & $<.001$ & & \\
\hline treatments & .38 & $<.001$ & & \\
\hline care providers & .30 & $<.001$ & & \\
\hline patient organizations & .32 & $<.001$ & & \\
\hline law regulations related to health conditions & .26 & $<.001$ & & \\
\hline peer support forums & .27 & $<.001$ & & \\
\hline \multicolumn{5}{|l|}{ Performance tasks } \\
\hline Successfully completed tasks overall & $-{ }^{a}$ & & .18 & .09 \\
\hline Operational & & & .12 & .27 \\
\hline Formal & & & .19 & .07 \\
\hline Information & & & .05 & .62 \\
\hline Strategic & & & .11 & .30 \\
\hline
\end{tabular}

altem was not measured in this study

\section{Study 2}

\section{Participants}

Characteristics and Internet use of the 88 recruited participants in study 2 are shown in Table 1. Of all participants, 75 (85\%) had home Internet access. The average years of Internet experience was 9.3 (S.D. = 4.3) and average amount of Internet use was 12.2 hours a week (S.D. = 13.7).

\section{Performance tests}

Table 4 shows that the participants successfully completed an average of $73 \%(5.8 / 8)$ of the operational Internet skills tasks and an average of 73\% (2.9/4) of the formal Internet skills tasks. Of the information Internet skills tasks, an average of $50 \%$ (1.5/3) was completed successfully and of the strategic Internet skills tasks, 35\% (0.7/2). Only $28 \%$ $(25 / 88)$ of the participants were able to successfully complete all operational skills tasks, $39 \%(34 / 88)$ completed all formal skills tasks, $13 \%$ (11/88) completed all information skills tasks, and $20 \%(18 / 88)$ completed both the strategic skill tasks. No participants exceeded 
the maximum amount of time they were given for the assignments. Participants who were not able to complete the assignment decided to give up on the assignment before the official end time had elapsed. More details on the results of the performance tests and the general consequences for health seekers and providers are discussed elsewhere [32].

Table 4: Overview of successful task completion in performance tests

\begin{tabular}{lcc}
\hline Performance tasks & $\begin{array}{c}\text { Number of average tasks } \\
\text { completed M(S.D.) }\end{array}$ & \% of all tasks completed \\
\hline Operational tasks (8) & $5.74(2.15)$ & 72 \\
Formal tasks (4) & $2.83(1.20)$ & 71 \\
Information tasks (3) & $1.45(0.88)$ & 48 \\
Strategic tasks (2) & $0.72(0.78)$ & 36 \\
\hline
\end{tabular}

\section{Distributional properties}

As in study 1 , total scores on the eHEALS were approximately normally distributed with a slight skewness of -.80 . Floor and ceiling effects were acceptable, with no participants scoring the worst possible score (8), and four participants scoring the best possible score (40).

\section{Reliability and validity}

The internal consistency of the eHEALS was $\alpha=.92$. All items loaded on one single component in this study as well (eigenvalue $=5.1,63 \%$ of variance explained). The eigenvalue of the first component was 5.8 times larger than the eigenvalue of the second component (being .88). All items loaded high on this component, ranging from .75 to .86 (Table 2). The mean sum score of the scale was 27.6 (S.D. = 5.9).

No significant correlations between the eHEALS and either age $(r=-.08, P=.49)$ or education ( $r=.13, P=.25$ ) were found (Table 3). A significant, though weak, correlation was found between the eHEALS and quantity of Internet use $(r=24, P=.02)$. The correlations between the eHEALS and actual performance for overall successfully completed tasks and the four skills separately were weak and not significant (Table 3 ). Comparison on the four performance skills showed that the $50 \%$ of participants scoring above the median had a higher mean score on the eHEALS than the $50 \%$ of participants scoring below the median (Table 5). However, t-tests showed that none of these differences were significant (Table 5). 
Table 5: eHEALS mean scores of participants scoring below and above median scores on performance tasks

\begin{tabular}{|c|c|c|c|c|c|c|}
\hline Performance tasks & & Mean & S.D. & $\mathrm{t}$ & $\mathrm{df}$ & $P$ \\
\hline \multicolumn{7}{|l|}{ Operational tasks } \\
\hline & $50 \%$ below median & 3.38 & 0.85 & -.998 & 80.33 & .32 \\
\hline & $50 \%$ above median & 3.53 & 0.59 & & & \\
\hline \multicolumn{7}{|l|}{ Formal tasks } \\
\hline & $50 \%$ below median & 3.36 & 0.77 & -1.47 & 77.38 & .15 \\
\hline & $50 \%$ above median & 3.59 & 0.67 & & & \\
\hline \multicolumn{7}{|l|}{ Information tasks } \\
\hline & $50 \%$ below median & 3.43 & 0.69 & -.26 & 81.37 & .80 \\
\hline & $50 \%$ above median & 3.47 & 0.80 & & & \\
\hline \multicolumn{7}{|l|}{ Strategic tasks } \\
\hline & $50 \%$ below median & 3.38 & 0.74 & -.79 & 81.55 & .43 \\
\hline & $50 \%$ above median & 3.51 & 0.74 & & & \\
\hline
\end{tabular}

\section{Discussion}

The results of the two studies show that the eHEALS is unidimensional and has high internal consistency. Yet results of the validity tests showed that the eHEALS is not a valid measure of eHealth literacy.

With regard to the convergent validity, we hypothesized at least moderate positive correlations $(r>.4)$ between scores on the eHEALS and education, and at least moderate negative correlations $(r>.4)$ between the eHEALS and age. However, in both studies correlations between the eHEALS and either education or age were not significant. Although it should be noted that (selective) non-response might have had an influence, and that younger respondents ( $<30$ years of age) were slightly underrepresented in study 1 , we were surprised about the lack of these correlations, as various reviews have shown that these factors are the most predictive for (regular) health literacy [9,39]. In their study, Norman and Skinner [28] found no significant correlation between scores on eHEALS and age either, but in their study only adolescents in the age group of 13-21 years participated. To our knowledge, no other studies have examined the correlation between scores on eHEALS and age and education.

We hypothesized at least moderately positive correlations $(r>.4)$ between scores on the eHEALS and quantity of Internet use, since it is reasoned that the amount of time spent on the Internet has a positive influence on eHealth literacy [11]. However, whereas the correlations between the scores on eHEALS and Internet experience were in the expected direction, they appeared to be weak in both of our studies. The correlations between eHEALS and health-related Internet use were weak but slightly higher, with Spearman correlation coefficients ranging from .26 to .40 .

Concerning the predictive validity, the lack of significant correlations between the eHEALS and actual performance skills was surprising. Since the assignments used in study 2 were applicable to the general Internet user, one would at least expect some moderate correlations between the eHEALS scale and the performance results. Apparently, perceived skills (as obtained with the eHEALS) do not predict actual performance (as measured in study 2). Previous investigations on general computer skills have also shown that people tend to overestimate their computer skills, which results in a gap between 
self-reported skills and practice when actual skills are measured [41,42]. Furthermore, the comparison of all participants who scored below and above median scores on the performance test did not show any significant differences on the eHEALS either. From this we can conclude that the eHEALS does not have the power to distinguish between people with low health-related Internet skills and people with high health-related Internet skills. These results show that the eHEALS is not a valid instrument for assessing perceived health-related Internet skills.

We suggest a revision of the eHEALS, in a way that all four different skills are measured: (1) operational and (2) formal skills that measure practical use of computers and the Internet, and (3) information finding and (4) strategic skills that measure search strategies and skills to judge the found information. Also, questions might need to be formulated differently in order to prevent misunderstanding or differing interpretations. To this aim, qualitative research might provide more insight into the basis for participants' answers-for example, having people fill out the eHEALS with techniques such as cognitive interviewing or thinking-aloud methods $[43,44]$. When measuring all four different skills, we might obtain a more valid indication of eHealth literacy skills. This could also distinguish between what type of skills (groups of) people possess, after which proper implementation of interventions can bring about equal access to online health information for all subgroups.

\section{Limitations}

A limitation of both our studies is the voluntary basis on which participants were recruited. This could have caused a bias, because participants might already have been more interested in using the Internet and searching for information, which could have influenced the results. Concerning study 1 , only patients with rheumatic diseases were invited to participate. Therefore, this study might not be representative for other chronic conditions, since patients with rheumatic diseases are on average somewhat older. Concerning study 2 , because of the major labor intensity of performance tests and the very high travel costs of bringing participants nationwide to the university lab, it was not possible to test a random sample from the whole Dutch population. Although the study population size of 88 is not enough to generalize to the whole population, the applied quota sample for the categories of gender, age, and education hugely improved representativeness.

\section{Conclusions}

The eHEALS is found to be unidimensional, according to principal component analysis, and to be internally consistent, as assessed with Cronbach's alpha, but its validity is questionable. Expected correlations between the eHEALS and peoples' use of the Internet were weak. Moreover, scores on the eHEALS did not correlate with age, education, and scores on performance tasks, and the eHEALS was not able to distinguish between people with high and low health-related Internet skills. Therefore, more research is needed in order to develop a self-report instrument that validly measures eHealth literacy skills. We suggest incorporation of operational, formal, information, and strategic Internet skills to measure all aspects of eHealth literacy. 


\section{Acknowledgments}

The work of study 1 was supported by an unrestricted educational grant from Wyeth Pharmaceuticals, part of Pfizer Inc. This funding source had no involvement in data collection, analysis, or the preparation of this manuscript. 


\section{References}

1 Mancuso JM. Assessment and measurement of health literacy: an integrative review of the literature. Nurs Health Sci 2009; 11(1) :77-89.

2 Baker DW. The meaning and the measure of health literacy. J Gen Intern Med 2006; 21(8): 878-83.

3 Organisation for Economic Co-operation and Development and Statistics Canada. 2000. Literacy in the Information Age: Final Report of the International Adult Literacy Survey URL: http://www.oecd.org/dataoecd/48/4/41529765.pdf [accessed 2011-03-23] [WebCite Cache ID 5xOuCqCNO]

4 Twickler TB, Hoogstraaten E, Reuwer AQ, Singels L, Stronks K, Essink-Bot ML. [Low literacy and limited health literacy require health care measures]. Ned Tijdschr Geneeskd 2009; 153: A250.

5 Nutbeam D. The evolving concept of health literacy. Soc Sci Med 2008; 67(12): 2072-8.

6 Protheroe J, Nutbeam D, Rowlands G. Health literacy: a necessity for increasing participation in health care. Br J Gen Pract 2009; 59(567): 721-3.

7 Ad Hoc Committee on Health Literacy for the Council on Scientific Affairs, American Medical Association. Health literacy: report of the Council on Scientific Affairs. JAMA 1999; 281(6): 552-7.

8 Jordan JE, Buchbinder R, Osborne RH. Conceptualising health literacy from the patient perspective. Patient Educ Couns 2010; 79(1): 36-42.

9 Paasche-Orlow MK, Parker RM, Gazmararian JA, Nielsen-Bohlman LT, Rudd RR. The prevalence of limited health literacy. J Gen Intern Med 2005; 20(2): 175-84.

10 Nutbeam D, Kickbusch I. Advancing health literacy: a global challenge for the 21st century. Health Promot Int 2000; 15(3): 183-4.

11 Bodie GD, Dutta MJ. Understanding health literacy for strategic health marketing: eHealth literacy, health disparities, and the digital divide. Health Mark Q 2008; 25(1-2): 175-203.

12 Beacom AM, Newman SJ. Communicating health information to disadvantaged populations. Fam Community Health 2010; 33(2): 152-62.

13 Brandtweiner $\mathrm{R}$, Donat $\mathrm{E}$, Kerschbaum J. How to become a sophisticated user: a two-dimensional approach to e-literacy. New Media Soc 2010; 12(5): 813-33.

14 Dominick GM, Friedman DB, Hoffman-Goetz L. Do we need to understand the technology to get to the science? A systematic review of the concept of computer literacy in preventive health programs. Health Educ J 2010; 68(4): 296-313.

15 Van Deursen AJAM. Internet skills: Vital Assets in an Information Society. (Doctoral Dissertation): University of Twente, the Netherlands; 2010.

16 McCray AT. Promoting health literacy. J Am Med Inform Assoc 2005; 12(2): 152-63.

17 Coiro J. Reading comprehension on the Internet: Expanding our understanding of reading comprehension to encompass new literacy's. Reading Teacher 2003; 56(5): 458-64.

18 Griffin JM, Partin MR, Noorbaloochi S, Grill JP, Saha S, Snyder A, Nugent S, Baines Simon A, Gralnek I, Provenzale D, van Ryn M. Variation in estimates of limited 
health literacy by assessment instruments and non-response bias. J Gen Intern Med 2010; 25(7): 675-81.

19 Chang BL, Bakken S, Brown SS, Houston TK, Kreps GL, Kukafka R, Safran C, Stavri PZ. Bridging the digital divide: reaching vulnerable populations. J Am Med Inform Assoc 2004; 11(6): 448-57.

20 Davis TC, Long SW, Jackson RH, Mayeaux EJ, George RB, Murphy PW, Crouch MA. Rapid estimate of adult literacy in medicine: a shortened screening instrument. Fam Med 1993; 25(6): 391-5.

21 Parker RM, Baker DW, Williams MV, Nurss JR. The test of functional health literacy in adults: a new instrument for measuring patients' literacy skills. J Gen Intern Med 1995; 10(10): 537-41.

22 Weiss BD, Mays MZ, Martz W, Castro KM, DeWalt DA, Pignone MP, Mockbee J, Hale FA. Quick assessment of literacy in primary care: the newest vital sign. Ann Fam Med 2005; 3(6): 514-22.

23. Ishikawa $\mathrm{H}$, Takeuchi $\mathrm{T}$, Yano E. Measuring functional, communicative, and critical health literacy among diabetic patients. Diabetes Care 2008; 31(5): 874-9.

24 McCormack L, Bann C, Squiers L, Berkman ND, Squire C, Schillinger D, OheneFrempong J, Hibbard J. Measuring health literacy: a pilot study of a new skills-based instrument. J Health Commun 2010; 15 Suppl 2: 51-71.

25 Van Deursen AJAM, Van Dijk JAGM. Measuring Internet skills. Int J Hum Comput Interact 2010; 26(10): 891-916.

26 Van Deursen AJAM, Van Dijk JAGM. Using the Internet: skill related problems in users' online behavior. Interact Comput 2009; 21: 393-402.

27 Van Deursen AJAM, Van Dijk JAGM, Peters O. Rethinking Internet skills: the contribution of gender, age, education, Internet experience, and hours online to medium- and content-related Internet skills. Poetics 2011; 39: 125-144.

28 Norman CD, Skinner HA. eHEALS: The eHealth Literacy Scale. J Med Internet Res 2006; 8(4): e27.

29 Brown CA, Dickson R. Healthcare students' e-literacy skills. J Allied Health 2010; 39(3): 179-84.

30 Robinson C, Graham J. Perceived Internet health literacy of HIV-positive people through the provision of a computer and Internet health education intervention. Health Info Libr J 2010; 27(4): 295-303.

31 Norman CD, Skinner HA. eHealth literacy: essential skills for consumer health in a networked world. J Med Internet Res 2006; 8(2): e9.

32 van Deursen A, van Dijk J. Internet skills performance tests: are people ready for eHealth? J Med Internet Res 2011; 13(2): e35.

33 van der Vaart R, Drossaert CH, Taal E, van de Laar MAFJ. Patient preferences for a hospital-based rheumatology Interactive Health Communication Application and factors associated with these preferences. Rheumatology (Oxford) 2011; 50(9): 1618-26.

34 World Health Organization. 2011. Process of Translation and Adaptation of Instruments URL:

http://www.who.int/substance_abuse/research_tools/translation/en/index.html [accessed 2011-03-23] [WebCite Cache ID 5xOujOr4a] 
35 Cronbach L. Coefficient alpha and the internal structure of tests. Psychometrika 1951; 16(3): 297-334.

36 Streiner DL, Norman GR. Health Measurement Scales: A Practical Guide to Their Development and Use. Oxford: Oxford University Press; 2003.

37 Comrey AL, Lee HB. A First Course in Factor Analysis. Hillsdale, NJ: Erlbaum; 1992.

38 Terwee CB, Bot SD, de Boer MR, van der Windt DA, Knol DL, Dekker J, Bouter LM, De Vet HC. Quality criteria were proposed for measurement properties of health status questionnaires. J Clin Epidemiol 2007; 60(1): 34-42.

39 Martin LT, Ruder T, Escarce JJ, Ghosh-Dastidar B, Sherman D, Elliott M, Bird CE, Gremont A, Gasper C, Culbert A, Lurie N. Developing predictive models of health literacy. J Gen Intern Med 2009; 24(11): 1211-6.

40 Trochim W, Donnelly JP. The Research Methods Knowledge Base. Mason, $\mathrm{OH}$ : Atomic Dog; 2007.

41 Merritt K, Smith KD. Di Renzo Jr JC. An investigation of self-reported computer literacy: is it reliable? Issues Inf Syst 2005; 6(1): 289-95.

42 Van Vliet P, Kletke MG, Chakraborty G. The measurement of computer literacy: a comparison of self-appraisal and objective tests. Int J Hum Comput Stud 1994; 40: 835-57.

43 Collins D. Pretesting survey instruments: an overview of cognitive methods. Qual Life Res 2003; 12(3): 229-38.

44 Willis GB. Cognitive Interviewing: A Tool for Improving Questionnaire Design. Thousand Oaks, CA: Sage; 2005. 
Chapter 7

\section{Measuring actual eHealth literacy among patients with rheumatic diseases: a qualitative analysis of problems encountered using Health 1.0 and Health 2.0 applications}




\begin{abstract}
Background: The Internet offers diverse opportunities for disease management, through information websites (Health 1.0) and interactive applications such as peer support forums, online consults and insight into electronic medical records (Health 2.0). However, it requires various skills to benefit from Health 1.0 and Health 2.0 applications for one's own health; so-called "eHealth literacy".
\end{abstract}

Objectives: To study the eHealth literacy of patients with rheumatic diseases and the types of problems they encounter when using the Internet in relation to their disease.

Methods: In two studies, patients were asked about their current disease-related Internet use and their eHealth literacy was observed during performance tests. In study 1, 15 patients (aged 39-74) performed six information-retrieval tasks on the Internet (Health 1.0). In study 2, 16 patients (aged 24-72) performed three Health 2.0 tasks on a hospitalbased patient web portal and two (Health 2.0) tasks on interactive websites. Participants were asked to think aloud while performing the assignments, and screen activities were recorded. Types and frequency of problems were identified by two independent researchers and coded into categories using inductive analysis.

Results: Almost all patients in our studies had searched the Internet for information about rheumatic diseases in the past. Fewer patients had used Health 2.0 applications, but many were nevertheless enthusiastic about the possibilities after finishing the assignments. However, nearly all participants experienced difficulties, and a substantial number of participants was not able to complete all assignments. Encountered problems could be divided into six sequential categories: (1) operating the computer and Internet browser, (2) navigating and orientating on the web, (3) utilizing search strategies, (4) evaluating relevance and reliability, (5) adding content to the web, and (6) protecting and respecting privacy. Most severe difficulties occurred in levels 3 and 4; in formulating a search query, evaluating the source of the information, and in scanning a website for relevant information.

Conclusions: Many patients have insufficient skills to properly use Health 1.0 and Health 2.0. Formulating proper search strategies and evaluating the found information caused problems among the majority of patients. Concerning Health 2.0, use and awareness of these applications is low and patients should be guided in the use of them. Our findings may contribute to the awareness of patients' eHealth literacy problems among health professionals, and stress the importance of usability guidelines in web design. 
Since patients with chronic diseases are encouraged to become more empowered and to play a larger role in the management of their own disease, easily accessible health information is essential [1]. Currently, the Internet is one of the main sources of health information and research shows that many patients use it frequently [2,3]. Online access to health information is a positive development; studies have shown that people with chronic diseases who use the Internet, have better self-care practices than those who do not $[4,5]$. With the improved web technology (Web 2.0), the Internet has become more than an online encyclopedia. Not only can information be received from the Internet, but people can also add content to the Internet themselves. Health 2.0 is a term that is used for these interactive applications within health care [6]. This evolution of the Internet means that patients can communicate together online to share and find acknowledgement of their disease experiences through peer support forums [7], social network websites, and health care rating sites. Furthermore, hospitals are increasingly offering patients Interactive Health Communication Applications, which are web-based patient portals that enable patients to participate online in their treatment, by communicating with care providers, monitoring symptoms using online diaries, and by accessing their electronic medical records. All these Health 2.0 applications have great potential and could change health care in a positive way $[6,8,9]$. Nevertheless, using the Internet in relation to health requires a certain level of eHealth literacy, which covers a diverse range of skills $[10,11]$. Norman defines eHealth literacy as "the ability to seek, find, understand, and appraise health information from electronic sources and apply the knowledge gained to addressing or solving a health problem" [11]. It should be noted, however, that this definition is limited to skills needed for Health 1.0 applications and that additional skills are needed for typical Health 2.0 applications [12].

A number of previous studies have shown that using the Internet to collect information requires skills on several levels. On a lower level, operational and navigation skills are essential-the competence to use a computer and an understanding of the World Wide Web and its multi-layer structure (including competencies to operate Internet browsers and search engines). On a higher level, people need skills to find and judge information, which requires the ability to generate relevant search queries, choose relevant information from the enormous amount of search results, and judge the reliability and validity of the information $[13,14]$. Research on Internet skills of people has so far focused on the general, healthy population $[13,15]$, and to a larger extent on adolescents and students [16-19]. Skills of patients with chronic diseases have not been studied yet, so it is unclear to what extent patients can benefit from the large amount of online information that is being offered. Additionally, studies up until now have not taken into account interactive Health 2.0 applications [12]. Using Health 2.0 applications asks for additional skills, such as being able to express oneself clearly in online social interactions, the ability to distinguish professional from non-professional advice [12], and protecting one's privacy and respecting that of others when adding content to the Internet [6]. Due to the rapid developments on the Internet and the shift to web 2.0 applications, these skills should be taken into account to measure the complete spectrum of eHealth literacy. The aim of this study was to gain an in-depth insight into Health 1.0 and 2.0 literacy skills of patients with rheumatic diseases. 


\section{Methods}

\section{Study components}

Two performance tests were conducted to investigate the skills of patients when using online information, communication, and participation sources with regard to rheumatic diseases. Study 1 was predominantly aimed at information retrieval through healthrelated websites and reading along on peer support forums (Health 1.0), study 2 was aimed at the use of interactive online applications (Health 2.0). In both studies, a qualitative design was used to get in-depth insight into patients' strategies when using both kinds of applications. Patients were observed and were asked to think aloud [20] while performing various online assignments.

\section{Participants}

Participants in study 1 were selected from an existing patient panel, which was initiated in cooperation between the University of Twente and Twente's largest hospital, both located in Enschede, the Netherlands. Patients who are registered on this panel $(n=146)$ are willing to volunteer in rheumatology research. A convenience sample from this panel was selected, based on attendance of these panel members at the research meeting introducing the upcoming study. Panel members that were present $(n=30)$ were asked to fill out a form with their contact information if they were willing to participate in the study. Half of the panel members $(15 / 30,50 \%)$ filled out the form, and were subsequently called to explain the process of the study and to schedule an appointment. All appointments, except two, took place at the university, to ensure that all participants were tested in the same environment. Two patients preferred to be interviewed at their home due to the travel distance.

In study 2, participants were selected from the consult database of the rheumatology clinic of University Medical Centre, Utrecht. Participants who had a visit scheduled at the outpatient department of the clinic received an invitation letter by their nurse practitioner. Patients who were not able to speak Dutch and patients who needed an intensive infusion treatment during their hospital visit (which could cause limited mobility, tiredness, and nausea) were excluded. In total, 45 letters explaining the purpose and the process of the study were sent. The researcher called each recipient a few days after the letters were received to ask if they were willing to participate. Of the 45 patients, $17(38 \%)$ gave their consent. An appointment for this study was scheduled on the same day as their existing upcoming appointment in the hospital. In both studies, patients were asked to sign an informed consent form at the beginning of the session, which included information on the recording, anonymity, and confidentiality of the data, and the possibility to end the session at any moment. In total, 15 patients participated in study 1 and 16 patients in study 2 . One participant dropped out during study 2 because he felt uncomfortable in the test setting. After these sessions, data saturation was reached, meaning that no new problems occurred during the last three observations [21]. 


\section{Procedure and materials}

The sessions started with a short survey which assessed demographic information (age, gender, and education), illness related information (diagnosis and disease duration), and Internet experience (amount of Internet use, years of Internet experience, self-perceived Internet skills, and usage of health-related applications on the Internet). The survey also contained a questionnaire on rheumatic-related physical problems when using a computer [22]. When all the items were completed, the practical component of the session started. In both studies, all participants used the same hardware, with the same settings. According to the "thinking-aloud method" [20], subjects were explicitly instructed to think aloud as they executed the assignments, which allowed the interviewer to get a better understanding of the cognitive processes the participant used to search and judge the information, and to formulate questions or messages. It was emphasized that the assignments were not to test the quality of participants' Internet skills, but solely to observe how they used the Internet. The online assignments were recorded using Morae Recorder version 3.2.1 (TechSmith, Okemos, MI, USA), which captures images, sounds, and all screen activities. A description of all assignments is shown in Textboxes 1 and 2.

In study 1 , participants could search the Internet freely during the assignments and skills on several levels were needed to complete the assignments (see Textbox 1). Assignment 2 was the only exception in this study, where all patients were limited to performing the assignment on a single website (the website of the Dutch Arthritis Foundation), which served as a reference to test patients' operational skills of the computer and web browser.

In study 2, assignments 1,2 , and 3 had to be performed on a research account of a hospital-based patient web portal, and assignments 4 and 5 on specific interactive websites (see Textbox 2). These assignments were specifically aimed at measuring Health 2.0 related skills, as patients were asked to add their own content. The assignments asked for skills in addition to information retrieval, such as expressing oneself in online social interactions, distinguishing professional from non-professional advice, and protecting one's privacy and respecting that of others. The Health 1.0 assignments contained pilot tests investigating the relevance of the assignments to rheumatology patients, to ensure that the information-retrieval assignments reflected realistic scenarios. The Health 2.0 assignments were based on results from previous studies [2,23], which highlight applications that patients would find relevant and useful. We therefore only asked nurse practitioners to help us frame the scenarios for the Health 2.0 assignments.

In both studies, the order of the assignments was randomized for each participant, because a learning effect was expected during the assignments. By randomizing the sequence of the assignments this effect would not occur at the same assignments for every patient. After each assignment in study 2, participants were asked if they would use the interactive application in the future, what they would use it for, and how they would take privacy issues into account. These interviews were video-recorded with Morae Recorder as well. 
Textbox 1: Description of Health 1.0 assignments in study 1

1. Formulate a disease-related question you have searched for in the past, and show how you would approach this on the Internet.

2. Open a well-known Dutch rheumatology website [24] and perform the following tasks: find a specific page using the menu structures, download a PDF file, close the additional window, go one page back, use the search engine to search for "osteoarthritis", open the fourth search result and save that page using the favorites bar.

3. You have had sore wrists and hands for a while and you think it might be osteoarthritis. Retrieve the symptoms of osteoarthritis on the Internet and mention four of them.

4. You are using MTX medication for your rheumatic symptoms, but as a side effect you feel nauseated. Retrieve three tips from fellow patients on a patient support forum on how to lessen nausea as a side effect from this medication.

5. You are experiencing sore feet due to your rheumatic symptoms and you want to buy adapted shoes to relieve the pain. Find four key issues to consider when buying adapted shoes.

6. You would like some advice on how to exercise properly in spite of your arthritis. Find a physical therapist in your neighborhood that is familiar with therapy for rheumatic diseases.

Textbox 2: Description of Health 2.0 assignments in study 2

1. Use your electronic medical record to: (a) find and interpret your latest lab results and compare them to your previous values, and (b) to interpret the accompanying treatment plan.

2. Monitor disease symptoms by: (a) filling out a disease diary for one day, and (b) interpret two previous diaries.

3. Use the e-consultation (electronic or online consultation) application to: (a) find and interpret a closed e-consultation, and (b) to write a new e-consultation in which you ask advice on how to bring your medication with you on vacation to Morocco.

4. Open a peer support forum [25] and: (a) retrieve two tips from fellow patients on nausea as a side effect from MTX medication, and (b) add your own tip on this subject.

5. Open a health care rating website [26], find your hospital and: (a) read two reviews, and (b) add your own review about the hospital (you do not have to send it).

\section{Data analysis}

Descriptive analyses of patients' socio-demographics, health characteristics, healthrelated Internet use, and rheumatic-related physical problems when using a computer were performed with Statistical Package for the Social Sciences, version 20.0 (IBM SPSS Inc, Chicago, IL, USA). Performances on the assignments were analyzed using Morae Manager version 3.2.1 (Techsmith, Okemos, MI, USA). In study 1, two researchers inductively developed a coding scheme in which all patients' actions were independently coded and categorized into main categories and further into subcategories [27]. To get an indication of the number of participants that experienced problems in each category, we counted the number of patients that experienced each defined problem in a specific assignment, and we counted the number of individual participants that experienced each defined problem in the total test (see Table 4, last column). The difficulty of the assignments was then accessed based on the number of participants that experienced more than one problem in each assignment (see Table 4, bottom row). 
Study 2 used the same coding scheme as study 1, which was expanded to account for Health 2.0 literacy problems. In both studies, three other outcomes per participant were measured. First, completion of the assignment was registered as "completed independently", "completed with help" (when a hint or intervention from the research leader was needed), or "not completed". The research leader only provided assistance if a patient said he or she was about to give up on the assignment. If the patient did not say this, but was clearly lost or frustrated, the research leader asked the patient if he/she would have quit a similar search at this point if he/she were at home. If the answer was yes, the research leader provided some assistance. Due to the variation in determination among patients to finish the assignments independently, the moment until assistance was offered varied between 1 minute and 20 minutes. Second, the time needed to perform the assignment was registered, but only for the participants that completed the assignment. Finally, the performance was registered, which was scored as "good", "reasonable", or "poor", according to the skills participants used to execute the assignment. The performance was rated as "good" when both researchers agreed that the operational skills and strategic skills were adequate, "reasonable" if not all skills were shown convincingly, and "poor" if patients showed severe problems on all skill levels. The interviews in study 2 were transcribed verbatim and coded inductively. Differences in codes and the distribution among the codes were discussed between the researchers, until consensus was reached. In case of doubts (which occurred in a few occasions), a third independent researcher was involved to come to a conclusion.

\section{Results}

\section{Participants}

Participant characteristics are shown in Table 1 . The majority of the participants were female, and the mean age was 56.4 and 48.6 for study 1 and 2, respectively. Most participants were diagnosed with rheumatoid arthritis and had had the disease for several years. Table 2 shows participants' current, disease-related Internet use. Most participants used the Internet on a regular basis and rated their own Internet skills as "good". The large majority of participants had searched for online disease-related information (28/31, $90 \%)$. Some Health 2.0 applications were used by a substantial group of participants, such as using health care reviews $(10 / 31,32 \%)$, ordering medications online $(10 / 31,32 \%)$, or sending an e-consultation (9/31, 29\%). However, fewer participants used other Health 2.0 applications, such as adding content to a peer support forum $(4 / 31,13 \%)$ or posting a health care review $(1 / 31,3 \%)$.

\section{Physical problems when operating the computer}

Computer-related problems caused by physical impairments in the questionnaire were reported by seven participants in study $1(7 / 15,47 \%)$, and 6 participants in study $2(6 / 16$, $38 \%$; data not shown). Problems were related to their chair $(8 / 31,26 \%)$, mainly finding a comfortable chair, or a good position in the chair; keyboard (8/31, 26\%), mainly pressing individual keys, finding a good position for their hands, and becoming stiff or tired from typing; the mouse $(7 / 31,23 \%)$, mainly double clicking, finding a good position for their hand and becoming stiff or tired from using the mouse; and the monitor $(7 / 31,23 \%)$, 
mainly finding a good position and getting tired from looking at the screen. During the performance of the assignments, three participants mentioned difficulties due to physical impairments (3/31, 10\%); one participant had to stand up for a while to stretch her legs and two participants mentioned they had trouble typing, one due to a wrist splint.

Table 1: Participants' socio-demographics and illness related information in the two studies

\begin{tabular}{lrr}
\hline Characteristic & Study $1(\mathrm{n}=15)$ & Study $2(\mathrm{n}=16)$ \\
\hline Gender, $\mathrm{n}(\%)$ & $3(20)$ & $3(19)$ \\
$\quad$ Male & $12(80)$ & $13(81)$ \\
$\quad$ Female & & \\
Age & $56.4(10.5)$ & $48.6(14.2)$ \\
$\quad$ Mean (S.D.) & $39-74$ & $24-72$ \\
$\quad$ Range & & \\
Education, $n$ (\%) & $4(26)$ & $4(25)$ \\
$\quad$ Low & $2(13)$ & $6(38)$ \\
Middle & $9(60)$ & $6(36)$ \\
$\quad$ High & & $12(75)$ \\
Diagnosis, $n$ (\%) & $10(67)$ & $0(0)$ \\
$\quad$ Rheumatoid Arthritis & $3(20)$ & $3(19)$ \\
Osteoarthritis & $0(0)$ & $1(6)$ \\
Ankylosing Spondylitis & $3(20)$ & $0(0)$ \\
Other rheumatic disease & $1(7)$ & $9.1(7.4)$ \\
$\quad$ Unknown & & $2-25$ \\
Years since diagnosis & $13.5(13.1)$ & \\
$\quad$ Mean (S.D.) & $3-52$ & \\
Range & & \\
\hline
\end{tabular}


Table 2: General and disease-related Internet use in the two studies

\begin{tabular}{lrr}
\hline & Study $1(\mathrm{n}=15)$ & Study $2(\mathrm{n}=16)$ \\
& $\mathrm{n}(\%)$ & $\mathrm{n}(\%)$ \\
\hline Amount of Internet usage & $11(73)$ & $14(88)$ \\
(Almost) every day & $3(20)$ & $1(6)$ \\
Several days a week & $1(7)$ & $0(0)$ \\
About 1 day a week & $0(0)$ & $1(6)$ \\
(Almost) never & & \\
Internet experience in years & $13(87)$ & $14(88)$ \\
$\geq 5$ years & $2(13)$ & $2(12)$ \\
$<1$ year & & \\
Self-assessed Internet skills & $0(0)$ & $1(6)$ \\
Excellent & $6(40)$ & $6(38)$ \\
Good & $3(20)$ & $3(19)$ \\
Average & $6(40)$ & $4(25)$ \\
Reasonable & $0(0)$ & $2(13)$ \\
Poor & & \\
Number of respondents who have ever online: $(\mathrm{n}, \%)$ & $13(87)$ & $15(94)$ \\
searched for information on rheumatic diseases & $8(53)$ & $8(50)$ \\
read a peer support forum or social media website & $5(33)$ & $5(31)$ \\
read a health care review & $4(27)$ & $6(38)$ \\
ordered medications at the pharmacy & $2(13)$ & $7(44)$ \\
asked a question to their health care provider & $5(33)$ & $0(0)$ \\
monitored disease symptoms & $2(13)$ & $3(19)$ \\
logged onto their own electronic medical record & $4(27)$ & $0(0)$ \\
scheduled an appointment with their health care provider & & \\
posted a message on a peer support forum or social media & $1(7)$ & $0(19)$ \\
website & $2(13)$ & $0(0)$ \\
shared personal medical information with others & $1(7)$ & $1(7)$ \\
poined an online self-management course & & \\
\hline & & \\
\hline
\end{tabular}

\section{$\underline{\text { Study } 1}$}

\section{Execution of Health 1.0 assignments and problems encountered}

Table 3 shows that the first three information-retrieval assignments (retrieving information one had previously searched for, performing operational assignments, and finding four symptoms of osteoarthritis) went rather well for most participants. The last three assignments (searching for tips from fellow patients, finding key aspects of adapted shoes, and finding a specialized physiotherapist in the neighborhood), however, were more difficult. These assignments could not be completed by almost half of the participants, many performed poorly in searching for the right answer and the median times to complete these assignments were greater than the first three tests. 
Table 3: Completion, performance, and time needed for completion on the Health 1.0 assignments $(\mathrm{n}=15)$

\begin{tabular}{lllllll}
\hline Assignment $^{\mathrm{a}}$ & $1^{*}$ & $2^{* *}$ & 3 & 4 & 5 & 6 \\
\hline Completion, $\mathrm{n}(\%)^{\text {Independently }}$ & $11(79)$ & $8(57)$ & $12(80)$ & $7(47)$ & $8(53)$ & $8(53)$ \\
$\quad$ With help & $0(0)$ & $1(7)$ & $0(0)$ & $2(13)$ & $0(0)$ & $0(0)$ \\
$\quad$ Not completed & $3(21)$ & $5(36)$ & $3(20)$ & $6(40)$ & $7(47)$ & $7(47)$ \\
Performance, $\mathrm{n}(\%)$ & & & & & & \\
$\quad$ Good & $4(29)$ & $9(64)$ & $7(47)$ & $4(27)$ & $6(40)$ & $5(33)$ \\
$\quad$ Reasonable & $7(50)$ & $3(21)$ & $6(40)$ & $4(27)$ & $4(27)$ & $5(33)$ \\
$\quad$ Poor & $3(21)$ & $3(21)$ & $2(13)$ & $7(47)$ & $5(33)$ & $5(33)$ \\
Duration to complete the assignment (seconds) & & & & & \\
$\quad$ Median & 177 & 192 & 225 & 563 & 311 & 268 \\
$\quad$ Minimum & 60 & 103 & 115 & 274 & 247 & 186 \\
$\quad$ Maximum & 848 & 234 & 488 & 1095 & 512 & 524 \\
\hline
\end{tabular}

*One participant had never searched for information on her rheumatic disease $(n=14)$

**In assignment 2 , a mistake occurred due to a change in the texts on the particular website that was used. This change in text occurred between the time of the pilot study and the first official session and was therefore, unfortunately, discovered during the first session due to which data of participant 1 could not be used $(n=14)$

${ }^{a} 1$. Retrieve previous searched disease information; 2 . Perform operational tasks; 3 . Search for four symptoms of osteoarthritis; 4 . Search for three tips from fellow patients on MTX side effects; 5 . Retrieve four key aspects when buying adjusted shoes; 6 . Find a physiotherapist specialized in rheumatic diseases in your neighborhood.

${ }^{\text {b}}$ Time of participants who did not complete the assignment were not included.

Observed problems among participants when performing the six Health 1.0 assignments could be coded into four categories (see Table 4): (1) operating the computer and Internet browser, (2) navigating and orientating, (3) utilizing search strategies, and (4) evaluating relevance and reliability of web content.

\section{Operating the computer and Internet browser}

The first category of problems concerned operating the computer and Internet browser. Participants experienced difficulties when using the hardware of the computer, and when using the main buttons and fields in the Internet browser. Concerning the hardware of the computer, five participants experienced problems when using the keyboard, mainly to locate keys. Difficulties operating the mouse were experienced by six participants during one or more assignments, especially keeping control over movements of the mouse, and double clicking on buttons. Regarding the use of the Internet browser, nine participants did not use the address bar when asked to navigate to a particular web address, but they used the search engine to type in the web address. One participant asked: "If I type something in Google, do I have to type ".nl' at the end?" [Female, 62 years old]. Six participants lost track of the cursor when they wanted to type something in a field, which would cause confusion (e.g. "Where am I?" [Female, 39 years old]).

The buttons in the browser that caused the most problems were the 'close' button, the multiple tabs, and the scrollbar. Five participants did not know how to close the Internet browser during one or more assignments, after an assignment had ended. Two of 
them kept clicking on the 'back' button to go back to the beginning of the search: "Is it necessary to do what I'm doing now? Should I click this button ['back'] until the arrow disappears? Or can I just close it all at once, without erasing anything?" [Female 62 years old]. Another participant minimized the window instead of closing it, and one participant tried clicking on the stop button of the address bar. In assignment 2, where patients were explicitly asked to open and close a second tab, four participants were not able to fulfill the task. Participants did not seem to understand that they had two separate tabs open, parallel to each other, so they were not aware that they could close one tab, while keeping the other open. Problems associated with the scrollbar included loss of control over the scroll function, which caused the text to speed by. Overall, operational problems were not assignment-specific and did not occur too often for most patients; six participants experienced problems repeatedly.

\section{Navigating and orientating}

The second category of problems concerned navigating and keeping orientation in the Internet browser and on websites. Overall, the multilayer structure of the Internet caused problems, which was often observed when a PDF file was opened. A few participants did not understand that a PDF file is not a website, and that a PDF file has a different navigation structure, in which scrolling is much more important and web links often do not exist. Furthermore, because websites often combine navigation structures (such as navigation trails (breadcrumbs), navigation buttons/tabs or internal hyperlinks, keeping orientation sometimes caused difficulties among patients. The different navigation structures should enable visitors to retrieve webpages via different routes. However for four participants this caused disorientation in one or more assignments. These patients did not notice that the different navigation structures led to the same web pages and they lost track of their location in the website, or they thought the page was still loading, while they were actually already on it.

When navigating through a website, drop-down lists, web links and search engines were often not used as intended. Not all participants understood that drop-down lists function as a 'hidden' menu, therefore, the mechanism of the list was problematic for many of them. Particularly in a double drop-down list, where a drop-down list unfolds into another drop-down list (which was used in assignment 2), nine participants experienced difficulties, since they were not able to click on a button before the list closed again. Seven participants experienced several problems with web links in one or more assignments, for example not recognizing a relevant link or clicking on a word which was not a link (e.g. "Shouldn't there be a little hand here?" [Female, 52 years old]). Interestingly, a small group of participants generated a large amount of the problems encountered during navigation and orientation. These were the same participants that experienced the most operational problems. 
Table 4: Problems and number of participants experiencing those problems in Health 1.0 assignments $(n=15)$

\begin{tabular}{|c|c|c|c|c|c|c|c|}
\hline Assignment $^{a}$ & $1^{*}$ & $2^{* * *^{c}}$ & 3 & 4 & 5 & 6 & Total $^{b}$ \\
\hline \multicolumn{8}{|c|}{ Operating the computer and Internet browser, $\mathrm{n}(\%)$} \\
\hline $\begin{array}{l}\text { Operating the keyboard/ } \\
\text { locating keys }\end{array}$ & 2 (14) & $1(7)$ & $0(0)$ & $1(7)$ & $1(7)$ & $0(0)$ & $5(33)$ \\
\hline $\begin{array}{l}\text { Controlling the mouse/ } \\
\text { clicking the mouse }\end{array}$ & $4(29)$ & $3(21)$ & $2(13)$ & $2(13)$ & $3(20)$ & $1(7)$ & $6(40)$ \\
\hline $\begin{array}{l}\text { Using of the URL bar to } \\
\text { open a web address }\end{array}$ & $1(7)$ & $8(57)$ & $0(0)$ & $0(0)$ & $0(0)$ & $0(0)$ & $9(60)$ \\
\hline Losing track of the cursor & $0(0)$ & $1(7)$ & $1(7)$ & $2(13)$ & $2(13)$ & $1(7)$ & $6(40)$ \\
\hline $\begin{array}{l}\text { Closing the Internet browser } \\
\text { Using and closing more }\end{array}$ & $3(21)$ & $1(7)$ & $3(20)$ & $2(13)$ & $3(20)$ & $3(20)$ & $5(33)$ \\
\hline windows & $0(0)$ & $4(29)$ & $0(0)$ & $2(13)$ & $0(0)$ & $1(7)$ & $6(40)$ \\
\hline Using the scroll bar & $1(7)$ & $0(0)$ & $0(0)$ & $0(0)$ & $1(7)$ & $0(0)$ & $2(13)$ \\
\hline $\begin{array}{l}\text { Participants with }>1 \text { problem } \\
\text { per assignment }\end{array}$ & $2(14)$ & $5(36)$ & $2(13)$ & $2(13)$ & $2(13)$ & $1(7)$ & $6(40)$ \\
\hline \multicolumn{8}{|c|}{ Navigating and orientating, $\mathrm{n}(\%)$} \\
\hline $\begin{array}{l}\text { Using and understanding } \\
\text { a PDF file } \\
\text { Keeping orientation on }\end{array}$ & $2(14)$ & $0(0)$ & $0(0)$ & $1(7)$ & $0(0)$ & $0(0)$ & $2(13)$ \\
\hline a website & $0(0)$ & $1(7)$ & $2(13)$ & $2(13)$ & $2(13)$ & $1(7)$ & $4(27)$ \\
\hline Using drop-down lists & $1(7)$ & $9(64)$ & $0(0)$ & $0(0)$ & $1(7)$ & $1(7)$ & $9(60)$ \\
\hline $\begin{array}{l}\text { Recognizing and using } \\
\text { web links }\end{array}$ & 2 (14) & $3(21)$ & $2(13)$ & $2(13)$ & $3(20)$ & $2(13)$ & 7 (47) \\
\hline $\begin{array}{l}\text { Using a search engine } \\
\text { within a website }\end{array}$ & $0(0)$ & $3(21)$ & $0(0)$ & $0(0)$ & $0(0)$ & $0(0)$ & $3(20)$ \\
\hline $\begin{array}{l}\text { Participants with }>1 \text { problem } \\
\text { per assignment }\end{array}$ & $0(0)$ & $3(21)$ & $2(13)$ & $1(7)$ & $3(20)$ & $1(7)$ & $5(33)$ \\
\hline \multicolumn{8}{|c|}{ Utilizing search strategies, $\mathrm{n}(\%)$} \\
\hline $\begin{array}{l}\text { (Too) broad search query } \\
\text { (Typing) errors in search }\end{array}$ & $6(43)$ & $\mathrm{n} / \mathrm{a}$ & $5(33)$ & $12(80)$ & $6(40)$ & $9(60)$ & $15(100)$ \\
\hline query & $4(29)$ & $5(36)$ & $7(47)$ & $3(20)$ & $3(20)$ & $2(13)$ & $14(93)$ \\
\hline $\begin{array}{l}\text { Choosing a relevant search } \\
\text { result }\end{array}$ & $5(36)$ & $\mathrm{n} / \mathrm{a}$ & $8(53)$ & $9(60)$ & $7(47)$ & $7(47)$ & $13(87)$ \\
\hline $\begin{array}{l}\text { Keeping focus on the needed } \\
\text { information }\end{array}$ & $5(36)$ & $0(0)$ & $2(13)$ & $6(40)$ & $5(33)$ & $7(47)$ & $11(73)$ \\
\hline $\begin{array}{l}\text { Participants with }>1 \text { problem } \\
\text { per assignment }\end{array}$ & $8(57)$ & $0(0)$ & $8(53)$ & $12(80)$ & $5(33)$ & $9(60)$ & $14(93)$ \\
\hline \multicolumn{8}{|c|}{ Evaluating relevance and reliability, $\mathrm{n}(\%)$} \\
\hline $\begin{array}{l}\text { Not checking the source of } \\
\text { the information } \\
\text { Opening only one search }\end{array}$ & $8(57)$ & $\mathrm{n} / \mathrm{a}$ & $14(93)$ & $14(93)$ & $13(87)$ & $12(80)$ & $14(93)$ \\
\hline result & $4(29)$ & $\mathrm{n} / \mathrm{a}$ & $11(73)$ & $13(87)$ & $7(47)$ & $7(47)$ & $15(100)$ \\
\hline $\begin{array}{l}\text { Searching in commercial } \\
\text { websites }\end{array}$ & $2(14)$ & $\mathrm{n} / \mathrm{a}$ & $2(13)$ & $2(13)$ & $6(40)$ & $4(27)$ & $11(73)$ \\
\hline $\begin{array}{l}\text { Scanning a website for } \\
\text { relevant information }\end{array}$ & $3(21)$ & $0(0)$ & $5(33)$ & 7 (47) & $4(27)$ & $3(20)$ & $12(80)$ \\
\hline Selecting a relevant answer & $3(21)$ & $\mathrm{n} / \mathrm{a}$ & $3(20)$ & $4(27)$ & $8(53)$ & $6(40)$ & $11(73)$ \\
\hline
\end{tabular}


Participants with $>1$ problem

per assignment

$6(43) \mathrm{n} / \mathrm{a}$

$14(93)$

$14(93)$

$12(80) \quad 12(80) \quad 14(93)$

${ }^{a}$ 1. retrieve previous searched disease information; 2 . perform operational tasks; 3 . search for four symptoms of osteoarthritis; 4 . search for three tips from fellow patients on MTX side effects; 5 . retrieve four key issues when buying adjusted shoes; 6 . find a physiotherapist specialized in rheumatic diseases in your neighborhood.

${ }^{b}$ Number of participants that experienced this particular problem at least once during the complete tests ( 6 assignments). The numbers in the rows do not add up, since a patient could experience the same problem during several assignments.

${ }^{\mathrm{C}}$ This assignment was aimed at operational and navigation skills, therefore most strategic skills were not applicable (n/a)

*One participant had never searched for information on her rheumatic disease $(n=14)$.

${ }^{* *}$ A mistake occurred due to a change in the texts on the particular website that was used. This change in text occurred between the time of the pilot study and the first official session and was therefore, unfortunately, discovered during the first session. Therefore, the data of participant 1 could not be used $(n=14)$.

\section{Utilizing search strategies}

A third category of problems was observed in participants' search strategies. The majority of these problems occurred in the first stage of the search where the search query was formulated. Often participants started searching with only one query, which was too broad to complete the assignment. A few participants did not seem to understand that they could adjust or expand their query and they blamed the computer for not being able to find the right information: "When I click on this [search result] I expect to find the right information. That is what I expect from the computer." [Female, 63 years old]. A second major problem in formulating a search query was typing and spelling errors ("At home I would get my dictionary." [Female, 39 years old]). Not all participants were aware of their mistakes and did not use the autocorrect function from Google, which led to flawed search results, or very few search results. A frequent problem in the second stage of participants' search strategies occurred in selecting a website from the list of search results. Many participants randomly chose one of the first search results on top of the page. When selecting a search result, they did not seem to look at the URL or the description of the site just below to get an indication of the content of the website (e.g. "I just try the first one."[Female, 45 years old]). Only one participant in a single assignment looked further than the first page with search results. One participant mentioned that "The most important results are shown on the first page anyway." [Male, 62 years old], however, some participants did not seem to realize that the search results extended after the first page. The last problem in applying a logical search strategy was the loss of focus on the required information. For example, patients became distracted by other information they found interesting (e.g. "Here I read osteoarthritis is hereditary, my sister recently has sore shoulders as well.." [Female, 74 years old]). Overall, all participants experienced difficulties in their search strategies at some point. However, most participants showed a learning curve and altered their search strategies as the study progressed, while four patients did not seem to be aware of their mistakes and used the same trial-and-error method in several assignments. 


\section{Evaluating relevance and reliability}

The last category of observed problems, evaluating relevance and reliability of web content, caused the largest number of problems. Almost none of the participants consciously checked the source or the topicality of the information. No one verified the information they found on one website with information from another website. Participants only opened a second search result when they could not find the correct answer in the first one. However, not all participants seemed to understand that they could go back to the list of search results to explore a different website. One woman was searching on a peer support forum for people suffering from hyperhidrosis (excessive sweating), instead of a peer support forum for rheumatoid arthritis, but did not go back to the search results to something relevant. Eventually she asked the research leader, "Are you sure the information can be found on a patient forum?" [Female, 39 years old]. Many participants did not seem to be aware of different sources of information. Only three participants made a remark about the occurrence of sponsored hits at the top and on the right side of the search results. Furthermore, when searching on a website, many participants did not scan the website for relevant information to fulfill the assignment. Participants would select buttons with irrelevant titles and read webpages verbatim without considering the relevance of the information. In the peer support forum, this occurred regularly. One participant selected a random topic on rheumatoid arthritis ["keep having knee pains"] and read all the messages out loud, even though they were not relevant for the assignment. In fact, she commented that, "there are so many messages here, and you need to work through them all. What a waste of time" [female, 59 years old]. Many participants did not give different value to the information provided by different sources, such as a commercial company, a peer support forum, or a national foundation.

\section{Study 2}

\section{Execution of Health 2.0 assignments and problems encountered}

In study 2, the majority of the participants completed all assignments; most of them without help (Table 5). Not all participants were able to start and complete all assignments, because they were tired after completing three or four assignments, or because they had to leave for their doctors' consult. Ten participants (10/16, 63\%) started all assignments and nine participants (9/16, 56\%) completed all assignments. Assignments 2 (filling out a diary), 3a (writing an e-consultation) and $5 b$ (posting a health care review) were the most difficult for participants as these assignments required addition of content to the web. The minimum and maximum duration varied widely between participants within each assignment, which is an indication of the different skill levels between participants. From the interviews, we found that almost all participants had no experience with the assignments. No one had monitored their disease symptoms before or posted a health care review. One patient $(1 / 16,6 \%)$ had previously sent an e-consultation, three patients $(3 / 16,19 \%)$ had posted a message on a peer support forum, and three patients $(3 / 16,19 \%)$ had consulted their electronic medical records before. Nevertheless, after finishing the assignments, the patients perceived the e-consultation and access to the 
electronic medical records especially valuable. Eleven patients $(11 / 16,67 \%)$ would like to use an e-consultation in the future, and fourteen patients $(14 / 16,89 \%)$ reported they would open their electronic medical records at home.

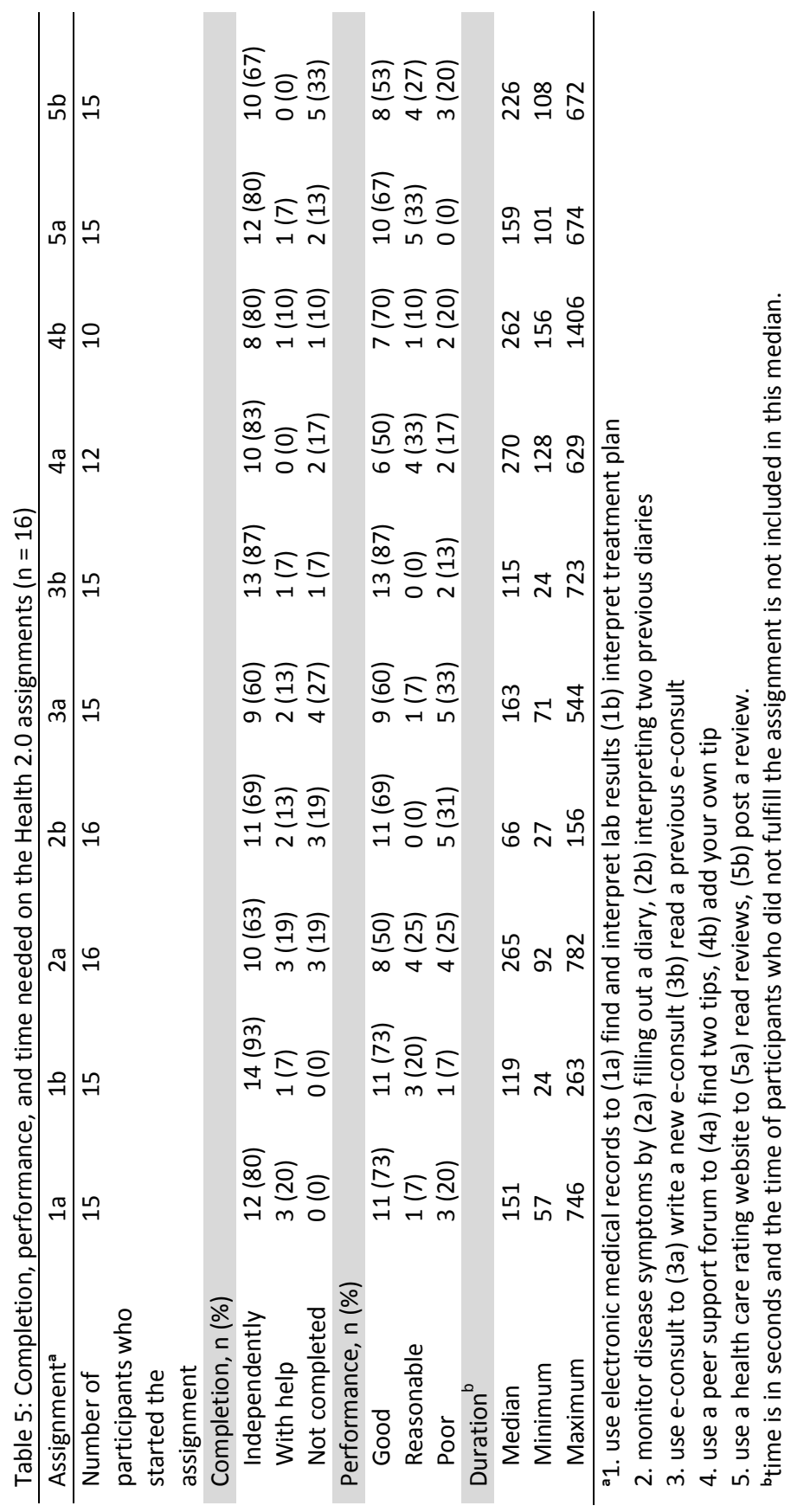


Many of the problems encountered in study 2 corresponded to those found in study 1 . However, it should be noted that in study 2, the participants were somewhat assisted, as they were guided to specific websites. Therefore. we restricted the report of results in study 2 to an overview of the observed additional problems in Health 2.0 assignments in category 4 (evaluating relevance and reliability), category 5 (adding personal content to the web in assignments $2 a, 3 a, 4 b$ and $5 b$, Table 6), and category 6 (protecting and respecting privacy).

\section{Evaluating relevance and reliability}

A new subcategory in evaluating relevance and reliability, which was added to the findings of study 1 was reading and interpreting the information correctly (not shown in Table). This category had to be added since information on the specified patient web portal was reliable, and mostly relevant, but participants still had to read and interpret the information correctly. This was of particular concern in assignment 1 , in which participants had to interpret several laboratory results and compare them to previous values. Reading and interpreting the information correctly caused problems among seven participants, mostly because they had difficulties to see which lab results were the most recent, and because they did not take into account the given information about reference values. Four participants assumed that increased lab values were always bad (e.g. "The levels are higher than the last time, that is bad, right?" [Female, 24 years old]), and three participants reported that they did not know if the values worsened or not (e.g., "I'm no expert in this; I have never studied these things." [Female, 65 years old]). Only one participant reported she would be worried if those were her personal data and she would call her doctor immediately. The other participants reported that they probably would have heard it from their rheumatologist if anything was wrong, or they would ask about it in their next consult, call their care provider, or send an e-consultation.

Table 6: Health 2.0 problems with adding personal content to the web, including amount of participants experiencing those problems $(n=16)$

\begin{tabular}{lrrrrr} 
& $2 a$ & $3 a$ & $4 b$ & $5 b$ & Total $^{b}$ \\
& $n=16$ & $n=15$ & $n=10$ & $n=15$ & $n=16$ \\
\hline $\begin{array}{l}\text { Numsignment } \\
\text { Number of participants who experienced problems }\end{array}$ & & & & \\
associated with adding personal content to the web, $\mathrm{n}(\%)$ & & & & \\
Using proper fields for adding data & $3(19)$ & $6(40)$ & $5(50)$ & $3(20)$ & $10(63)$ \\
Using capital letters and punctuation marks & $11(69)$ & $8(53)$ & $4(40)$ & $2(13)$ & $13(82)$ \\
Spelling & $5(31)$ & $2(13)$ & $4(40)$ & $2(13)$ & $8(50)$ \\
Using appropriate header and sender & & & & & \\
information & $\mathrm{n} / \mathrm{a}^{\mathrm{c}}$ & $7(47)$ & $6(60)$ & $0(0)$ & $10(63)$ \\
Formulating a question or message & $4(25)$ & $7(47)$ & $2(20)$ & $4(27)$ & $10(63)$ \\
Participants with > 1 problem per assignment & $6(38)$ & $10(67)$ & $3(30)$ & $5(33)$ & $14(88)$ \\
\hline
\end{tabular}

a 2. monitor disease symptoms by (2a) filling out a diary; 3 . use the e-consult service to (3a) write a new e-consultation; 4 . use a peer support forum to (4b) add your own tip; 5 . use a health care rating website to $(5 b)$ post a review.

${ }^{\mathrm{b}}$ Number of participants which experienced this particular problem during the complete test (5 assignments). The numbers in the rows do not add up, since one patient could experience the same problem during several assignments.

${ }^{\mathrm{C}}$ Using headers and sender information was not applicable in assignment 2. 


\section{Adding personal content to the web}

Difficulties with adding personal content to the web existed in several subcategories and were related to the correct formulation of the message or question to be placed on the web (Table 6). First, there were several practical issues in adding content to the web. Some participants experienced difficulties in using the proper fields for their information. For example, when writing an e-consultation, one participant wrote her question in the subject field. Other participants forgot to fill in a subject for the e-consultation, or an addressee to send the e-consultation to. As a result, the 'send' button did not become active. This was not understood by all participants, and three participants thought that the e-consultation was sent anyway (e.g. "he is sending my message now, right?" [Female, 24 years old]). Subsequently, there were many minor problems with the actual writing of a message, namely spelling errors, lack of punctuation, and capital letters. These errors could influence the readability of the content and how well the message was understood. Third, several participants found it difficult to reflect on whom the reader of their message would be, and what tone would be appropriate. For example, when writing an econsultation to their care provider in the patient web portal, it would be convenient to use a header and conclude with a name, surname, and maybe a patient number. However, when writing on a peer support forum, messages can be more informal and one might explicitly not conclude the message with a name (or use a nickname) for privacy matters (see next section). Some participants did not seem to be aware of this difference. Lastly, and perhaps most importantly, half of the participants showed problems in the actual formulation of a message or a question. They were not able to reflect on what information was necessary for the reader to understand their message or question. Also, participants used incomplete sentences in their messages (e.g. "sometimes have feeling in rheumatology that things are intertwined, mb too busy" [Female, 35 years old]), or asked an irrelevant question (e.g. "Don't I need medication because it's so warm over there??" [Male, 48 years old]).

\section{Protecting and respecting privacy}

The last category of observed problems comprised of the protection of one's own privacy and respecting that of others. During the assignments it was difficult to code how participants handled their privacy, because the assignments were fictional and participants did not actually have to save or send their added content. Very few participants mentioned their privacy during the assignments; therefore, the findings presented here are based on what participants mentioned during the assignments and on the interviews afterwards. Concerning access to electronic medical records or using econsultations, no one made a remark about privacy during the assignments or in the interview afterwards. Apparently, all participants were confident that their data was secure in the patient web portal. Nevertheless, three participants would not monitor their disease symptoms due to privacy issues, although this assignment was performed on the same web portal. Two participants reported they did not like the idea of putting all their information online for anyone to view and access (e.g. "I am an Internet user from a previous generation; I don't put down my whole life story online. It might go wrong and then all my information is out in the open." [Female, 35 years old]). One participant read 
the accompanying text when filling out her monitoring diary, and saw that her care providers had access to the monitored data as well, which discouraged use: "Oh, my care provider is reading along? For me that's a reason not to use it!" [Female, 57 years old].

With regard to the two assignments outside of the patient web portal (using a peer support forum and a health care rating site), more participants seemed aware of privacy issues. A message was added to the peer support forum by 1 out of 9 (11\%) participants, four mentioned only their surname, and five participants did not sign their message at all. However, in eight occasions, it was not clear if this was on purpose or not, because participants did not explain their choice. Only one participant specifically said that she did not want to be judged by the readers, and therefore left out their name. Of these nine participants, four would use a peer support forum in the future. All these participants reported that they would only write general information about themselves and that they would never write anything about others without their consent. Out of the ten participants that filled in a health care review, eight would use the website again in the future. However, only two participants would use the website to complain about a care provider, when a mistake was made: "I would only report it if a mistake was made, for I would hope to prevent that for someone else." [Female, 45 years old]. The other participants would not use the website to place a negative review because they would rather speak to their care provider in person about the issue and do not want to negatively sway the opinion of others.

\section{Relationship between patient characteristics and eHealth literacy}

We explored if there were any correlations between the performance on the assignments, patients' age, level of education, and perceived Internet skills (see supplementary tables in Appendix 1). We found that patients who are higher educated, younger, and have higher self-perceived Internet skills, on average completed more assignments independently, performed better, and encountered fewer problems. However, these data should be interpreted with care as the sample size was small.

\section{Discussion}

In these two studies, a representative sample of patients with rheumatic diseases performed Health 1.0 and Health 2.0 assignments on the Internet. While a substantial number of patients reported to experience physical uneasiness when using the computer (e.g., stiffness and tiredness) in the questionnaire, only three participants mentioned actual physical problems during the assignments. Nevertheless, using the Internet for health-related searches for a restricted amount of time seemed to be feasible for most participants. Furthermore, our results showed that a substantial group of patients were not able to fully use disease-related Internet applications for their own benefit. Problems in Health 1.0 information retrieval were found in four categories: (1) operating the computer and Internet browser, (2) navigating and orientating, (3) utilizing search strategies, and (4) evaluating relevance and reliability, which correspond largely with categories found in a previous study by Van Deursen and Van Dijk among healthy people [28]. About one-third of the participants in our study had severe problems in operating the computer, the Internet browser, and in navigating and orientating on the web. While 
these problems were often overcome, they did cause a substantial amount of inefficiency and frustration, withholding participants from fully using all the options the computer and Internet offers. Moreover, the more complex information and evaluation skills caused frequent problems for most of the patients. Many struggled with choosing a relevant search query, selecting a reliable search result, and browsing a website to find the right answer to a specific question. It seemed that a substantial part of the sample was using a trial-and-error method for searching the Internet. Strikingly, only three to four participants out of 15 were critical about the websites they visited and the information they retrieved from the Internet. The remaining participants did not seem to be aware of the source of the information, who exploited the website they searched on, and when the information was last updated. This is worrisome, since previous research studies have shown that many rheumatology-related websites provide unreliable information [29].

Although studies have been conducted to evaluate particular Health 2.0 applications [30,31], to our knowledge, no previous studies have been performed on Health 2.0 literacy of patients with chronic diseases and their ability to perform a variety of Health 2.0 assignments. This approach has enabled us to study Health 2.0 skills rather than evaluating the usability of a single application. During the assignments, we observed problems with operation, navigation, and information skills that corresponded with problems found in the Health 1.0 applications. However, since we provided patients with the direct website of the Health 2.0 applications, the Health 1.0 skills were not fully examined in this part of the study and the focus was on specific Health 2.0 problems. Most patients had little or no experience in using services to communicate with other patients, care providers, or with checking their own health status online, which corresponds with previous research among rheumatology patients [2]. Problems in doing so were mostly found in evaluating relevance and reliability (category 4) and in two additional categories: (5) adding personal content to the web, and (6) protecting and respecting privacy. When adding personal content, several patients had trouble with using the content fields correctly, formulating a message and writing it down properly, and keeping in mind who the reader(s) of the message would be. With reference to privacy issues, participants often mentioned being reluctant to add content to the web. It was difficult for the participants to reflect on the reader(s) of their information and what impact it would have on privacy when posting a message. Overall, it seemed that due to a lack of experience in online communication, many patients were insecure about when and how to use Health 2.0 applications. This lack of Health 2.0 use was seen in previous research as well [32]. Interpreting electronic health records caused some problems, mostly because patients were not able to locate the relevant information and to put the information in the right context. This was partly due to incorrect interpretation of numbers, which also relates to numeracy skills [33]. Problems with interpreting electronic medical records are a concern that health professionals have previously reported [34,35]. Nevertheless, the action that patients would take in reaction to their personal data was generally appropriate. Keeping patient accessible records clear and limited to the essence of the content would presumably overcome most of the observed difficulties [35]. After finishing the Health 2.0 assignments, many patients were enthusiastic about the possibilities the Internet could provide, and to become more involved in their own health care process, especially by using the applications that were provided by their own hospital. Two thirds of all 
participants would like to use e-consultations in the future, and almost all patients reported they would open their electronic medical records at home, now that they have seen the service. Many patients were simply unaware of their options and/or anxious to use them themselves before the study. Therefore, patients need to be guided and encouraged to use Health 2.0 applications, and they should be informed by care providers about the privacy disclosures in such applications.

A limitation of our studies was the research setting in which participants performed the assignments. Although we aimed to formulate assignments that were relevant to patients with rheumatic diseases and stressed that the study was not an exam, patients were probably more nervous than if they were in a natural setting. Participants were probably also focused on completing the assignments quickly, which could influence the quality with which they performed. Furthermore, in several Health 2.0 assignments, patients were asked to spontaneously formulate a fictive question or message, which turned out to be difficult for some participants and might have complicated the assignment. Nevertheless, our studies demonstrate that most patients have considerable problems with using the Internet for health-related purposes. Although our studies were restricted to patients with rheumatic diseases, we feel that our results are generalizable for other health conditions, especially as only a minority of the participants' perceived physical problems during the tests. Moreover, the assignments used in our performance tests (e.g., using e-consultations, health care rating sites and peer support forums) might be relevant to patients with different conditions. Because of the qualitative nature of our studies, we cannot draw strong conclusions on the most frequent eHealth literacy problems that patients encounter, and on which groups of patients encounter most problems. However, our studies showed that the majority of participants experienced difficulties on several levels, even though our research population was heterogeneous in age, education level, and had quite some experience in using the Internet. Previous research has shown that a higher education does not guarantee better Internet skills $[36,37]$ and other studies among higher educated populations confirm these results. For example, Hughes et al [38] showed that doctors often choose their search results based on navigational bias and a focus on what is known, and Stellefson et al [39] found that many health professional college students are rather unconfident when evaluating information from the Internet. Furthermore, a younger age and more Internet experience might enhance operational skills, but previous studies have found that strategic eHealth literacy problems are still frequently present among students who grew up using the Internet $[16,17,19]$. Some exploratory analysis on our data, however, indicated that patients with a higher educational level, younger age, and higher perceived Internet skills completed more assignments, performed better, and encountered fewer problems. All in all, it should be acknowledged that a broad range of eHealth literacy problems exist, but future research should focus on which groups of people struggle with specific categories of eHealth literacy problems.

From our results, it seemed that several shifts were necessary to make online information, communication, and participation services more beneficial in rheumatology. First of all, the problems that were observed in these studies cannot solely be attributed to the patients' skills, since the usability of Health 1.0 and Health 2.0 applications also plays a major role in overcoming operational, navigation, and information problems. 
Websites and interactive applications should be designed in a user-centered manner to overcome problems that many novice Internet users may experience $[2,10,23,40]$. In order to reach this, guidelines should be followed to focus on keeping a website plain and simple regarding navigation structures and usage of buttons [41]. Furthermore, it is essential that texts are written on a level that is understandable for the majority of the population [42]. Usability of Health 2.0 applications could, moreover, be increased by explaining their function, use, and privacy procedures in the application itself, for example using demonstration videos. Finally, to ensure that usability goals are reached, websites should be tested with representative end-users in several stages of the development $[43,44]$. Health care organizations could also play a role in tuning the level of online applications to patients' eHealth literacy, by developing websites and patient web portals which provide reliable and valuable information [25]. Second, patients should be informed and educated about proper use and protection of privacy on the web. This could be realized in (online) eHealth literacy courses, which seem to be promising $[45,46]$. Third, tools could be developed which care providers can use in consult, in order to gain attention among patients for both the possibilities and the risks of the Internet [47]. A final necessity that follows from our results, is an eHealth literacy measurement instrument that can identify a broad range of skills. The eHEALS scale by Norman [48] or the Functional, Communicative, and Critical Health Literacy Scales by Ishikawa [49] offer good starting points for this, provided that Health 2.0 skills measures are added.

In conclusion, patients with rheumatic diseases often seek online disease-related information and online interactive applications that help patients to get more involved in learning and caring for their disease are promising. However, the majority of the patients lack the skills to use both Health 1.0 and Health 2.0 properly for their own benefit. Problems include operating, navigating, searching the Internet, critically evaluating online content, and adding personal content while keeping privacy in mind. To decrease these problems, changes should be made in the design process of websites and online applications. Awareness, measurement, and education in eHealth literacy should also be increased.

\section{Acknowledgements}

We would kindly like to thank all the patients that participated in the two studies. Also, we would like to thank Ellen Meenhuis, Petra Eland-de Kok, Susanne Bakker-van Wijk, Judy Ammerlaan, Harmieke van Os-Medendorp, and Jeanine van der Giessen for their involvement in the study design, participant recruitment and/or data collection. These studies were supported by an unrestricted grant from MSD. 


\section{Appendix 1}

Supplementary table a: Completed tasks, performance and number of encountered problems related to education level, age and perceived Internet skills in study 1 (6 tasks) ( $n=15)$

\begin{tabular}{lccccc}
\hline $\begin{array}{l}\text { Participant } \\
\text { characteristics }\end{array}$ & $\begin{array}{c}\mathrm{n} \text { independently } \\
\text { completed tasks } \\
\text { (median) }\end{array}$ & $\begin{array}{c}\mathrm{n} \text { performed tasks (median) } \\
\text { Education level }\end{array}$ & Reasonable & Good & $\begin{array}{c}\mathrm{n} \\
\text { encountered } \\
\text { problems }\end{array}$ \\
\hline $\begin{array}{l}\text { Low }(\mathrm{n}=6) \\
\text { Middle to high }(\mathrm{n}=9)\end{array}$ & 3.5 & 1 & 2 & 2 & 15 \\
Age & 4 & 0 & 2 & 2 & 19 \\
Young $(<50, \mathrm{n}=4)$ & 5 & 0 & 1.5 & 2.5 & 12 \\
Elder $(\geq 50, \mathrm{n}=11)$ & 3 & 1 & 2 & 2 & 19 \\
Perceived Internet skills & & & & & \\
Poor to average $(\mathrm{n}=6)$ & 3 & 0 & 3 & 2 & 19 \\
Good to excellent $(\mathrm{n}=9)$ & 4 & 1 & 1 & 4.5 & 10 \\
\hline
\end{tabular}

Supplementary table b: Completed tasks, performance and number of encountered problems related to education level, age and perceived Internet skills in study 2 (10 tasks) ( $n=16)$

\begin{tabular}{|c|c|c|c|c|c|}
\hline \multirow{2}{*}{$\begin{array}{l}\text { Participant } \\
\text { characteristics }\end{array}$} & \multirow{2}{*}{$\begin{array}{l}\mathrm{n} \text { independently } \\
\text { completed tasks } \\
\text { (median) }\end{array}$} & \multicolumn{3}{|c|}{$\mathrm{n}$ performed tasks (median) } & \multirow{2}{*}{$\begin{array}{c}\mathrm{n} \\
\text { encountered } \\
\text { problems }\end{array}$} \\
\hline & & Poor & Reasonable & Good & \\
\hline \multicolumn{6}{|l|}{ Education level } \\
\hline Low $(n=6)$ & 4.5 & 4 & 3.5 & 0.5 & 20 \\
\hline Middle to high $(n=10)$ & 10 & 0 & 2.5 & 6.5 & 8.5 \\
\hline \multicolumn{6}{|l|}{ Age } \\
\hline Young $(<50, n=9)$ & 10 & 0 & 2 & 6 & 8 \\
\hline Elder $(\geq 50, n=7)$ & 6 & 3 & 3 & 1 & 15 \\
\hline \multicolumn{6}{|l|}{ Perceived Internet skills } \\
\hline Poor to average $(n=9)$ & 6 & 1 & 3 & 4 & 14 \\
\hline Good to excellent $(n=7)$ & 10 & 0 & 2 & 6 & 9 \\
\hline
\end{tabular}




\section{References}

1 Powell JA, Darvell M, Gray JAM. The doctor, the patient and the world-wide web: how the Internet is changing healthcare. J R Soc Med 2003; 96: 74-6.

2 Van der Vaart R, Drossaert CHC, Taal E, Van de Laar MAFJ. Patient preferences for a hospital based rheumatology Interactive Health Communication Application, and factors associated with these preferences. Rheumatology 2011; 50(9): 1618-26.

3 Hay MC, Cadigan J, Khanna D, Strathmann C, Lieber E, Altman R, McMahon M, Kokhab M, Furst DE. Prepared patients: Internet information seeking by new rheumatology patients. Arthrit Care Res 2008; 59(4): 575-82.

4 Robinson C, Graham J. Perceived Internet health literacy of HIV-positive people through the provision of a computer and Internet health education intervention. Health Info Libr J 2010; 27(4): 295-303.

5 Rice RE. Influences, usage, and outcomes of Internet health information searching: Multivariate results from the Pew surveys. Int J Med Inform. 2006; 75(1): 8-28.

6 Eysenbach G. Medicine 2.0: Social Networking, Collaboration, Participation, Apomediation, and Openness. J Med Internet Res 2008; 10(3): e22.

7 Van Uden-Kraan CF, Drossaert CHC, Taal E, Shaw BR, Seydel ER, Van de Laar MAFJ. Empowering processes and outcomes of participation in online support groups for patients with breast cancer, arthritis and fibromyalgia. Qual Health Res 2008; 18(3): 405-17.

8 Demiris G, Afrin LB, Speedie S, Courtney KL, Sondhi M, Vimarlund V, Lovis C, Goossen W, Lynch C. Patient-centered applications: use of information technology to promote disease management and wellness. A white paper by the AMIA knowledge in motion working group. J Am Med Inform Assoc. 2008; 15(1): 8-13.

9 Murray E, Burns J, See Tai S, Lai R, Nazareth I. Interactive health communication applications for people with chronic disease. Cochrane Database of Syst Rev 2009; 1.

10 Nguyen BV, Burstein F, Fisher J, Wilson C. Taxonomy of usage problems for improving user-centric online health information provision. AMCIS Proceedings 2011 Aug; 65. Detroit, Michigan, USA.

11 Norman CD, Skinner HA. eHealth literacy: essential skills for consumer health in a networked world. J Med Internet Res 2006; 8(2): e9.

12 Norman C. eHealth Literacy 2.0: Problems and Opportunities With an Evolving Concept. J Med Internet Res 2011; 13(4): e125.

13 Van Deursen A, van Dijk J. Internet skills performance tests: are people ready for eHealth? J Med Internet Res 2011; 13(2): e35.

14 Chan CV, Kaufman DR. A Framework for Characterizing eHealth Literacy Demands and Barriers. J Med Internet Res 2011; 13(4): e94.

15 Eysenbach G, Köhler C. How do consumers search for and appraise health information on the world wide web? Qualitative study using focus groups, usability tests, and in-depth interviews. Br Med J 2002; 324(7337): 573-7.

16 Hargittai E. Digital Na(t)ives? Variation in Internet Skills and Uses among Members of the "Net Generation". Sociol Inq 2010; 80(1): 92-113. 
17 Gui M, Argentin G. Digital skills of internet natives: Different forms of digital literacy in a random sample of Northern Italian high school students. New Media Soc 2011; 13(6): 963-80.

18 Gaddhar SF, Valerio MA, Garcia CM, Hansen L. Adolescent Health literacy: the importance of credible sources of online health information. J Sch Health 2012;82(1):28-36.

19 Stellefson M, Hanik B, Chaney B, Chaney D, Tennant B, Chavarria, EA. eHealth literacy among college students: a systematic review with implications for eHealth education. J Med Internet Res 2011; 13(4): e102.

20 Ericsson KA, Simon HA. Verbal reports as data. Psychol Rev 1980; 87: 215-51.

21 Guest G, Bunce A, Johnson L. How many interviews are enough?: an experiment with data saturation and variability. Field Methods 2006; 18(1): 59-82.

22 Baker NA, Rogers JC, Rubinstein EN, Allaire SH, Wasko MC. Problems Experienced by People With Arthritis When Using a Computer. Arthrit Care Res 2009; 61(5): 614-22.

23 Van der Vaart R, Drossaert CHC, Taal E, Van de Laar MAFJ Experiences and preferences of patients with rheumatic diseases regarding an interactive health communication application. Proceedings of the 2nd eTELEMED International Conference on eHealth, Telemedicine, and Social Medicine; 2010 Feb 10-16; Saint Martin; 64-71.

24 www.reumabond.nl. 2013-01-14. URL:http://www.reumabond.nl. Accessed: 201301-14.

25 www.reumaforum.nl. 2013-01-14.URL: http://www.reumaforum.nl. Accessed: 2013-01-14.

26 www.zorgkaartnederland.nl . 2013-01-14. URL:http://www.zorgkaartnederland.nl. Accessed: 2013-01-14.

27 Patton MQ. Qualitative Research and Evaluation Methods. 3rd Ed. California: Sage Publications; 2002.

28 Van Deursen AJAM, Van Dijk JAGM. Using the Internet: skill related problems in users' online behavior. Interact Comput 2009; 21: 393-402.

29 Ansani NT, Vogt M, Henderson BA, McKaveney TP, Weber RJ, Smith RB, Burda M, Kwoh CK, Osial TA, Starz T. Quality of arthritis information on the Internet. Am J Health-Syst Pharm 2005; 62(11): 1184-9.

30 Nijland N, Gemert-Pijnen J, Boer H, Steehouder MF, Seydel ER. Evaluation of Internet-Based Technology for Supporting Self-Care: Problems Encountered by Patients and Caregivers When Using Self-Care Applications. J Med Int Res 2008; 10(2): e13.

31 Nambisan P. Evaluating patient experience in online health communities: Implications for health care organizations. Health Care Manage Rev 2011; 36(2): 124-33.

32 Lupianez-Villanueva F, Angel Mayer M, Torrent J. Opportunities and challenges of Web 2.0 within the health care systems: an empirical exploration. Inform Health Soc Care 2009; 34(3): 117-26.

33 Rothman RL, Montori VM, Cherrington A, Pignone MP. Perspective: the role of numeracy in health care. J Health Commun 2008; 13(6): 583-95. 
34 Ross SE, Todd J, Moore LA, Beaty BL, Wittevrongel L, Lin CT. Expectations of patients and physicians regarding patient-accessible medical records. J Med Internet Res 2005; 7: e13.

35 Van der Vaart R, Drossaert CHC, Taal E, Van de Laar MAFJ. Giving rheumatology patients online home access to their electronic medical record (EMR): advantages, drawbacks and preconditions according to care providers. Rheumatol Int 2012 [Epub ahead of print].

36 Van Deursen AJAM, Van Dijk JAGM, Peters O. Rethinking Internet skills: the contribution of gender, age, education, Internet experience, and hours online to medium- and content-related Internet skills. Poetics 2011; 39(2): 125-44.

37 Neter E, Brainin E. eHealth Literacy: Extending the Digital Divide to the Realm of Health Information. J Med Internet Res 2012; 14(1): e19.

38 Hughes B, Wareham J. Doctors' Online Information Needs, Cognitive Search Strategies, and Judgments of Information Quality and Cognitive Authority: How Predictive Judgments Introduce Bias Into Cognitive Search Models. J Am Soc Inf Sci Tech 2010; 61(3): 433-52.

39 Stellefson M, Hanik B, Chaney DJ, Tennant B. Analysis of eHealth Search Perspectives Among Female College Students in the Health Professions Using $\mathrm{Q}$ Methodology. Med Internet Res 2012; 14(2): e60.

40 Burnstein F, Fisher J, McKemmish S, Manaszewicz R, Malhotra, P. User centred quality health information provision: benefits and challenges. Proceedings of the 38th Annual Hawaii International Conference on System Sciences 2005; 6.

41 Johnson CM, Johnson TR, Zhang J. A user-centered framework for redesigning health care interfaces. J Biomed Inform 2005; 38(1): 75-87.

42 Hirsh JM, Gardner EM. A Pilot Study to Determine Whether Patients are Likely to Understand the Educational Information Available On-Line About Arthritic Disorders. J Clin Rheumatol 2009; 15(7): 367-8.

43 Kreps GL, Neuhauser L. New directions in eHealth communication: Opportunities and challenges. Patient Educ Couns 2010; 78(3): 329-36.

44 Van Gemert-Pijnen JEWC, Nijland N, Van Limburg M, Eng B, Ossebaard HC, Kelders SM, Eysenbach G, Seydel ER. A holistic framework to improve the uptake and impact of eHealth technologies. J Med Internet Res 2011; 13(4): e111.

45 Car J, Lang B, Colledge A, Ung C, Majeed A. Interventions for enhancing consumers' online health literacy. Cochrane Database of Systematic Reviews 2011; 6.

46 Xie B. Effects of an eHealth literacy Intervention for older adults, J Med Internet Res 2011; 13(4): e90.

47 Diaz JA, Sciamanna CN, Evangelou E, Stamp MJ, Ferguson T. Brief report: what types of Internet guidance do patients want from their physicians? J Gen intern Med 2005; 20(8): 683-5.

48 Norman CD, Skinner HA. eHEALS: The eHealth Literacy Scale. J Med Internet Res 2006; 8(4): e27.

49 Ishikawa $\mathrm{H}$, Takeuchi T, Yano E. Measuring functional, communicative, and critical health literacy among diabetic patients. Diabetes Care 2008; 31(5): 874-9. 
Chapter 8

\section{Design and implementation of a rheumatology patient web portal}




\section{Design of a rheumatology patient web portal}

The previous studies yielded valuable insights related to the content and usability requirements of the application. Based on these results we started the design phase of our rheumatology patient web portal. In this phase, patients were involved again, following participatory design principles. The application was designed using several feedback loops, following the usability engineering method as described by Nielsen [1]. Using this empirical method, several different interfaces and prototypes were evaluated to keep patients' preferences of the content, "look and feel", and navigation structure of the web portal into account.

In order to do this, the content and navigation requirements of patients and care providers, as found in chapters 2, 3 and 4, were translated in a principal design plan, which was presented to students of the minor "Web presence" at Saxion Hogeschool, Enschede. Based upon these requirements, the students designed two distinct mock-up sets which were used in interviews with a small group of patients. In these interviews pros and cons of both designs with regard to clarity, color, design and navigation were examined. We found that patients had a strong preference for a simple and straight design, in order to quickly oversee what kinds of information were provided. Large buttons with icons that displayed the main themes and the login section of the portal were perceived as useful, to get a grip on the navigation of the portal. Furthermore, remarks were made about contrast in colors of text and background, easy accessible contact information, a proper search engine, and recognition marks to show the portal was provided by the Arthritis Centre Twente. Using the feedback from these interviews this design loop was repeated once more, with a different group of students, which resulted in a third set of mock-ups of the application. These designs were presented to a different group of patients, which generated new feedback to improve the prototype further. Patients made suggestions for the naming of the buttons in the portal and they preferred that buttons would change colors when being clicked on, all to improve conscious navigation through the portal. Many patients reported that they felt the colors blue and green were suitable for the portal, since these express professionalism and calmness. The combined information derived from this whole process was considered in the development of the final design, by a professional web designer. Subsequently, the web portal was programmed accordingly.

\section{Overview of the patient web portal}

The web portal consists of three main sections which contain different kinds of services. Figure 1 provides an overview of the main pages of the portal. The first section contains general information on rheumatic diseases, treatment options, and an overview of the care and support which is available for patients. The second section contains information on the Arthritis Centre Twente. This is mostly practical information on locations of the center's clinics, its care providers and their expertise, news of the center, and scientific research that is performed at/in collaboration with the center. The third section of the patient web portal is locked via login, through which patients of the center can access (parts of) their own electronic medical records. Patients can view data on their diagnosis, current medication and medication history, blood results and disease activity. Also, patients can monitor disease-related outcome measures, such as quality of life and 
functional status. All data is accompanied by written information and (where possible) charts and graphs to clarify the fluctuation in scores along a timeline, using colors to explain the data compared to norm scores. Figure 2 shows a screenshot of the homepage of the portal, figure 3 shows the main page of section 1 . Figures 4 and 5 provide screenshots of pages in the login section.

\section{Implementation and use of the patient web portal}

At the introduction of the portal, health care providers form the Arthritis Centre Twente were given a demonstration. Patients who were diagnosed with rheumatoid arthritis were sent an information letter and accompanying flyer to announce the web address of the portal and to explain its services. We chose to actively approach this patient group since they were the first to be able to look up data about their disease activity, medication and questionnaire scores in the web portal. In the months thereafter, posters, flyers and a page on a digital information board were displayed in the waiting rooms of the center to attract attention to the web portal among all patients of the Centre.

In the first five months after implementation, log files registered almost 5000 visitors on the patient web portal (from mid-June 2012 until mid-November 2012). In total, 45\% ( $\mathrm{n}=$ 2235) of visitors came from the region of Twente, where the Arthritis Centre Twente is located. Most were single time visitors (68\%), however, almost 1223 visitors returned to the website twice $(10 \%)$, three times $(4 \%)$, or more than 3 times $(10 \%)$. Half of the visitors $(50 \%)$ were so-called 'bouncers' who visited the web portal for less than 10 seconds. The visit duration of the other half varied from 30 seconds (10\%) up to 30 minutes (5\%). The mean number of visited pages was 4.4, ranging from 1 (mostly bouncers: $46 \%$ ) to more than 20 pages (3\%). The five web pages that were visited most often were "Treatment and Medication" (1072 page views), "Team Arthritis Centre Twente" (745 page views), "What is rheumatism" (558 page views), "Medication folders" (449 page views), and "Aids and services" (438 page views). On the login section of the patient portal, 210 unique patients logged in. In this part, the page on which patients can view their latest blood results was visited most often (396 page views), followed by their medication overview (266 page views), diagnosis (262 page views) and disease activity score over time (242 page views).

In order to investigate if the design and navigation of the patient web portal was indeed usable for patients and to explore the impact of the portal among patients, an evaluation study was performed during the first five months that the portal was online. The following chapter will describe the results from this study. 


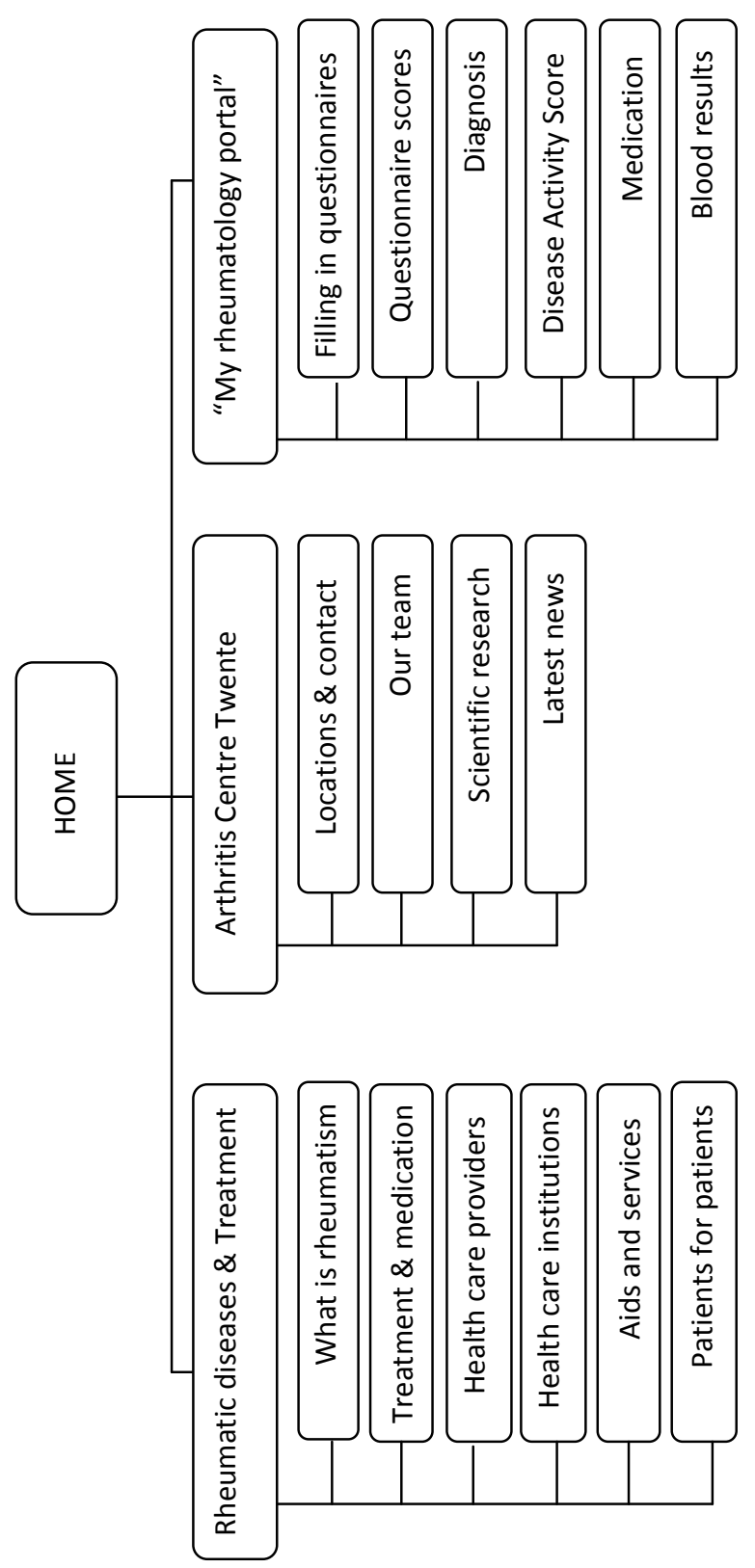

Figure 1: Overview of content of the patient web portal: www.reumacentrumtwente.nl 


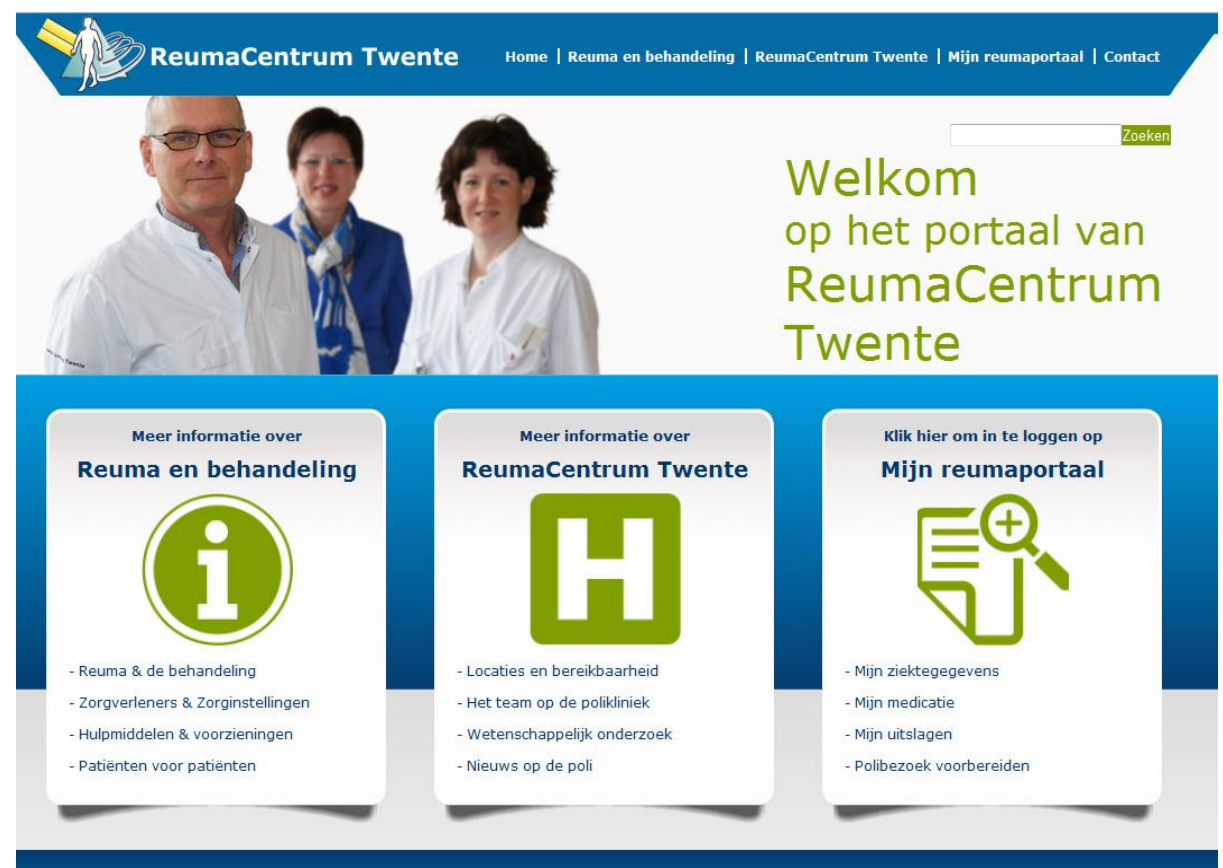

Figure 2: the homepage of the Arthritis Centre Twente patient web portal

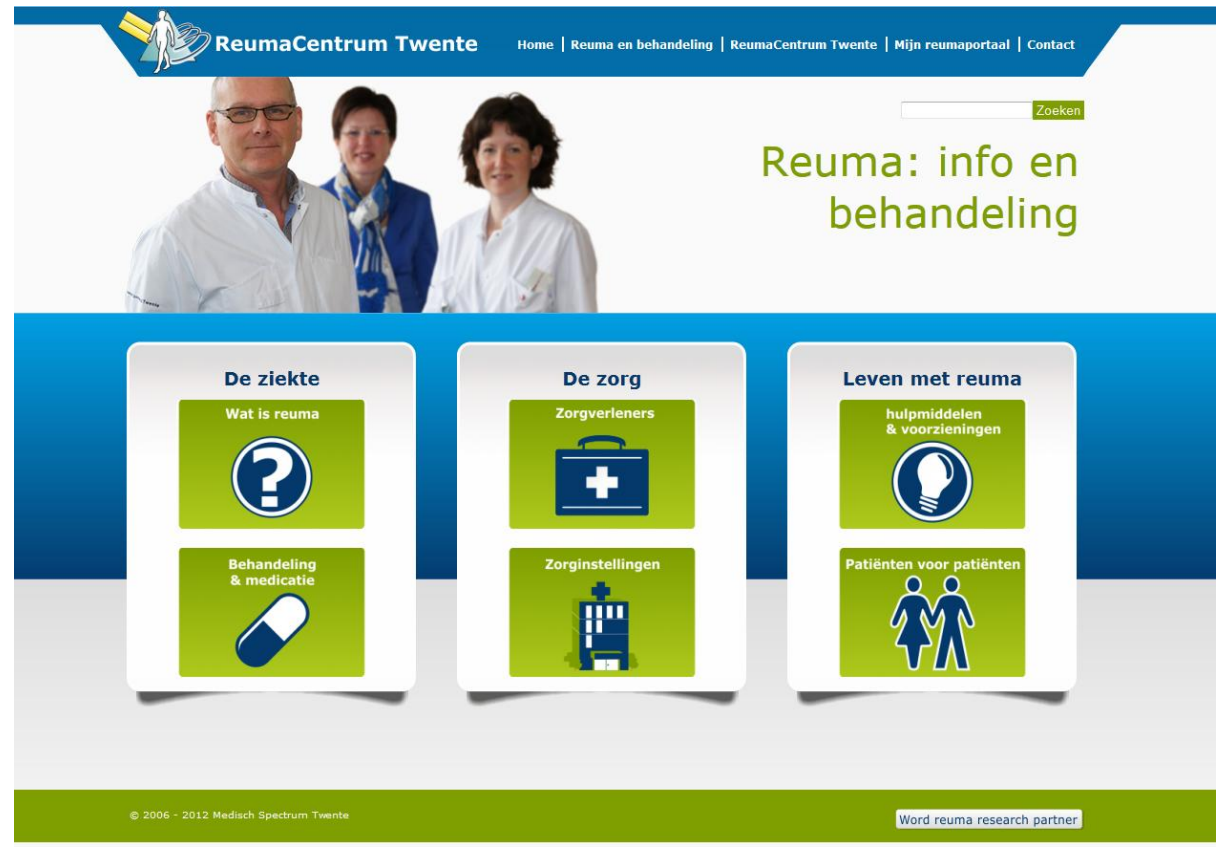

Figure 3: Section 1, information on rheumatic diseases and treatment 
DAS28

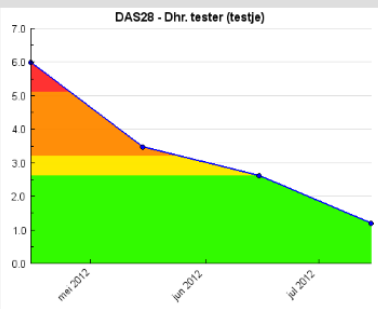

\begin{tabular}{|l|r|r|r|r|r|r|}
\hline Datum & DAS28 score & Aantal pijnlijke gewrichten & Aantal gezwollen gewrichten & Bloedbezinking & Algemeen welbevinden \\
\hline $15-07-2012$ & 1.20 & 0 & 0 & 5.0 & 5 \\
\hline $15-06-2012$ & 2.61 & 2 & 0 & 9.0 & 20 \\
\hline $15-05-2012$ & 3.47 & 3 & 1 & 13.0 & 30 \\
\hline $15-04-2012$ & 5.98 & 5 & 4 & 60.0 & 93 \\
\hline
\end{tabular}

\section{Wat is de DAS28?}

De Disease Activity Score (DAS28) is een ziekteactiviteit score. Deze score geeft inzicht in de activiteit van de ziekte. De score wordt berekend door een combinatie van het aantal pijnlijke en gezwollen gewrichten, de bloedbezinking (of CRP) en het cijfer dat u geeft aan de invloed van de reumatoìde artritis op het dagelijks leven (algemeen welbevinden).

Hoe hoger de ziekteactiviteit score, hoe actiever uw reumatoìde artritis is. De score kan lopen van 0 tot ongeveer 10 . We beschouwen de reumatoìde artritis als 'rustig' wanneer de ziekteactiviteit onder de 3,2 zit. Bij een lage ziekteactiviteit ervaren de meeste patiēnten ook minder klachten.

Wat doen we met deze score?

In overleg met uw reumatoloog kan uw medicatie worden aangepast aan de hand van uw DAS28 score. Bij een hoge score kan de medicatie verhoogd, of veranderd worden. Bij een lage score kan uw medicatie ongewijzigd worden voortgezet en soms voorzichtig worden afgebouwd. Reumatoilde artritis is echter wel een wisselende ziekte; uw klachten kunnen ook weer terugkomen en afstemming van uw medicatie blijft van groot belang.

Figure 4: Overview of patients' Disease Activity Score (DAS28) over time.

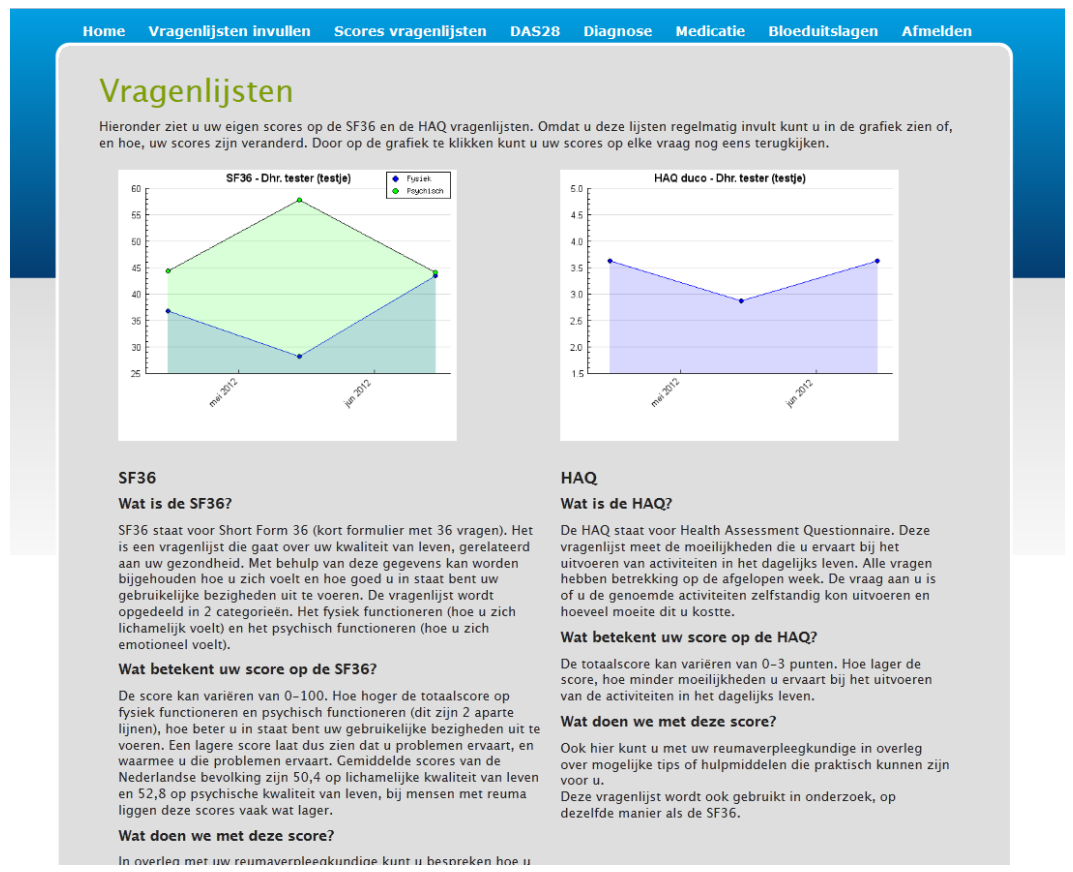

Figure 5: Overview of patient data on disease-related quality of life (SF36) and functional status (HAQ) 


\section{References}

1 Nielsen J. Usability Engineering. Second Edition; Morgan Kaufmann Publishers, 1994. 


\section{Chapter 9}

\section{Impact of patient-accessible Electronic Medical Records in rheumatology: use, satisfaction and effects on empowerment among patients}

Rosalie van der Vaart

Constance H.C. Drossaert

Erik Taal

K. Wiepke Drossaers-Bakker

Harald E. Vonkeman

Mart A.F.J. van de Laar

Submitted for publication 


\section{Abstract}

Objectives: To measure the use, satisfaction and impact on empowerment of a web portal which provides patients with rheumatoid arthritis home access to their electronic medical records (EMR).

Methods: A pretest-posttest study was conducted among 360 patients. Questionnaires assessed patients' socio-demographics, health literacy, Internet use, disease characteristics, and empowerment before and after launching a hospital-based patient web portal. To measure empowerment, patients' satisfaction with care, trust in their rheumatologist, self-efficacy in patient-provider communication, illness perceptions, and medication adherence were assessed. The post-test included questions on web portal use, satisfaction, and self-perceived impact due to web portal use.

Results: $54 \%$ of respondents with Internet access had viewed their EMR. Respondents were positive about the ease of use and usefulness of the portal and reported very few problems. Age $(P=.03)$, amount of Internet use $(P=.01)$ and self-perceived Internet skills $(P=.03)$ significantly predicted web portal use. Of the respondents who had logged in, $44 \%$ reported feeling more involved in their treatment and $37 \%$ felt they had more knowledge about their treatment. Significant differences over time were not found on the empowerment-related instruments.

Conclusion: The current portal succeeded in offering patients access to their EMR in a usable and understandable way. While its true impact is difficult to grasp, a relevant portion of the patients felt more empowered due to the web portal. Offering patients home EMR access appears to be a valuable addition to the care process, with the potential of involving patients more in their own treatment. 
Since many rheumatic diseases are chronic and can have a large impact on patients' lives, it is essential that patients get involved in their treatment and have proper self-care practices [1,2]. Increasing patients' responsibilities and autonomy is also essential for the redesign of health services from current disease- or institutional-centered models to patient-centered models of care, in order to keep expenses under control [3,4]. The implementation of information and communication technologies in health care can play an essential role in this shift, as it enables an extension of care outside the walls of health care institutions [5]. A technology that is slowly emerging in health care is the ability to provide patients online home-access to their electronic medical records (EMRs), via hospital-based patient web portals [6,7]. The key benefit of this application is that patients can (repeatedly) read the documentation on their disease and treatment, at home, which has the potential to empower patients in their care process $[8,9]$.

Previous research has suggested that patient web portals with EMR-access may influence health care on several levels. First of all, it provides transparency of medical data, which could reduce medical errors, increase patients' trust in care providers and could enhance patient satisfaction [10,11,12]. Secondly, patients' knowledge and understanding of the disease and treatment may be enhanced by these applications [13]. Being better informed, patients would be better able to communicate with their health care provider and may, therefore, be more involved in decision making processes $[13,14]$. Thirdly, patients may gain a feeling of greater control over their disease and treatment, which could positively influence treatment adherence [15], and even clinical outcomes [16].

While patient access to medical records could benefit health care, an online application might not suit everyone. Previous studies have shown that users of online applications are often relatively young and highly educated [17]. Furthermore, patients' abilities to use (online) health information, also called "health literacy" are assumed to be related to acceptance of online applications [18]. Up until now, little is known on the predictors for using home access to medical records or on the difficulties that patients experience when using this service.

Hospitals increasingly offer patients home access to their EMR, but to the best of our knowledge, no studies have thus far been conducted in the field of rheumatology. Still, previous studies have shown that patients are indeed interested in this option $[19,20]$ and both rheumatologists and nurses believe that it could have a positive impact on the empowerment of their patients [21]. Based upon these studies, a web portal was designed following user-centered design principles [22], which offers information on rheumatic diseases, treatments, and available aids and support (www.reumacentrumtwente.nl). Additionally, the patient web portal contains a personal secure login section, where patients can find their diagnosis, current medication and medication history, blood results, actual and previous disease activity, and outcomes on quality of life related instruments. All data is accompanied by written information and (where possible) charts and graphs to show the fluctuation in scores along a timeline using colors to compare the data to norm scores. The purpose of this study was to assess the use, satisfaction, and the impact of the portal on patient empowerment among patients suffering from rheumatoid arthritis. 


\section{Methods}

A pretest-posttest design was used, conducting a survey in the month before the patient web portal went online (TO), and five months after the portal went online (T1).

\section{Patients and procedure}

In total, 415 patients diagnosed with RA, conform the 1987 American College of Rheumatology classification criteria, were selected from the patient database of the Arthritis Centre Twente in Enschede, the Netherlands. Treating rheumatologists $(n=6)$ were asked to exclude those patients from the selection who were deceased $(n=10)$, or had had their last consultation longer than one year ago $(n=24)$. Other reasons for rheumatologists to exclude patients were: not diagnosed with RA ( $n=3$ ), severe comorbidity $(n=4)$ or change of hospital $(n=1)$. In total, 42 patients were excluded. The 373 remaining patients were sent a personal invitation letter and a paper-and-pencil questionnaire on TO. A reminder was sent to those patients who did not respond within two weeks. One invitation was returned as undeliverable and six patients called or emailed to report that they were not interested in participation. After the pretest, all (but these seven) patients received an invitation to visit the portal and to log in with a personal account, which could be obtained in person in the clinic. Five months later, the same sample was approached with a personal letter and posttest questionnaire, with a reminder after two weeks, excluding the seven patients that had withdrawn $(n=366)$. At T1, four questionnaires were returned as undeliverable and two patients were deceased. Therefore, the total number of patients who received the questionnaire on both T0 and T1 is 360 .

\section{Instruments}

To investigate predictors of patient web portal use, the questionnaire on T0 comprised of socio-demographics, health literacy, Internet use, and disease characteristics. The assessed socio-demographics included: age, gender, education level, marital status, and employment. Health literacy was measured using a translated and adapted version of the Health literacy scales by Ishikawa $[23,24]$. This is a 14 -item instrument measuring health literacy at three levels. Cronbach's alpha found in our translated instrument was .92, which corresponds with the original version of the instrument [Ishikawa, 2008]. Internet use was measured by asking patients if they had Internet access, and if so, how often they used it on a 5-point scale ranging from "daily" (1) to "(almost) never" (5), how many years of Internet experience they had, and what their self-perceived Internet skills were, ranging from "very good" (1) to "poor" (5). Concerning disease characteristics, patients were asked when they had been diagnosed, how often they had visited their rheumatologist over the past 6 months, and what their self-perceived general health was, in a range from "poor"(1) to "excellent" (5).

To be able to investigate the impact of the patient web portal, five validated instruments were included that measure empowerment-related constructs on which change could be expected due to the use of the portal. Satisfaction with care was measured by items based on the QUOTE rheumatic patients [25]. Six items were used measuring satisfaction with the rheumatologist and the nurse practitioner, respectively. 
For example, "my rheumatologist knows my problems very well" and "my rheumatologist takes me seriously". Response options ranged from "not at all" (1) to "definitely" (4). The possible range of scores for both scales was 6 to 24, with 24 representing a high satisfaction with care. Cronbach's alphas were .83 and .87 respectively. Trust in the rheumatologist was measured with the Trust In Physicians short form (TRIP_sf), which is based on the Cologne-Patient-Questionnaire scale "trust in physicians" and which measures different aspects of a trusting physician-patient-interaction [26]. Items could be answered using a 5-point Likert scale ranging from "do not agree at all" (1) to "completely agree" (5), with a possible score ranging from 5 to 20 , with 20 representing a high trust in the rheumatologist. Cronbach's alpha was .93. Self-efficacy in patient-provider communication was assessed with the 5-item version of the Perceived Efficacy in PatientPhysician Interactions questionnaire (PEPPI-5), which assesses the subjective sense of patients' confidence when interacting with their physicians [27]. The instrument has been translated and validated for the Dutch situation [28]. Each item begins with "how confident are you in your ability to..." and participants respond to each question on a 5point Likert scale ranging from "not at all confident" (1) to "very confident" (5). The range of possible scores is 5 to 25 , with 25 representing the highest patient self-efficacy. Cronbach's alpha of this instrument was .96 in our data. Illness perception was assessed with the Revised IIIness Perception Questionnaire (IPQ-R). The subscales 'Personal control' (6 items), 'Treatment control' (5 items), and 'Illness coherence' (5 items) were used, which assess personal control and self-efficacy beliefs, belief in the treatment, and understanding of the illness, respectively [29]. All items can be answered on a 5-point Likert scale ranging from "strongly disagree" (1) to "strongly agree" (5), which makes the possible range of scores 6 to 30 and 5 to 25 , with 30 and 25 representing the highest perceived control. Cronbach's alphas of the subscales were .52, .72, and .76, respectively. Medication adherence was assessed with the Morisky Medication Adherence scale (MMA), which measures medication-taking behavior using eight items. Response categories are yes/no for seven dichotomous items and a 5-point response ranging from "always" (1) to "never" (5) for the last item, which was dichotomized [30,31]. Scores were recoded, so that higher scores represent a better medication adherence, with eight representing perfect adherence. Cronbach's alpha was .66.

The questionnaire on T1 comprised of the same measures as the pre-test, except for health literacy. To assess use and satisfaction with the patient web portal, several questions were added to the post-test, including: (1) use and moment of use of the website section and login section of the portal, (2) sharing of the personal information from the portal with others, (3) perceived ease of use, clarity, usefulness and completeness of the portal, (4) problems encountered on the portal, and what was done to solve them, (5) difficulties with understanding information in the login section, and (6) occurrence of wrong information in the login section. Additionally, questions were asked on the self-perceived impact of the portal. These questions covered the same constructs as the aforementioned instruments, but asked patients directly if they felt that the portal caused an increase, decrease, or did not change anything concerning these outcomes (see Table 5 for an overview of all topics). 


\section{Data analysis}

Analyses were performed using the Statistical Package for the Social Sciences (version 20.0 IBM SPSS Inc, Chicago, IL, USA). To analyze differences in age and gender at baseline between patients who did return the questionnaire at T0 and/or T1 and those who did not, the Mann-Whitney test was applied for age and the chi-square for gender. Descriptive statistics were used to summarize socio-demographics, Internet-related and disease characteristics, use of the portal, satisfaction with the portal and perceived impact of the portal. To explore relationships between patient characteristics and portal usage (non-use, website only use, and login use), the Kruskal-Wallis test was applied for continuous variables and the chi-square for discrete variables. Whenever a significant difference was found, pairwise comparisons were performed to further analyze differences between groups, using Mann-Whitney or chi-square tests. Additionally, multi-nominal logistic regression was used to analyze which variables uniquely predicted patient web portal use. To analyze the effect of portal use, Analysis of Covariance was used, in which scores on T1 of non-users, website users and login users were compared, including their T0 scores as covariate. For all analyses, $p$-values $<0.01$ (two-tailed) were used as criterion for statistical significance, as multiple comparisons were executed.

\section{Results}

\section{Respondents}

Of the 372 patients who received the questionnaire at T0, 259 (70\%) sent it back completed. At T1, 360 patients were sent the questionnaire, of which 214 (59\%) completed it. A total of 194 (54\%) patients completed both questionnaires. There were no differences in age or gender between responders and non-responders on TO. At T1 and in the paired samples, there were no differences between responders and non-responders in gender, but the mean age of responders was 4.2 years higher $(P=.01)$ and 3.6 years higher $(P=.02)$, respectively.

\section{Patient web portal use}

Of all respondents on $\mathrm{T} 1$, more than half (54\%) reported to have used the patient web portal, and 86 respondents (40\%) reported to have logged in to view their personal information (Table 1). Of all respondents with Internet access, $70 \%$ had used the portal and $54 \%$ had logged in. Lack of Internet access was the most frequent reason for not using the portal $(n=56)$. Other reasons not to have used the portal were: "I planned to but didn't have time yet" $(n=30)$, "I'm not interested" ( $n=19)$, "I tried, but something went wrong" ( $n=7)$, "I don't know how to visit the portal" ( $n=5)$, "I didn't think of it" $(n=3)$, and "I know what I want to know about RA" ( $n=2)$.

Of the respondents who logged in on the patient web portal, $60(70 \%)$ reported to do this in the week before a consultation with their rheumatologist or nurse practitioner. Sixteen respondents (19\%) reported doing this after their consultation (data not shown in Table). Of the respondents who logged in on the portal, 29 (34\%) shared their personal information with a family member. The other participants did not show their information to anyone else. 
Table 1: patient web portal usage of respondents at T1 $(n=214)$

\begin{tabular}{lrrrr} 
Patient web portal use & \multicolumn{2}{c}{$\begin{array}{c}\text { All respondents } \\
(\mathrm{n}=214) \\
\mathrm{n}(\%)\end{array}$} & \multicolumn{2}{c}{$\begin{array}{c}\text { Respondents with } \\
\text { home Internet } \\
\text { access ( } \mathrm{n}=158) \\
\mathrm{n}(\%)\end{array}$} \\
\hline Respondents that used the patient web portal & 115 & $(54)$ & 111 & $(70)$ \\
$\quad 1$ time & 41 & $(19)$ & 38 & $(24)$ \\
2 times & 47 & $(22)$ & 46 & $(29)$ \\
3 times or more & 27 & $(13)$ & 27 & $(17)$ \\
Respondents that used the website only & 29 & $(14)$ & 26 & $(16)$ \\
Respondents that logged in & 86 & $(40)$ & 85 & $(54)$ \\
\hline
\end{tabular}

\section{Predictors of patient web portal use}

Table 2 shows the personal and Internet-related characteristics of the respondents at T1. The overall mean age was 62 (S.D. = 13.3), ranging from 20 to 86 years old. Two thirds of the respondents were female, which is representative for our population. Overall, respondents reported using the Internet regularly, but only a minority (31\%) rated their own Internet skills as "good" to "very good". Univariate analyses showed that age, marital status, education level, employment, health literacy and all Internet-related characteristics were significantly related to portal usage. Non users were more often older, single, lower educated and unemployed. Respondents with a higher level of health literacy were more inclined to log in on the portal, as well as respondents who used the Internet more often, had more years of experience, and perceived their own skills as better.

Table 3 shows an overview of health-related characteristics of the respondents on T1. Most patients had been diagnosed with RA for more than a year, and visited the rheumatology clinic regularly. The majority of respondents perceived their general health as good or excellent. None of these characteristics were significantly related to portal use. Further analyses with multi-nominal logistic regression (in which all variables that were related to portal use in the univariate analyses were included as predictor variables), showed that all variables together explained $59 \%$ of the variance $\left(R^{2}=.59\right.$ (Nagelkerke), model $\left.\chi^{2}(22)=94.04, P<.001\right)$. Patient web portal use was significantly predicted by age $(b$ $=.09$, Wald $\chi^{2}(1)=4.72, P=.03$ ), with younger respondents being more inclined to use the portal. Logging in at the patient web portal was significantly predicted by selfperceived Internet skills $\left(b=-.96\right.$, Wald $\left.\chi^{2}(1)=4.74, P=.03\right)$ and amount of Internet use ( $b$ $=-.70$, Wald $\left.\chi^{2}(1)=6.07, P=.01\right)$. 
Table 2: Personal and Internet-related characteristics of respondents on T1 and differences between patient web portal users and non-users $(n=214)$

\begin{tabular}{|c|c|c|c|c|c|}
\hline Characteristic & $\begin{array}{c}\text { Total } \\
(n=214)\end{array}$ & $\begin{array}{l}\text { Non-users } \\
(n=99)\end{array}$ & $\begin{array}{c}\text { Website-only } \\
\text { users } \\
(n=29)\end{array}$ & $\begin{array}{l}\text { Login users } \\
\qquad(\mathrm{n}=86)\end{array}$ & $P^{1}$ \\
\hline \multicolumn{6}{|l|}{ Personal characteristics } \\
\hline Age (M, (S.D.)) & $62(13.2)$ & $66(14)^{\mathrm{ac}}$ & $63(11)^{a b}$ & $56(11)^{b c}$ & .000 \\
\hline Gender (\% female) & $140(65 \%)$ & $69(70 \%)$ & $14(48 \%)$ & $57(66 \%)$ & n.s. \\
\hline $\begin{array}{l}\text { Marital status (\% living } \\
\text { together) }\end{array}$ & $170(80 \%)$ & $68(70 \%)^{\text {ac }}$ & $26(90 \%)^{a}$ & $76(88 \%)^{c}$ & .000 \\
\hline \multicolumn{6}{|l|}{ Education level } \\
\hline low & $86(40 \%)$ & $54(55 \%)^{\text {ac }}$ & $8(28 \%)^{a}$ & $24(28 \%)^{c}$ & .001 \\
\hline medium & $89(42 \%)$ & $29(29 \%)$ & $15(52 \%)$ & $45(52 \%)$ & \\
\hline high & $33(15 \%)$ & $11(11 \%)$ & $6(21 \%)$ & $16(19 \%)$ & \\
\hline missing & $6(3 \%)$ & $4(4 \%)$ & $0(0 \%)$ & $1(1 \%)$ & \\
\hline Employment (\% working) & $72(34 \%)$ & $24(24 \%)^{c}$ & $10(34 \%)$ & $38(44 \%)^{c}$ & .02 \\
\hline $\begin{array}{l}\text { Health literacy (M(S.D.)) } \\
(\mathrm{n}=157)^{2}\end{array}$ & $38.6(7.2)$ & $36.5(7.6)^{c}$ & $37.9(7.2)$ & $40.9(6.1)^{c}$ & .001 \\
\hline \multicolumn{6}{|c|}{ Internet-related characteristics } \\
\hline \multicolumn{6}{|c|}{ Amount of Internet use } \\
\hline $\begin{array}{l}\text { Daily to several days a } \\
\text { week }\end{array}$ & 117 (55\%) & $27(27 \%)^{c}$ & $17(59 \%)^{b}$ & $73(85 \%)^{c b}$ & .000 \\
\hline One day a week or less & $50(23 \%)$ & $30(30 \%)$ & $9(31 \%)$ & $11(13 \%)$ & \\
\hline Missing (no home & $47(22 \%)$ & $43(43 \%)$ & $3(10 \%)$ & $1(1 \%)$ & \\
\hline \multicolumn{6}{|l|}{ Internet access) } \\
\hline \multicolumn{6}{|c|}{ Years of Internet experience } \\
\hline$<5$ years & $44(21 \%)$ & $21(21 \%)^{c}$ & $10(34 \%)^{b}$ & $13(15 \%)^{\mathrm{cb}}$ & .001 \\
\hline$\geq 5$ years & $113(53 \%)$ & $26(26 \%)$ & $16(55 \%)$ & 71 (83\%) & \\
\hline Missing & $57(27 \%)$ & $52(53 \%)$ & $3(10 \%)$ & $2(2 \%)$ & \\
\hline \multicolumn{6}{|l|}{ Self-perceived Internet skills } \\
\hline Good to very good & $66(31 \%)$ & $11(11 \%)^{c}$ & $6(21 \%)^{b}$ & $49(57 \%)^{c b}$ & .000 \\
\hline Average to reasonable & 75 (35\%) & $28(28 \%)$ & $16(55 \%)$ & 31 (36\%) & \\
\hline Poor & $22(10 \%)$ & $13(13 \%)$ & 5 (17\%) & $4(5 \%)$ & \\
\hline Missing & $51(24 \%)$ & 47 (47\%) & $2(7 \%)$ & $2(2 \%)$ & \\
\hline
\end{tabular}

${ }^{1}$ Kruskal-Wallis or Chi-square tests

${ }^{2}$ Scale ranges from 14 (low level of health literacy) to 56 (high level of health literacy); data from T0

${ }^{a}$ significant difference between non-users and website-only users

${ }^{\mathrm{b}}$ significant difference between website-only users and login users

${ }^{\mathrm{c}}$ significant difference between non-users and login users 
Table 3: Health-related characteristics of respondents at T1 and differences between users and nonusers $(n=214)$

\begin{tabular}{lrrrrr}
\hline Characteristic & Total & Non-users & Website-only & $\begin{array}{r}\text { Login } \\
\text { users }\end{array}$ & $P^{1}$ \\
& $(\mathrm{n}=214)$ & $(\mathrm{n}=99)$ & users $(\mathrm{n}=29)$ & $(\mathrm{n}=86)$ & \\
\hline Time since diagnosis & & & & & \\
$<5$ years ago & $150(70 \%)$ & $67(68 \%)$ & $22(76 \%)$ & $61(71 \%)$ & n.s. \\
$\geq 5$ years ago & $60(28 \%)$ & $28(28 \%)$ & $7(24 \%)$ & $25(29 \%)$ & \\
missing & $4(2 \%)$ & $4(4 \%)$ & $0(0 \%)$ & $0(0 \%)$ & \\
Number of clinic visits in the past 6 months & & & & \\
$0-1$ & $66(31 \%)$ & $36(36 \%)$ & $8(28 \%)$ & $22(26 \%)$ & n.s. \\
2 & $118(55 \%)$ & $53(54 \%)$ & $16(55 \%)$ & $49(57 \%)$ & \\
3 or more & $23(11 \%)$ & $5(5 \%)$ & $4(14 \%)$ & $14(16 \%)$ & \\
Missing & $7(3 \%)$ & $5(5 \%)$ & $1(3 \%)$ & $1(1 \%)$ & \\
Self-perceived general health & & & & & \\
Good to excellent & $126(59 \%)$ & $54(55 \%)$ & $20(69 \%)$ & $52(60 \%)$ & n.s. \\
Reasonable to poor & $86(40 \%)$ & $43(43 \%)$ & $9(31 \%)$ & $34(40 \%)$ & \\
Missing & $2(1 \%)$ & $2(2 \%)$ & $0(0 \%)$ & $0(0 \%)$ & \\
\hline
\end{tabular}

${ }^{1}$ Chi-square tests

\section{Satisfaction with the patient web portal}

The portal was positively appraised and most login users found their personal information "fairly easy" to "very easy" to understand (Table 4). When logging in on the portal, 15 respondents experienced a single problem. As a result, three respondents left the portal, three asked for help, and nine kept trying until they succeeded. Concerning the nature of the difficulties, four respondents reported an overall struggle with the Internet (e.g. "I find using the Internet complicated"). The others did not mention a reason for their problem. Two respondents reported reoccurring problems with logging in on the portal. One of them requested a new account, and one called the web host. Nine respondents who had logged in on the portal reported finding incorrect information. Six respondents reported the nature of this mistake, which concerned medication or blood test information that was out-of-date in all cases. Three respondents brought this up during a consultation with their doctor and one participant called the hospital. Five respondents reported not taking any action (yet) because: "I thought it wasn't important", "I didn't know who to contact", and "I was too insecure to contact anyone". Two respondents were waiting until their next consultation to bring it up.

\section{Subjective impact of the patient web portal}

Several positive changes were perceived by patients who had logged in on the portal (Table 5). A large part of the respondents felt that they were more involved in their treatment and that they understood their treatment better due to the patient web portal. One third of all login users felt that the quality of care was higher as a result of the portal. Also, according to a large part of the respondents, knowledge about the disease, understanding of what care providers explain, communication with the care providers, and trust in the care providers was increased. Additionally, some patients reported to search less for health information by themselves, as a result of the information provided 
by the hospital-based portal. Only one participant perceived a negative change, he/she felt less involved in the treatment due to the patient web portal. No further adverse effects were reported by the participants.

Table 4: Appraisal, comprehension and accuracy of the login part of the patient web portal $(n=86)$

\begin{tabular}{|c|c|c|}
\hline & M (S.D.) & $\mathrm{n}(\%)$ \\
\hline \multicolumn{3}{|l|}{ Appraisal of the login part $(n=64-75)^{1}$} \\
\hline Ease of use & $4.4(.8)$ & \\
\hline Clarity & $4.3(.7)$ & \\
\hline Usefulness & $4.3(.7)$ & \\
\hline Completeness & $4.1(.9)$ & \\
\hline \multicolumn{3}{|l|}{ Comprehension of the login pages $(n=63-72)^{2}$} \\
\hline DAS28 (disease activity) & $3.4(.7)$ & \\
\hline Medication (history) & $3.5(.6)$ & \\
\hline Blood results & $3.5(.5)$ & \\
\hline Feedback on monitored data & $3.5(.6)$ & \\
\hline \multicolumn{3}{|c|}{ Encountered problems when logging in on the patient web portal } \\
\hline 1 problem & & $15(17)$ \\
\hline 2 problems & & $2(2)$ \\
\hline Found incorrect (our-of-date) information & & $9(10)$ \\
\hline \multicolumn{3}{|c|}{$\begin{array}{l}1 \text { answer options ranged from } 1 \text { (very negative) to } 5 \text { (very positive) } \\
2 \text { answer options ranged from } 1 \text { (very difficult) to } 4 \text { (very easy) }\end{array}$} \\
\hline Outcome measure & $\begin{array}{c}\text { Website-only users } \\
(\mathrm{n}=29) \\
\mathrm{n}(\%)\end{array}$ & $\begin{array}{c}\text { Login users } \\
\quad(n=86) \\
n(\%)\end{array}$ \\
\hline \multicolumn{3}{|l|}{ Using the patient web portal increased my ... } \\
\hline involvement in the treatment & $1(3 \%)$ & $38(44 \%)$ \\
\hline knowledge about the treatment & $2(7 \%)$ & $32(37 \%)$ \\
\hline quality of care & $2(7 \%)$ & $25(29 \%)$ \\
\hline knowledge about the disease & $2(7 \%)$ & $21(24 \%)$ \\
\hline understanding of what care providers explain & $0(0 \%)$ & $21(24 \%)$ \\
\hline self-efficacy in communication with care providers & $0(0 \%)$ & $16(19 \%)$ \\
\hline trust in my care provider & $0(0 \%)$ & $14(16 \%)$ \\
\hline insight into the need of medication therapy & $1(3 \%)$ & $12(14 \%)$ \\
\hline medication adherence & $0(0 \%)$ & $8(9 \%)$ \\
\hline communication with others about my disease & $0(0 \%)$ & $6(7 \%)$ \\
\hline number of online searches for health information & $0(0 \%)$ & $4(5 \%)$ \\
\hline \multicolumn{3}{|l|}{ Using the patient web portal decreased my ... } \\
\hline number of online searches for health information & $0(0 \%)$ & $15(17 \%)$ \\
\hline worries about my health & $1(3 \%)$ & $3(3 \%)$ \\
\hline involvement in the treatment & $0(0 \%)$ & $1(1 \%)$ \\
\hline
\end{tabular}

\section{Pre-post test results on impact of the patient web portal}

Analyses of Covariance revealed that the $\mathrm{T} 1$ scores on the empowerment-related outcome measures did not differ between the three groups (non-users, website only users and login-users), suggesting that portal use has not yielded significant improvements in any of 


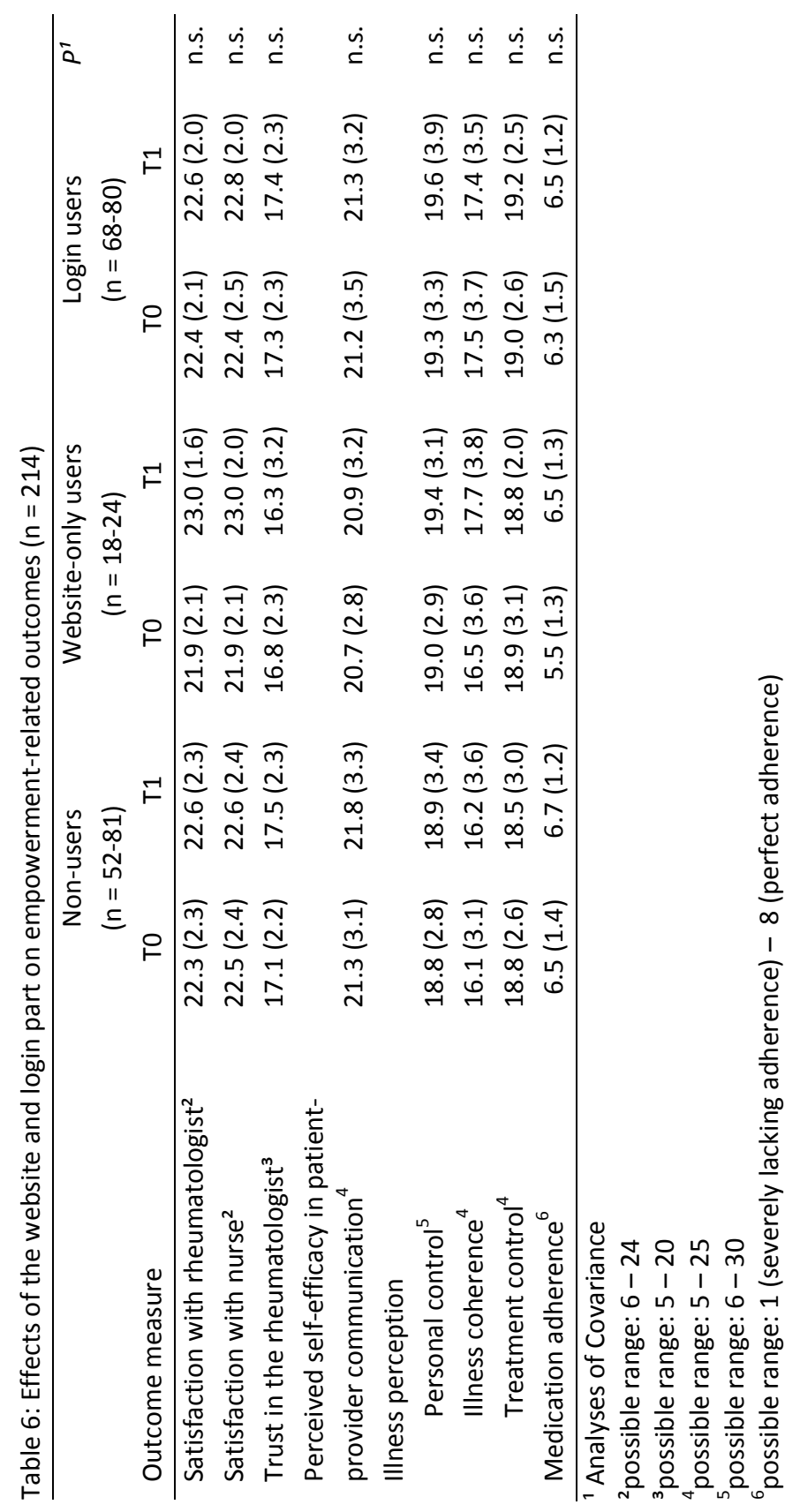


the assessed outcomes (Table 6). It should be noted, however, that ceiling effects at T0 were found for satisfaction with the rheumatologist and nurse, trust in the rheumatologist and self-efficacy in the patient-provider communication, which means that at least $15 \%$ of respondents scored the highest possible score on these outcomes (45\%, 52\%, 30\% and $29 \%$ respectively). Additionally, $56 \%$ scored 7 out of 8 on medication adherence. While this cannot be defined as a ceiling effect, room for improvement is also limited on this outcome.

\section{Discussion}

Our study shows that there is a large interest among rheumatoid arthritis patients for a hospital-based rheumatology web portal. More than half of the respondents with Internet access logged in on the portal, to view their personal data. Also, of all the non-users in our sample only $10 \%$ reported not wanting to use the portal because they were not interested. The other non-users either had no access to the Internet, or intended to visit the portal in the future. Still, it must be noted that these results should be interpreted with care due to a possible response bias. Reported usage from other studies on patient web portals with EMR access varies from only 6\% [32] to up to $86 \%$ [33]. However, it is difficult to compare the results of our study with these previous studies, as they differ widely in types of patient groups and in the additional services that were provided. Notable is that the portion of patients in our study that logged in to view their personal information is much larger than the portion that only viewed the general information on the patient web portal. Previous studies have also found that personal information, and especially laboratory results, are more useful than general information to patients with chronic conditions [13]. Concordantly, we can conclude that our portal with EMR access foresees in a need in these patients.

One of the aims of our study was to investigate determinants of use of the application. Of all the included variables, only age was a significant predictor of general portal use: younger patients were more inclined to visit the portal. This corresponds to what was found in much of the previous research on predictors of use of online applications $[16,17,34]$. Because the mean age of our sample was 62 , our data shows that older generations in the Netherlands do actively use the Internet, the proportion of which will only increase in the upcoming generations. As expected, self-perceived Internet skills and amount of Internet use significantly predicted logging in on the patient web portal. Previous research focusing on adoption of patient web portals, has also found that computer literacy can be a barrier in the uptake of health technologies $[35,36]$. It would be interesting to study whether more active encouragement and guidance from care providers towards patients with low (e)health literacy would affect their interest and use of the application.

Our portal was designed with a strong focus on the end-user, in which patients were invited to be actively involved in the determination of the content and the design of the portal. Also, together with rheumatology care providers, we made an effort to present up to date DAS28 and lab results in a clear overview. Previous studies have shown that care providers are hesitant about patient EMR access because it could confuse patients $[21,37,38]$, but our results show that patients found the portal usable and understandable. 
Additionally, 'mistakes' that were found in the patient-accessible EMR only concerned data that was slightly out-of-date and the few patients that experienced this handled these issues very well. While it should be noted that our patient-accessible EMR contained only a selection from the full medical records, it seems that when implemented carefully, expected drawbacks hardly occur. This confirms that a user-centered design is beneficial in the development of patient web portals. Further research should also explore care providers' experiences with patients who use the portal and the changes in work flow that they perceive, in order to determine to what extent the patient web portal changes health care processes.

Evaluating the impact of the patient web portal, we could not find significant differences over time in empowerment-related outcomes. Nevertheless, patients did report to perceive a larger involvement in, and understanding of, their treatment. Patients also reported that using the portal improved their knowledge of their disease and that they were more capable of understanding their care providers. Most patients reported using the service prior to a consultation, which could indicate that they used it to prepare for the conversation with their doctor or nurse [34,38]. Two recent systematic reviews on the effects of patient web portals with EMR access show that only a few other studies have included empowerment-related outcomes into their evaluations, with small and inconclusive results $[13,10]$. Tuil et al. [9], who conducted a study among patients undergoing IVF treatment, could not detect any enhancement on patient empowerment over time either. Ross et al. [15], who evaluated a portal with EMR access among patients with congestive heart failure, found improvements in medication adherence and a small trend in increased self-efficacy and satisfaction with patient-provider communication. Looking at our data, two explanations could be possible for the lack of change over time. Firstly, the timeframe between both measurements might have been too small. If the posttest had been assessed at a later moment in time, and if patients would have had the chance to use the portal more regularly, especially in relation to more consultations, effects would perhaps have been more visible. Secondly, the instruments used might not have been responsive enough to measure a difference. Large ceiling effects were found on the outcomes before using the patient web portal, leaving little room for improvement. It is conceivable that patients who completed the questionnaires were already satisfied and involved patients, preempting any measurable increase of these outcomes. Perhaps the more subjective method of directly asking patients about the perceived impact might be a more valuable assessment of actual patient web portal impact. To enhance the impact of the portal, more attention might be paid to its content during consultations, so that patients might learn how to use the information from their records for their own benefit $[39,40]$.

In conclusion, a hospital-based rheumatology patient web portal with EMR access offers rheumatoid arthritis patients usable and understandable access to personal information. While the actual impact on patient empowerment is difficult to measure, a large part of patients does feel more informed and involved in their own treatment due to the portal. 


\section{Acknowledgements}

We would kindly like to thank the participants of the surveys, and the rheumatologists and rheumatology secretariat of Medisch Spectrum Twente, Enschede, for their participation and contribution to this study. This work was supported by an unrestricted educational grant from Pfizer Inc. This funding source had no involvement in data collection, analysis or the preparation of this manuscript. 


\section{References}

1 Carlin CS, Christianson JB, Keenan P, Finch M. Chronic Illness and Patient Satisfaction. Health Serv Res 2012; 47(6): 2250-72.

2 Arvidsson S, Bergman S, Arvidsson B, Fridlund B, Tingström P. Psychometric properties of the Swedish Rheumatic Disease Empowerment Scale, SWE-RES-23. Musculoskelet Care 2012; 10(2): 101-9.

3 Ruland CM, Andersen T, Jeneson A, Moore S, Grimsbø GH, Børøsund E, Ellison MC. Effects of an Internet support system to assist cancer patients in reducing symptom distress. Cancer Nurs 2013; 36(1): 6-17.

4 Wagner EH, Austin BT, Davis C, Hindmarsh M, Schaefer J, Bonomi A. Improving chronic illness care: translating evidence into action. Health Affairs 2001; 20: 64-78.

5 Buntin MB, Burke MF, Hoaglin MC, Blumenthal D. The benefits of health information technology: a review of the recent literature shows predominantly positive results. Health Affair 2011; 30(3): 464-71.

6 Fisher B, Fitton R, Poirier C, Stables D. Patient record access - the time has come! Br J Gen Pract 2007; 57(539): 507-11.

7 Eysenbach G. Medicine 2.0: social networking, collaboration, participation, apomediation, and openness. J Med Internet Res 2008; 10: e22.

8 Gravis G, Protière C, Eisinger F, Boher JM, Tarpin C, Coso D, Cappiello, M, Camerlo J, Genre D, Viens P. Full access to medical records does not modify anxiety in cancer patients. Cancer 2011; 117(20): 4796-804.

9 Tuil WS, Verhaak CM, Braat DDM, de Vries Robbé PF, Kremer JAM. Empowering patients undergoing in vitro fertilization by providing Internet access to medical data. Fertil Steril 2007; 88(2): 361-8.

10 Ammenwerth E, Schnell-Inderst P, Hoerbst A. The impact of electronic patient portals on patient care: a systematic review of controlled trials. J Med Internet Res 2012; 14(6): e162.

11 Chaudhry B, Wang J, Wu S, Maglione M, Mojica W, Roth E, Morton SC, Shekelle PG. Systematic review: impact of health information technology on quality, efficiency, and costs of medical care. Ann Intern Med 2006 May 16; 144(10): 742-52.

12 Winkelman WJ, Leonard KJ, Rossos PG. Patient-perceived usefulness of online electronic medical records: employing grounded theory in the development of information and communication technologies for use by patients living with chronic illness. J Am Med Inform Assoc 2005; 12: 306-14.

13 Urowitz S, Smith K, Alkazaz N, Apatu E, Quartey NK, Wiljer D. Patient accessible electronic health records for the chronically ill: a review of the literature. J Hosp Admin 2012; 1(2): 64-72.

14 Goldberg, HI, Ralston JD, Hirsch IB, Hoath JI, Ahmed KI. Using an Internet comanagement module to improve the quality of chronic disease care. Jt Comm J Qual Patient Saf 2003; 29(9): 443-51.

15 Ross SE, Moore LA, Earnest MA, Wittevrongel L, Lin CT. Providing a web-based online medical record with electronic communication capabilities to patients with congestive heart failure: randomized trial. Journal of Medical Internet Research 2004; 6(2): e12. 
16 Grant RW, JS Wald, Schnipper JL, Gandhi TK, Poon EG, Orav EJ, Williams DH, Volk LA, Middleton B. Practice-linked online personal health records for type 2 diabetes mellitus: a randomized controlled trial. Archives of Internal Medicine 2008; 168(16): 1776-82.

17 Or CKL, Karsh B. A systematic review of patients acceptance of consumer health information technology. J Am Med Inform Assoc 2009; 16: 550-60.

18 Norman CD, Skinner HA. eHealth literacy: essential skills for consumer health in a networked world. J Med Internet Res 2006; 8(2): e9.

19 Van der Vaart R, Drossaert CHC, Taal E, Van de Laar MAFJ. Experiences and preferences of patients with rheumatic diseases regarding an interactive health communication application. Proceedings of the 2nd eTELEMED International Conference on eHealth, Telemedicine, and Social Medicine; 2010 Feb, Saint Martin:64-71 doi: 10.1109/eTELEMED.2010.16.

20 Van der Vaart R, Drossaert CHC, Taal E, Van de Laar MAFJ. Patient preferences for a hospital based rheumatology Interactive Health Communication Application, and factors associated with these preferences. Rheumatology 2011; 50(9): 1618-26.

21 Van der Vaart R, Drossaert CHC, Taal E, Van de Laar MAFJ. Giving rheumatology patients online home access to their electronic medical record (EMR): advantages, drawbacks and preconditions according to care providers. Rheumatol Int 2012, ePub ahead of print.

22 Van Gemert-Pijnen JEWC, Nijland N, Van Limburg M, Eng B, Ossebaard HC, Kelders SM, Eysenbach G, Seydel ER. A holistic framework to improve the uptake and impact of eHealth technologies. J Med Internet Res 2011; 13(4): e111.

23 Ishikawa $\mathrm{H}$, Takeuchi T, Yano E. Measuring functional, communicative, and critical health literacy among diabetic patients. Diabetes Care 2008; 31(5): 874-9.

24 Van der Vaart R, Drossaert CHC, Taal E, Ten Klooster PM, Hilderink-Koertshuis RTE, Klaase JM, Van de Laar MAFJ. Validation of the Dutch functional, communicative and critical health literacy scales. Pat Educ Couns 2012; 89(1): 82-8.

25 Van Campen C, Sixma HJ, Kerssens JJ, Peters L, Rasker JJ. Assessing patients' priorities and perceptions of the quality of health care: the development of the quote-rheumatic-patients-instrument. Br J Rheumatol 1998; 37(4): 362-8.

26 Ommen O, Janssen C, Neugebauer E, Bouillon B, Rehm K, Rangger C, Erli HJ, Pfaff H. Trust, social support and patient type-Associations between patients perceived trust, supportive communication and patients preferences in regard to paternalism, clarification and participation of severely injured patients. Patient Educ Couns 2008; 73(2): 196-204.

27 Maly RC, Frank, JC, Marshall GN, DiMatteo MR, Reuben DB. Perceived Efficacy in Patient-Physician Interactions (PEPPI): validation of an instrument in older persons. J Am Geriatr Soc 1998; 46: 889-94.

28 Ten Klooster PM, Oostveen JCM, Zandbelt LC, Taal E, Drossaert CHC, Harmsen EJ, van de Laar MAFJ. Further validation of the 5-item Perceived Efficacy in PatientPhysician Interactions (PEPPI-5) scale in patients with osteoarthritis. Patient Educ Couns 2012; 87(1): 125-30.

29 Moss-Morris R, Weinman J, Petrie KJ, Horne R, Cameron LD, Buick D. The revised Illness Perception Questionnaire (IPQ-R). Psychol Health 2002; 17(1): 1-16. 
30 Morisky DE, Green LW, Levine DM. Concurrent and predictive validity of a selfreported measure of medication adherence. Med Care 1986; 24(1): 67-74.

31 Morisky DE, Ang A, Krousel-Wood M, Ward HJ. Predictive Validity of a Medication Adherence Measure in an Outpatient Setting. J Clin Hypertens 2008; 10(5): 348-54.

32 Zhou Y, Garrido T, Chin H, Wiesenthal A, Liang L. Patient access to an electronic health record with secure messaging: impact on primary care utilization. Am J Manag Care 2007; 13(7): 418-24.

33 Bhavnani V, Fisher B, WinWeld M, Seed P. How patients use access to their electronic GP record: a quantitative study. Fam Pract 2010; 0: 1-7.

34 Kahn JS, Hilton JF, Van Nunnery T, Leasure S, Bryant KM, Hare CB, Thon DH. Personal health records in a public hospital: experience at the HIV/AIDS clinic at San Francisco General Hospital. J Am Med Inf Assoc 2010; 17(2): 224-8.

35 Greenhalgh T, Hinder S, Stramer K, Bratan T, Russell J. Adoption, non-adoption, and abandonment of a personal electronic health record: case study of HealthSpace. BMJ 2010; 341: c5814.

36 Zickmund SL, Hess R, Bryce CL, McTigue K, Olshansky E, Fitzgerald K, Fischer GS. Interest in the use of computerized patient portals: Role of the provider-patient relationship. J Gen Intern Med 2008; 23(Suppl 1): 20-6.

37 Ross SE, Todd J, Moore LA, Beaty BL, Wittevrongel L, Lin CT. Expectations of patients and physicians regarding patient-accessible medical records. J Med Internet Res 2005; 7: e13.

38 Wiljer D, Leonard K, Urowitz S, Apatu E, Massey C, Kwarley Quartey N. The anxious wait: assessing the impact of patient accessible EHRs for breast cancer patients. BMC Med Inform Decis Mak 2010; 10(1): 46.

39 Ralston JD, Hirsch IB, Hoath J, Mullen M, Cheadle A, Goldberg HI. Web-Based Collaborative Care for Type 2 Diabetes: A pilot randomized trial. Diabetes Care 2009; 32(2): 234-9.

40 Osborn, CY, Satterwhite Mayberry L, Mulvaney SA, Hess R. Patient Web Portals to Improve Diabetes Outcomes: A Systematic Review. Curr Diab Rep 2010; 10(6): 42235. 
Chapter 10

General discussion 
The Internet is gaining an increasing impact in health care. Nowadays, many health care institutions and hospitals offer their patients online information, facilities to communicate online with care providers or fellow patients, and tools to improve patients' participation in their treatment process, such as online decision aids, symptom monitoring tools, or home-access to electronic medical records [1-3]. These so-called eHealth applications can improve patient empowerment, and support patients to play a larger role in the management of their disease [4]. In rheumatology, patient involvement in their treatment is highly encouraged. Essential components in the treatment are education and assistance in self-management and coping with the disease [5,6]. Also, regular monitoring of patient reported outcomes such as quality of life and physical functioning have a great potential to enhance treatment [7]. Online information and support applications could contribute to achieve these goals. The aim of this project was to develop and evaluate an Interactive Health Communication Application, or patient web portal, that is provided by the Arthritis Centre Twente. The web portal was designed to contain a variety of services that are needed by patients, which should fit in current clinical practice according to care providers, and should meet the "ehealth literacy" level of patients in order to maximize usability. To reach this goal, a user-centered approach was used. Below, several essential steps in this process will be addressed in which the strengths and limitations of our performed studies, and future directions for research, will be discussed.

\section{Developing eHealth applications with a user-centered approach}

Although patient web portals are increasingly developed and may be beneficial to patients, research has shown that many online health applications are not used by the target group as intended [8]. From a patient viewpoint, this can be explained by the fact that online applications often do not fit the needs of patients or the applications are too complicated to use [8]. From an organizational viewpoint, many eHealth projects are not properly implemented in regular health care processes, because care providers are hesitant to change their workflow, or because the applications are not feasible in clinical practice $[10,11]$. Several stakeholders, such as patients, health professionals and health care institutions can have diverse values and interests which could facilitate or hamper the uptake or implementation in health care. In this project, the CeHRes roadmap [12] was used to develop a patient web portal while taking the needs and skills of the main stakeholders into account.

The use of this approach yielded positive outcomes on several levels. First of all, by using contextual inquiry and value specification as described in chapters 2 and 3 , patients were actively involved and could express their needs concerning online information and support. Second, paying attention to patients' needs and wishes and taking patients seriously might have created commitment to the application among them. Since patients had been involved in, and were updated on the portal, they may have become (more) curious to use it. Third, in the design process (chapter 8) patients were repeatedly asked for their input and feedback on several mock-up versions, to ensure that not only the content, but also the design of the portal would be acceptable and usable for patients. Accordingly, the design was kept simple, using large buttons with icons and not too many layers of information. Previous research has shown that many problems with eHealth 
applications are due to inadequate usability $[13,14]$. In chapter 7 , where a study on patients' eHealth literacy is described, we also found that many websites cause usage problems among our target group. The evaluation of the patient web portal, described in chapter 9, showed that our application succeeded to offer useful (personal) information in an understandable way. While we cannot prove a causal relation between our usercentered development and the positive evaluations on perceived usefulness and ease of use, our findings suggest that including patients in all stages of the development has been successful. We therefore recommend that a user-centered approach should be used in the future development of eHealth applications.

Contextual inquiry and value specification was also used among rheumatology care providers. In chapter 4, we described how care providers were involved to map the benefits or drawbacks of providing patients access to their electronic medical records (EMR). The results showed us that care providers were not keen on providing patients full access to their EMR. However, presenting a selection of all the data in the medical records was perceived as beneficial for patient involvement, by most care providers. In order to keep the information clear and usable to patients, graphs and explanations were developed in close cooperation with care providers. Whereas other studies on evaluations of patient EMR access have found that patients sometimes struggle with understanding their personal information [15-17], this might have been overcome if care providers and patients had been involved in the design of the application. Moreover, by including care providers in the development process we also ascertained that the application was not pushed into the care process; care providers had a voice in the content of the application, and helped in embedding the application in the care process.

Although we feel that including end-users in the developmental process has lead to a better (more patient-centered) portal, the developmental process has not been easy, and we have encountered various challenges during this process. In all phases, the balance between needs, requirements, programming feasibility and available recourses had to be weighed. To reach the best attainable goals with an eHealth application, a multidisciplinary design team of patients, care providers and decision makers, as well as designers and ICT-developers should be included from an early stage in the development. Overall, the studies in this thesis have provided valuable insights into the needs and requirements concerning online information and support within rheumatology. Furthermore, the complete overview of these studies suggests that involving the endusers in all stages of the development adds value to an application on multiple levels. With these positive results, our studies further validated the CeHRes roadmap, and we strongly recommend using such an elaborate stepwise plan in future projects.

\section{Determinants of use for a hospital-based patient web portal}

To date, many health care institutions offer websites for patient information and support. Yet little is known about the uptake of these facilities and the characteristics of the main user groups [9]. Patient web portals differ largely in target population (e.g. primary care, general practitioners offices, or specific chronic conditions [15,18-21]), web portal content (e.g. combinations with e-consultations or self-management support $[18,22,23]$ ) and reported numbers on usage. Previous studies have reported user numbers from only $6 \%$ 
[18] up to $86 \%$ [15]. Our results in chapter 9 showed that $70 \%$ of the respondents with Internet access visited the patient web portal, and more than half logged in to view their EMR. When investigating which variables are associated with use, we found that only higher age and more Internet experience were significant predictors of web portal use. It can be assumed that the strength of these predictors will decrease over time, because the Internet is gaining a larger role in every aspect of our lives and Internet use is increasing throughout the entire population. The results of our evaluation on determinants of use confirm the results of our needs-assessment study in chapter 3 , in which we did not find any other clear associated variables. Previous studies on other patient web portals also do not show consistent predictors $[8,24]$. Overall, this indicates that the use of patient web portals is wide spread among a diverging range of patients.

Still, it would be interesting to investigate if active encouragement and support from care providers could further improve uptake of the portal, especially among the elderly and less Internet experienced patients. Also, experiments with persuasive technology elements, such as reminders when new data is online, might encourage nonusers to log in, or might reinforce adherence to the application among patients that already use it [25].

\section{The value of access to the EMR in empowering patients}

While a growing number of hospitals world-wide is offering patients home-access to their EMR, studies on the impact of this service are scarce [26]. Only a few studies have focused on the effect that patient web portals with EMR access have on the empowerment of patients in their treatment, and none have been performed within rheumatology [27]. Our evaluation study of the web portal in chapter 9 did not show any significant changes in patient empowerment over time. These results agree with what has been found previously in other studies, in which the impact on patient empowerment over time could neither be found $[19,21]$. In our study, possible explanations for the lack of differences between pretest and posttest could be the time frame of the study and the ceiling effects on the outcome measures. Nevertheless, when assessing the perceived impact of the application according to patients, our results suggest a positive effect. Patients who had accessed their EMR indicated that they felt more involved in their treatment and that they had more knowledge about their disease. From the difference between these results one might wonder what the most valid method is to measure change in satisfaction with health care and empowerment, especially when patients already score high on these outcomes at the pre-test. Studies in health care have shown that patients often judge past (health) statuses differently than how they judged the same status in the present, known as response shift [28]. This phenomenon can confound the change over time on empowerment-related outcomes, since patients' judgment of their (past) empowerment will shift. When asking patients retrospectively about changes over time, the measurement will become more subjective. Still, outcomes such as satisfaction with care, trust in professionals, self-efficacy, and treatment control are, in fact, subjective variables.

In our study we were predominantly focused on how access to the EMR could empower patients. However, this application may change rheumatology practice on other levels as well. For example, in chapter 4 we found that some care providers felt patient 
EMR access could require extra work or would change their work processes, because they would have to explain more to patients, or the emphasis of the consultation would lay too much on the EMR. Previous studies have shown inconsistent results on changes in work load due to implementation of a patient web portal [27]. Therefore, studies on the changes that the application has brought about in the care process and in the routines of health care providers would gain insight into the effects of the patient web portal on different outcomes..

\section{Measuring eHealth literacy of patients}

Whereas online applications have the potential to change health care in a positive way, these benefits may not be eminent for everyone. Differences in skills among patients to use online health information and applications [13,29] might cause a digital divide between those who are able to benefit from online services and those who are not $[30,31]$. To properly use all the available services on the Internet, patients need to be eHealth literate; they have to be able to find, understand and apply health information to their own situation, while using electronic sources and taking the validity and reliability of the information into account [29]. To gain insight into the eHealth literacy skills of patients, observational research is needed. However, such studies are scarce $[32,33]$ and no studies previously have been performed on the eHealth literacy of patients. Chapter 7 of this thesis yielded new insights into patients' ability to use the Internet for healthrelated purposes. First of all, our study showed that a considerable number of participants did not have enough operational skills to effectively use a computer and the Internet. Second, the study showed that the majority of participants did not have enough eHealth literacy skills to be critical about online health information. As previous research has found that many of the available websites with information on rheumatic diseases are unreliable $[34,35]$, this lack of skills is worrisome. Care providers should be aware of the discrepancy between available information and patients' competences to use it, and they should have tools to give patients advice about reliable online information. Additionally, it appeared that many patients have little experience using Health 2.0 services and they are quite anxious about using them, which could hinder uptake of such initiatives. We would, therefore, strongly recommend taking the Internet skills of the target group into account when developing eHealth interventions and we suggest that an eHealth literacy scan is included in the CeHRes roadmap.

The methods that were used in chapter 7 to explore patients' eHealth literacy are very time-consuming and not suited for a quick assessment in clinical practice. In Chapters 5 and 6 we examined two instruments that seemed promising to measure a broad spectrum of health literacy [36] and eHealth literacy [37], using self-report questionnaires. These instruments have the potential to gain a quick insight into the (e)Health literacy of patients, however, the main finding of our two studies was that it is complicated to measure actual skills using self-report instruments. We found that items can be interpreted in several ways and that responses often measure a patient's perceived skills, instead of predicting their actual skills. While there are a range of other health literacy instruments [38], none of these instruments measure all essential competencies that are needed to properly use the Internet for health. Our studies lead to the conclusion that the 
development of a comprehensive eHealth literacy instrument is needed. Future studies should focus on the development of a more holistic assessment of eHealth literacy, which measures information-retrieval skills, critical evaluation skills, as well as Health 2.0 skills. To overcome self-report bias, this instrument should contain at least some practice tasks to measure actual skills of patients. For instance, a screen shot showing results from a search engine, out of which patients have to choose the most relevant options, or a screen shot from a website on which patients have to indicate which navigation path should be taken to find specific information.

\section{Practical implications}

While the focus in all our studies was on rheumatology, we feel that the insights gained in this thesis are to a large extent translatable to other disciplines in (chronic) health care. Interactive health communication applications, or patient web portals, can take on any shape, form and content and can impact health care on various levels. Therefore, they can add value to many different fields of health care. The first main recommendation that follows from this thesis is that proper needs and skills assessments are necessary to tailor the application to the target group. When doing so, the application will be grounded in the actual clinical setting, and its use, satisfaction and commitment in clinical practice will be enhanced. Second of all, we recommend that the impact of a patient web portal should be thoughtfully assessed among both patients and care providers over a long time period, in which studies on the impact of patient portals on the care process could deliver valuable insights. Lastly, the eHealth literacy of the specific target group should not be overlooked and awareness of the gaps between ICT-developers and end-users is essential in order to create an application that is usable for patients.

\section{Future directions: "rheumatology 3.0"}

Providing patients access to their electronic medical records and enabling them to monitor disease-related outcomes ("rheumatology 2.0") has been an important step in applying web technology in rheumatology to further involve patients in their treatment. Still, it would be interesting to integrate web applications more fully into clinical practice, to create more personalized health systems ("rheumatology 3.0") [39]. Studies in diabetes care, for example, in which access to the EMR is supported by assignments on datainterpretation and feedback from nurses have shown a positive impact on selfmanagement behavior due to the larger connection between standard care and the facilities on the patient web portal $[22,23]$. In rheumatology, web portals could, for example, be further integrated into clinical practice by letting patients fill in an online preconsultation screening. Such a pre-consultation screening can facilitate adjustment of the treatment at an individual level and could determine the content of a consultation to a certain extent [40]. At the Arthritis Centre Twente such screenings are already used among patients, but the derived data are mainly used for research purposes and are not often actively used in the consultation. Also, the content of the web portal could be adjusted based upon scores on screening instruments and consultations with care providers. Patients could, for instance, be offered an online decision aid if their medication treatment needs adjustment or a psychosocial support module if they score 
above a certain cut off score on psychological distress. Integrating web technology more fully with face-to-face consultations would further enhance the interactivity in rheumatology and would encourage patients further in being the owner of their own care.

In conclusion, this thesis provides an extensive overview of how web technology can be meaningfully integrated into health care. In doing so, requirements of both patients and care providers should be taken into account. Furthermore, proper assessment of patients eHealth literacy is essential, to fit the technology to the capabilities of the target group. Combining all results, this thesis offers perspective on how to further unfold the web technology evolution in the future, both practically and in scientific research. 


\section{References}

1 Dorr D, Bonner LM, Cohen AN, Shoai RS, Perrin R, Chaney E, Young AS. Informatics systems to promote improved care for chronic illness: a literature review. J Am Med Inform Assoc 2007; 14: 156-63.

2 Garcia-Lizana F, Sarria-Santamera A. New technologies for chronic disease management and control: a systematic review. J Telemed Telecare 2007; 13: 62-8.

3 Eysenbach G. Medicine 2.0: social networking, collaboration, participation, apomediation, and openness. J Med Internet Res 2008; 10: e22.

4 Murray E, Burns J, See Tai S, Lai R, Nazareth I. Interactive health communication applications for people with chronic disease. Cochrane Database of Syst Rev 2009; 1.

$5 \quad$ Katz PP. The stresses of rheumatoid arthritis: Appraisals of perceived impact and coping efficacy. Arthritis Care Res 1998; 11: 9-22.

6 Arvidsson S, Bergman S, Arvidsson B, Fridlund B, Tingström P. Psychometric properties of the Swedish Rheumatic Disease Empowerment Scale, SWE-RES-23. Musculoskelet Care 2012; 10(2): 101-9.

7 Buitinga L. Valuation of quality of life in rheumatoid arthritis. (Doctoral Dissertation): University of Twente, the Netherlands; 2012.

8 Or CKL, Karsh B. A systematic review of patients acceptance of consumer health information technology. J Am Med Inform Assoc 2009; 16: 550-60.

9 Wilson EV, Lankton NK. Modeling patients' acceptance of provider-delivered ehealth. J Am Med Inform Assoc 2004; 11: 241-8.

10 Buntin MB, Burke MF, Hoaglin MC, Blumenthal D. The benefits of health information technology: a review of the recent literature shows predominantly positive results. Health Affair 2011; 30(3): 464-71.

11 Karsh BT, Weinger MB, Abbott PA, Wears RL. Health information technology: fallacies and sober realities. J Am Med Assoc 2010; 17: 617-23.

12 Van Gemert-Pijnen JEWC, Nijland N, Van Limburg M, Eng B, Ossebaard HC, Kelders SM, Eysenbach G, Seydel ER. A holistic framework to improve the uptake and impact of eHealth technologies. J Med Internet Res 2011; 13(4): e111.

13 Nguyen BV, Burstein F, Fisher J, Wilson C. Taxonomy of usage problems for improving user-centric online health information provision. AMCIS 2011 Proceedings 2011; 65.

14 Yen P, Bakken S. Review of health information technology usability study methodologies J Am Med Inform Assoc 2012; 19: 413-22.

15 Bhavnani V, Fisher B, WinWeld M, Seed P. How patients use access to their electronic GP record: a quantitative study. Fam Pract 2010; 0: 1-7.

16 Earnest M, Ross SE, Wittevrongel L, Moore LA, Lin, CT. Use of a patient accessible electronic medical record in a practice for congestive heart failure: patient and physician experiences. J Am Med Inform Assoc 2004; 11: 410-7.

17 De Clercq PA, Hasman A, Wolffenbuttel BH. Design of a consumer health record for supporting the patient-centered management of chronic diseases. Stud Health Technol Inform 2001; 84: 1445-9. 
18 Zhou Y, Garrido T, Chin H, Wiesenthal A, Liang L. Patient access to an electronic health record with secure messaging: impact on primary care utilization. Am J Manag Care 2007; 13(7): 418-24.

19 Ross SE, Moore LA, Earnest MA, Wittevrongel L, Lin CT. Providing a web-based online medical record with electronic communication capabilities to patients with congestive heart failure: randomized trial. Journal of Medical Internet Research 2004; 6(2): e12.

20 Grant RW, JS Wald, Schnipper JL, Gandhi TK, Poon EG, Orav EJ, Williams DH, Volk LA, Middleton B. Practice-linked online personal health records for type 2 diabetes mellitus: a randomized controlled trial. Archives of Internal Medicine 2008; 168(16): 1776-82.

21 Tuil WS, Verhaak CM, Braat DDM, de Vries Robbé PF, Kremer JAM. Empowering patients undergoing in vitro fertilization by providing Internet access to medical data. Fertil Steril 2007; 88(2): 361-8.

22 Ralston JD, Hirsch IB, Hoath J, Mullen M, Cheadle A, Goldberg HI. Web-Based Collaborative Care for Type 2 Diabetes: A pilot randomized trial. Diabetes Care 2009; 32(2): 234-9.

23 Osborn, CY, Satterwhite Mayberry L, Mulvaney SA, Hess R. Patient Web Portals to Improve Diabetes Outcomes: A Systematic Review. Curr Diab Rep 2010; 10(6): $422-$ 35.

24 Heart T, Kalderon E. Older adults: Are they ready to adopt health-related ICT? Int J Med Inform 2011, [Epub ahead of print].

25 Kelders SM. Understanding adherence to web-based interventions. (Doctoral Dissertation): University of Twente, the Netherlands; 2012.

26 Ammenwerth E, Schnell-Inderst P, Hoerbst A. The impact of electronic patient portals on patient care: a systematic review of controlled trials. J Med Internet Res 2012; 14(6): e162.

27 Urowitz S, Smith K, Alkazaz N, Apatu E, Quartey NK, Wiljer D. Patient accessible electronic health records for the chronically ill: a review of the literature. J Hosp Admin 2012; 1(2): 64-72.

28 Schwartz CE, Andresen EM, Nosek MA, Krahn GL. Response shift theory: important implications for measuring quality of life in people with disability. Arch Phys Med Rehabil 2007; 88 (4): 529-36.

29 Norman CD, Skinner HA. eHealth literacy: essential skills for consumer health in a networked world. J Med Internet Res 2006; 8(2): e9.

30 Van Dijk, J. The deepening divide. Inequality in the information society. London: Sage, 2005.

31 Warschauer, M. Technology and social inclusion: Rethinking the digital divide. Cambridge, MA: MIT Press, 2003.

32 Hargittai E. Classifying and Coding Online Actions. Soc Sci Comput Rev 2004; 22: 210.

33 van Deursen A, van Dijk J. Internet skills performance tests: are people ready for eHealth? J Med Internet Res 2011; 13(2): e35. 
34 Ansani NT, Vogt M, Henderson BA, McKaveney TP, Weber RJ, Smith RB, Burda M, Kwoh CK, Osial TA, Starz T. Quality of arthritis information on the Internet. Am J Health-Syst Pharm 2005; 62(11): 1184-9.

35 Maloney S, Ilic D, Green S. Accessibility, nature and quality of health information on the Internet; a survey on osteoarthritis. Rheumatology 2005; 44: 382-5.

36 Ishikawa $\mathrm{H}$, Takeuchi T, Yano E. Measuring functional, communicative and critical health literacy among diabetic patients. Diabetes Care 2008; 31: 874-9.

37 Norman CD, Skinner HA. eHEALS: The eHealth Literacy Scale. J Med Internet Res 2006; 8(4): e27.

38 Mancuso JM. Assessment and measurement of health literacy: an integrative review of the literature. Nurs Health Sci 2009; 11: 77-89.

39 Giustini D. Web 3.0 and medicine: make way for the semantic web. BMJ 2007; 335: 1273-4.

40 Greenhalgh J. The applications of PROs in clinical practice: what are they, do they work, and why? Qual Life Res 2009; 18: 115-23. 
Chapter 11

Summary 
This thesis describes the development, implementation and evaluation of a hospital-based patient web portal in which patients are involved in all stages, in order to create a "rheumatology 2.0" application to empower patients in their care process. To reach this, several steps had to be taken which are addressed in the separate chapters.

The first three studies were conducted to explore the needs of (different groups of) patients and health care professionals, regarding the preferred content of the patient web portal. In chapter 2, a qualitative needs-assessment was performed among 18 patients with rheumatic diseases to gain an overview of their current Internet use, their vision on seven online information, communication and participation services which could improve their involvement in treatment, and their motivations to use those tools or not. We found that patients were enthusiastic about a hospital-based patient web portal, especially to find reliable information about the disease and treatment, about care and support, and personal information from their electronic medical records. Patients felt that it could increase the reliability of online information, and because it is a service from the hospital, it would give them confidence to use the application.

In chapter 3, the results of the first study were confirmed in a quantitative survey study, among a representative group of 227 patients with rheumatic diseases. Patients' intentions were examined in relation to the use of eight different online support services. Moreover, differences in needs between patients were explored, related to sociodemographics, health characteristics and health literacy. We found that patients' current health-related Internet use was mainly limited to searching for information. When offered by the hospital, most patients intend to use the web portal for various purposes. In particular the provision of information, the possibility of having online access to their own electronic medical records (EMR), and symptom monitoring when the care provider would use their data in the consultation were appreciated by the patients. Associated variables with reported intentions to use the different services were not found.

In chapter 4, facilitators and barriers according to rheumatology care professionals were explored, related to the online information and support needs of patients. A 2-step Delphi method was used, in which 13 rheumatologists and 9 nurses/nurse practitioners were first interviewed on their opinions, and their perceived preconditions related to patient access to their EMR. Subsequently, the same sample of care providers was asked to fill out a survey, based on the obtained qualitative data, to quantify the responses. The results of this study gave an overview of health professionals' highest regarded benefits and drawbacks concerning this service. The respondents were, overall, positive about providing patients home access to their medical record, because they felt that it might be a valuable next step into patient empowerment and in service towards the patient. We also found consensus on essential requirements, in that security must be optimal and content and presentation of data should be carefully considered.

To improve the accordance between the usability level of the web portal and patients' skills, three studies were performed on patients' (e)health literacy. Since there is no general agreement in literature on how to measure this ability, two promising instruments 
were validated for the Dutch situation. In chapter $\mathbf{5}$, we examined the validity of a Dutch translation of the Functional, Communicative and Critical health literacy scales by Ishikawa et al [2008]. The reliability and the structural, convergent and content validity of this instrument were examined in two quantitative, survey studies (among samples of patients with breast cancer $(n=79)$ and patients with rheumatic diseases $(n=209)$ and in one qualitative study, using cognitive interviewing, among 18 patients with rheumatic diseases. The results showed that the reliability of all scales was high and the convergent validity was satisfactory for functional and communicative health literacy. Nevertheless, the instrument showed floor and ceiling effects, and the comprehension of the items and the suitability of the response options raised some problems. To this end, adaptations to the scales were proposed in order to improve its validity.

In chapter 6 the validity of the eHealth Literacy Scale (eHEALS) was investigated, which is the only existing instrument that aims to measure eHealth literacy. In this study the internal consistency and the construct and predictive validity of a Dutch translation of the eHEALS were investigated in two populations: a sample of patients with rheumatic diseases $(n=189)$, and a stratified sample of the general Dutch population $(n=88)$. In the latter study, the scores on the eHEALS were compared to actual performance on a practice task (respondents were observed while carrying out a number of different tasks on the Internet). Results revealed that in both studies, the eHEALS was assessed as unidimensional and the internal consistency of the scale was high, which makes the reliability adequate. However, our findings suggested that the validity of the eHEALS instrument requires improvement, since the relationship with Internet use was weak and also the expected relationships with age, education, and actual performance on the practice tasks were not significant.

To gain better insight into the actual problems that patients encounter when using the Internet, we performed an observational study in chapter 7. In this study, 15 patients performed six information-retrieval tasks on the Internet, and 16 patients performed three tasks on a hospital-based patient web portal and two tasks on interactive websites. Participants were asked to think aloud while performing the assignments, and screen activities were recorded. The types of problems that patients encountered were categorized, and the frequency of those problems was counted, to provide an overview of the largest difficulties that patients experienced when using the Internet for health-related purposes. Encountered problems could be divided into six sequential categories: (1) operating the computer and Internet browser, (2) navigating and orientating on the web, (3) utilizing search strategies, (4) evaluating relevance and reliability, (5) adding content to the web, and (6) protecting and respecting privacy. The frequency of problems encountered in the study showed that many patients have insufficient skills to properly use the Internet for health-related purposes. To decrease these problems, changes should be made in the design process of websites and online applications, and awareness, measurement, and education in eHealth literacy should be improved.

Using all the results from chapter 2 to 7, the hospital-based patient web portal was designed (www.reumacentrumtwente.nl). Patients and health care providers were 
actively involved in this process, as is described in chapter 8 . The portal offers information about rheumatic diseases, treatments, and available aids and support. Additionally, the portal contains a section only available through login, where patients can find their diagnosis, current medication and medication history, blood results, disease activity, and patients can monitor quality of life related outcomes. In chapter 9, the use, satisfaction and impact of the portal were assessed in a pretest posttest study, among 360 patients suffering from rheumatoid arthritis. Questionnaires assessed patients' sociodemographics, health literacy, Internet use, disease characteristics, and empowerment, before and after launching the web portal. To measure empowerment, patients' satisfaction with care, trust in their rheumatologist, self-efficacy in patient-provider communication, illness perceptions, and medication adherence were assessed. The posttest included questions on use, satisfaction, and self-perceived impact of the portal. Our results showed that the use of the patient web portal was satisfactory and it succeeded to offer patients (personal) information in a usable and understandable way. Age, amount of Internet use, and self-perceived Internet skills significantly predicted portal use. Concerning the impact of the portal, differences over time on the empowerment-related outcomes could not be found, possibly due to the fact that patients were already very positive about their (involvement in) health care, leaving little room for improvement. However, a relevant part of the users reported to feel more involved in their treatment and having more knowledge about their treatment when they were asked about the perceived impact of the patient web portal. Therefore, we can conclude that the portal provides a valuable addition to the care process.

Chapter 10 provides a general discussion and conclusion on the main findings of this thesis. First of all, our studies confirmed that proper needs- and skills assessments are necessary to tailor an online health application to the target group. Both patients and care providers should be involved to ground the application in the actual clinical setting, and to enhance use, satisfaction and commitment in clinical practice. Second, we recommend that the impact of a web portal should be thoughtfully assessed among both patients and care providers over a long time period. Lastly, eHealth literacy of patients plays an essential role in using online information and support for their own benefit. Future research should aim at developing an instrument that measures patients' skills in information-retrieval, critical evaluation of information, and proper use of Health 2.0 services, using practice tasks to overcome self-assessment bias. Combining the results from all the studies in this thesis, we feel that this work has yielded enhanced insight into how to integrate web technology into health care in a meaningful way. Future directions should focus on how online support and face-to-face consultations can become more blended, in order to fully utilize the possibilities that web technology offers to enlarge patients' role in health care. 


\section{Samenvatting}

(Summary in Dutch) 
Reuma is een verzamelnaam voor een groot aantal veelvoorkomende chronische aandoeningen aan het bewegingsapparaat. De aandoeningen kenmerken zich voornamelijk door ontstekingen aan pezen en gewrichten, pijn, stijfheid en moeheid. Dit brengt veel beperkingen met zich mee en mensen met reuma ervaren vaak problemen in het dagelijks leven, bijvoorbeeld met werk, sociale activiteiten en beweging. In de behandeling van reuma neemt het leren omgaan met deze beperkingen een belangrijke plaats in. Patiënten krijgen veel informatie en ondersteuning om te leren wat hun ziekte inhoudt en om te ontdekken waar hun grenzen liggen. Informatie en ondersteuning via het internet kunnen hierbij een waardevolle rol spelen.

Veel mensen gebruiken het internet tegenwoordig al om (gezondheids)informatie op te zoeken en de laatste jaren is er in hoog tempo veel veranderd op het internet waardoor het nu ook gebruikt kan worden voor allerlei interactieve mogelijkheden. Patiënten kunnen bijvoorbeeld contact met elkaar zoeken via een forum en ze kunnen recensies lezen en plaatsen over hun zorgverleners. Ziekenhuizen bieden ook steeds vaker allerlei online mogelijkheden aan voor hun patiënten. Enerzijds is dit bedoeld om de zorg efficienter te maken, anderzijds verhoogt het ook de service vanuit het ziekenhuis, omdat de zorg niet meer hoeft te stoppen bij de deur van het ziekenhuis. Ziekenhuizen bieden bijvoorbeeld de mogelijkheid voor e-consults, waarbij er in een beveiligde omgeving emailcontact mogelijk is tussen een zorgverlener en een patiënt. Ook kunnen patiënten via het internet bijhouden hoe het gaat met hun klachten, waarmee men gemakkelijk inzicht krijgt in het beloop van een ziekte en behandeling over de tijd. Verder bieden een aantal ziekenhuizen patiënten de mogelijkheid om in te loggen in hun persoonlijke medische dossier, zo kunnen patiënten bijvoorbeeld zien hoe hun laatste bloedwaarden waren en wanneer de dosering van hun medicatie is aangepast. Wanneer dit soort mogelijkheden vanuit een ziekenhuiswebsite worden aangeboden, vaak gecombineerd met gezondheidsinformatie, noemen we dit een patiëntenportaal. Uit onderzoek blijkt dat patiëntenportalen de mogelijkheid bieden om patiënten meer te betrekken bij hun eigen ziekte en behandeling. Ook kan het patiënten sterken in de communicatie met hun zorgverleners, omdat ze meer kennis over de behandeling hebben en beter kunnen bijhouden wat er gaande is. De patiënt wordt zo meer eigenaar van zijn of haar behandeling en heeft een meer gelijkwaardige rol ten opzichte van de arts of verpleegkundige (patient empowerment).

Het is echter niet heel eenvoudig om een geschikt patiëntenportaal te ontwikkelen. Uit de literatuur blijkt dat het gebruik van online faciliteiten in de zorg vaak tegenvalt. Patiënten hebben niet altijd behoefte aan datgene wat het ziekenhuis ze biedt, of ze weten niet goed hoe of waarvoor ze de faciliteiten kunnen gebruiken. Zorgverleners zijn ook regelmatig terughoudend als het gaat om online informatie en applicaties. Ze voorzien ingrijpende veranderingen in hun werkprocessen en ze twijfelen of online ondersteuning wel zinvol en kosten-effectief is. Om rekening te houden met al deze zaken is het van belang om een aantal overwegingen zorgvuldig te maken bij het ontwikkelen en implementeren van een online faciliteit of applicatie. In de ontwikkeling van ons patiëntenportaal moet ten eerste rekening gehouden worden met de beoogde doelgroep of eindgebruikers; wat zijn hun wensen en motivaties. Ten tweede moet er rekening gehouden worden met de context waarin het portaal gebruikt moet worden en de inhoud die daarbij belangrijk is. Vervolgens moet het daadwerkelijke portaal zo gebruiks- 
vriendelijk mogelijk ontwikkeld worden, rekening houdend met de vaardigheden van de eindgebruikers. Als vierde moet het portaal geïmplementeerd worden en moeten de eindgebruikers weten dat het er is en hoe het gebruikt moet worden. De laatste stap is de evaluatie, om te kijken of het portaal daadwerkelijk gebruikt wordt, of men tevreden is en of het portaal een nuttige bijdrage levert aan de huidige zorg. Uit eerdere studies blijkt dat er nogal eens voorbij wordt gegaan aan één of meerdere stappen. Er is daardoor nog maar weinig bekend over hoe patiëntenportalen nuttig kunnen worden ingezet, met name in de reumatologie. Om de stappen goed toe te passen is het essentieel om belanghebbenden van verschillende niveaus te betrekken bij het project en om hen in alle stadia van ontwikkeling, implementatie en evaluatie als expert in te schakelen. Het doel van de onderzoeken in dit proefschrift was dan ook om een bruikbaar reumapatiëntenportaal te ontwikkelen wat de rol van reumapatiënten in hun behandeling versterkt.

\section{De inhoud van het reumapatiëntenportaal}

Het doel van het onderzoek in hoofdstuk $\mathbf{2}$ was om in kaart te brengen wat de waarden en wensen van mensen met reuma zijn, als het gaat om online informatie en ondersteuning. Door middel van interviews met 18 patiënten hebben we in beeld gebracht wat het huidige zorggerelateerde internetgebruik van patiënten is en wat voor voor- en nadelen ze zien in verschillende online mogelijkheden. Het ging daarbij om informatie over de ziekte en de behandeling en informatie over de zorg en ondersteuning, maar ook om meer interactieve mogelijkheden. Zo hebben we patiënten gevraagd naar hun mening over online communicatiemogelijkheden, zoals een patientenforum en e-consults met zorgverleners. Daarnaast hebben we gevraagd wat ze vinden van mogelijkheden die hun participatie in de behandeling vergroten, door het bijhouden van symptomen en klachten, of door de mogelijkheid om inzicht te krijgen in hun elektronische medisch dossier. Uit de interviews bleek dat patiënten enthousiast zijn over een portaal vanuit het ziekenhuis, met name om informatie op te zoeken, om vragen te stellen aan zorgverleners, en om hun persoonlijke informatie uit het medisch dossier in te kunnen zien. Het leek patiënten een prettig idee om één webadres te hebben waar betrouwbare en goede informatie te vinden was en het zou hen vertrouwen geven om het internet te gebruiken in relatie met hun zorg.

Hoofdstuk 3 beschrijft een onderzoek om deze resultaten te verifiëren bij een grotere steekproef. Het doel was om te onderzoeken in hoeverre patiënten daadwerkelijk de intentie hadden om het portaal en de verschillende onderdelen van het portaal te bezoeken als het beschikbaar zou zijn. Ook wilden we onderzoeken of er bepaalde kenmerken van patiënten zijn die samenhangen met een hogere intentie om het portaal te gaan gebruiken, bijvoorbeeld geslacht, leeftijd, opleidingsniveau, ernst van de ziekte, of gezondheidsvaardigheden. Een groep van 496 patiënten ontving hiervoor een vragenlijst, waarvan 227 patiënten de vragenlijst invulden. Uit de resultaten bleek dat veel patiënten de intentie hadden om het reumaportaal te gaan gebruiken als het beschikbaar zou zijn. De meeste respondenten gaven aan betrouwbare online informatie vanuit het ziekenhuis erg te zullen waarderen, evenals het inzien van hun persoonlijke gegevens uit het elektronisch medisch dossier. Verder zouden veel patiënten bereid zijn om hun symptomen en (fysiek en mentaal) functioneren te monitoren, mits zorgverleners deze 
informatie zouden gebruiken om te bespreken in het consult en om de behandeling op af te stemmen. Tegen onze verwachtingen in bleken geen van de persoons- of ziektegerelateerde variabelen te correleren met de intentie om (de onderdelen van) het reumaportaal te gaan gebruiken; de wensen van alle respondenten kwamen erg overeen.

Nadat de wensen en behoeftes van patienten duidelijk waren zijn we bij zorgverleners in de reumatologie nagegaan hoe zij de rol van het internet in de zorg zagen. In interviews hebben we 13 reumatologen en 9 verpleegkundigen van verschillende Nederlandse ziekenhuizen gevraagd wat zij als voor- en nadelen zagen van de verschillende mogelijkheden en hoe dit een plek zou kunnen krijgen in hun huidige manier van werken. Hoofdstuk 4 beschrijft de visie van zorgverleners op patiënttoegang tot het elektronisch medisch dossier. De meeste zorgverleners waren hier positief over en dachten dat het patiënten zou kunnen sterken in hun kennis en communicatie. Verder leek het de meesten een waardevolle service naar de patiënt toe, die de zorg transparanter zou maken. Wel had een groot deel van de zorgverleners twijfels over de capaciteiten van patiënten om alle data goed te interpreteren. Ze twijfelden of dit patiënten niet juist ongerust zou maken en of het niet veel meer tijd zou kosten in het consult, omdat ze meer zouden moeten uitleggen en meer aandacht zouden moeten besteden aan zaken die niet van direct belang waren voor de behandeling. De manier waarop de gegevens uit het dossier zouden worden weergegeven aan patiënten speelde daarbij een belangrijke rol volgens veel zorgverleners. Daarom bleek uit de meeste interviews dat zorgverleners een aantal voorwaarden wilden stellen om de service bruikbaar te maken in de praktijk. Om te onderzoeken wat de meest essentiële voorwaarden van zorgverleners waren hebben we na de interviews een korte vragenlijst opgesteld om overeenstemming te vinden over de belangrijkste voor- en nadelen en vereisten voor patiënttoegang tot het elektronisch medisch dossier. Hieruit werd duidelijk dat de meeste zorgverleners van mening waren dat er een filter op het dossier zou moeten komen, zodat patiënten alleen díe gegevens zouden kunnen inzien die zinvol zijn voor hun behandeling en die ook worden besproken in het consult met de arts. Heel concreet konden zorgverleners aangeven welke laboratoriumuitslagen er wel en niet in het patiëntendossier te zien zouden moeten zijn. Ook wilden veel zorgverleners niet dat patiënten inzicht zouden krijgen in hun persoonlijke aantekeningen, omdat hier vaak gedachten of suggesties van de arts in staan die nog moeten worden uitgezocht, wat tot onnodige stress zou kunnen leiden bij patiënten. Al met al werd er uit deze twee fases goed duidelijk hoe we patiënten het beste inzicht konden geven in hun persoonlijke medische gegevens op een manier die goed aansluit bij de werkwijze van zorgverleners.

\section{Vaardigheden om het internet te gebruiken}

Zoals eerder beschreven biedt het internet veel mogelijkheden om patiënten te informeren en om ze meer bij hun zorg te betrekken. Echter, patiënten hebben ook vaardigheden nodig om al die gezondheidsinformatie en applicaties goed te kunnen gebruiken. Men moet de informatie kunnen lezen, interpreteren en er iets mee kunnen doen in het dagelijks leven om er voordeel uit te halen. Dit noemen we gezondheidsvaardigheden ('health literacy'). Bovendien, wanneer de informatie via het internet beschikbaar is moet men ook in staat zijn een computer te bedienen en een 
internetbrowser te gebruiken. In interactieve applicaties moeten mensen daarnaast ook nog zelf informatie toe kunnen voegen aan het internet, goed letten op de beveiliging, en de privacy van zichzelf en anderen in de gaten houden. Deze combinatie van vaardigheden worden ook wel digitale gezondheidsvaardigheden genoemd ('eHealth literacy'). Er is tot nu toe weinig onderzoek gedaan naar de eHealth literacy van patiënten en er bestaat nog geen valide meetinstrument om al deze vaardigheden goed in kaart te brengen. Het is echter van groot belang om digitale gezondheidsvaardigheden te kunnen meten, onder andere om websites en applicaties, zoals het reumaportaal, goed af te stemmen op de vaardigheden van patiënten.

In het onderzoek dat beschreven is in hoofdstuk $\mathbf{5}$ hebben we de validiteit van een (vertaalde versie van een) bestaand meetinstrument onderzocht, wat beoogt om de gezondheidsvaardigheden van patiënten op drie niveaus te meten [Ishikawa, 2008]. Het instrument meet ten eerste functionele gezondheidsvaardigheden die nodig zijn bij het lezen van gezondheidsinformatie, bijvoorbeeld: 'Als $u$ bijsluiters of folders van uw huisarts/het ziekenhuis/de apotheek krijgt, hoe vaak komt het voor dat er woorden of tekens in staan die u niet kent?'. Ten tweede meet het instrument communicatieve gezondheidsvaardigheden, die nodig zijn bij het interpreteren en overbrengen van de informatie op anderen, bijvoorbeeld: 'Als u zelf op zoek gaat naar gezondheidsinformatie, hoe moeilijk vindt $u$ het om de gekregen of gevonden informatie goed te begrijpen?'. Ten derde meet het instrument kritische gezondheidsvaardigheden, deze zijn nodig bij het beoordelen van de informatie op betrouwbaarheid en juistheid, bijvoorbeeld: 'Als u zelf op zoek gaat naar gezondheidsinformatie, hoe moeilijk vindt $u$ het om te beoordelen of de informatie wel op u van toepassing is?'. We hebben twee groepen patiënten de vragenlijst laten invullen, een groep borstkankerpatiënten $(n=79)$ en een groep reumapatiënten $(n=$ 209). Uit de resultaten bleek dat de scores op het instrument niet samenhangen met leeftijd en opleidingsniveau, wat we wel verwacht hadden op basis van de literatuur. Ook bleek dat veel mensen de best mogelijke score haalden op functionele gezondheidsvaardigheden, waardoor de vraag rijst of een zelf-rapportage instrument wel een geschikte methode is om leesvaardigheden te meten. Mensen die laag zouden scoren op functionele gezondheidsvaardigheden hebben immers niet de capaciteit om de vragen in te vullen. Naast deze onderzoeken hebben we een kleine groep mensen $(n=18)$ het meetinstrument laten invullen terwijl ze hardop dachten. Zo kregen we inzicht in hoe deze mensen de vragen invulden. Hieruit bleek dat deelnemers sommige vragen verschillend begrepen en interpreteerden en dat deelnemers moeite hadden om diverse vragen in te vullen met de beschikbare antwoordcategorieën. Gebaseerd op de resultaten van dit onderzoek hebben we daarom aanbevelingen gedaan om het instrument te verbeteren.

In hoofdstuk 6 hebben we een tweede instrument onderzocht, wat zich focust op het meten van digitale gezondheidsvaardigheden; de eHealth Literacy Scale (eHEALS) [Norman, 2006]. Dit instrument was tot nu toe alleen beschikbaar in het Engels en was nog niet gevalideerd. Voorbeeldvragen uit dit instrument zijn: 'lk weet waar ik nuttige gezondheidsinformatie op het internet kan vinden' en 'lk kan onderscheid maken tussen gezondheidsinformatie van hoge en lage kwaliteit op het internet'. Dit instrument hebben we door twee groepen laten invullen, een groep reumapatiënten $(n=189)$, en een groep 
mensen uit de algemene populatie $(n=88$ ). We vonden ook bij deze vragenlijst geen relatie met leeftijd en opleidingsniveau, zoals we wel verwacht hadden. Bij de groep deelnemers uit de algemene populatie zijn de scores op het meetinstrument ook vergeleken met hun daadwerkelijke vaardigheden. Deze mensen werd namelijk gevraagd om een aantal gezondheidsgerelateerde zoektaken op het internet uit te voeren. Het bleek dat de vaardigheden die werden geobserveerd niet significant samenhingen met de vaardigheden die mensen zelf hadden gerapporteerd bij het invullen van het meetinstrument. Op basis van deze resultaten konden we concluderen dat het voor mensen lastig is om met een zelf-rapportage instrument de eigen vaardigheden goed in te schatten. Het meetinstrument meet daardoor niet goed wat het beoogd te meten.

Tot nu toe geven meetinstrumenten weinig duidelijkheid over de digitale gezondheidsvaardigheden van patiënten. Ook is er is tot nu toe nog geen onderzoek gedaan naar deze vaardigheden bij patiënten door middel van observaties. Om beter inzicht te krijgen in de digitale gezondheidsvaardigheden van reumapatiënten hebben we daarom in hoofdstuk 7 een observatie-onderzoek uitgevoerd. In dit onderzoek hebben 15 patiënten vijf zoektaken uitgevoerd op het internet, en 16 patiënten hebben interactieve taken uitgevoerd op het internet; drie taken op een patiëntenportaal en twee taken op interactieve websites. De deelnemers werden gevraagd om hardop te denken terwijl ze de opdrachten uitvoerden. Daarnaast werden hun schermactiviteiten, beeld en geluid opgenomen. Op deze manier kon precies worden geobserveerd hoe deelnemers de opdrachten uitvoerden en tegen welke problemen ze aan liepen. Er werd bijgehouden of patiënten de opdracht goed konden uitvoeren, hoe lang ze hier over deden, welke problemen ze ervaarden en hoe vaak die problemen voorkwamen. Het bleek dat wanneer de opdrachten complexer werden, er minder deelnemers waren die de opdrachten goed konden voltooien en ook de tijd waarin deelnemers de opdracht voltooiden liep dan verder uiteen. Daarnaast bleek het dat de deelnemers weinig ervaring hadden met interactieve applicaties, zoals het gebruiken van een patiëntenforum of het geven van een beoordeling over hun ziekenhuis. De problemen die deelnemers ervaarden konden worden ingedeeld in 6 categorieën: (1) bedienen van de computer en internet browser, (2) navigeren en oriënteren op het web, (3) zoekstrategieën toepassen, (4) relevantie en betrouwbaarheid van informatie beoordelen, (5) eigen tekst toevoegen op het web, en (6) beschermen en respecteren van privacy. Uit de kwantiteit van de problemen konden we concluderen dat een aanzienlijk gedeelte van de deelnemers niet voldoende vaardigheden had om het internet op een geschikte manier te gebruiken. Om deze problemen te voorkomen of verminderen is het van belang om rekening te houden met de digitale gezondheidsvaardigheden van de doelgroep bij het ontwikkelen van een website of online applicatie. Daarnaast zouden zorgverleners hier rekening mee kunnen houden, door patiënten te adviseren over gezondheidsgerelateerd internetgebruik.

\section{Ontwerp, implementatie en evaluatie van het patiëntenportaal}

Op basis van de resultaten uit hoofdstuk 2 tot 7 is er een patiëntenportaal ontwikkeld voor reumapatiënten van het ReumaCentrum Twente in Enschede (www.reumacentrumtwente.nl). In dit stadium werden patiënten ook actief betrokken om te zorgen dat het portaal zo gebruiksvriendelijk mogelijk werd en dat het ontwerp 
patiënten aansprak. Dit is beschreven in hoofdstuk 8. Het patiëntenportaal biedt informatie over reumatische aandoeningen, behandelingen, en beschikbare hulpmiddelen en ondersteuning. Verder bevat het portaal een gedeelte waar patiënten kunnen inloggen. Hier vindt men een overzicht van de diagnose, de huidige medicatie en medicatiegeschiedenis, bloedwaarden en de ziekteactiviteit die tijdens eerdere consults is gemeten. Daarnaast kunnen patiënten hun kwaliteit van leven en fysiek functioneren bijhouden met vragenlijsten en terugzien wat ze eerder hebben ingevuld.

In het onderzoek wat beschreven is in hoofdstuk $\mathbf{9}$ is het gebruik, de tevredenheid en de impact van het patiëntenportaal onderzocht. In totaal hebben 360 patiënten met rheumatoïde artritis twee keer een vragenlijst ingevuld; een voormeting voorafgaand aan de implementatie van het reumaportaal en een nameting nadat het portaal vijf maanden online was. Patiënten hebben in beide vragenlijsten dezelfde vragen ingevuld over hun demografische gegevens, health literacy, internetgebruik, hun reuma en hun rol in de behandeling. Om de rol van patiënten in de behandeling te meten hebben we verschillende gestandaardiseerde meetinstrumenten gebruikt om inzicht te krijgen in hun tevredenheid met de zorg, hun vertrouwen in de reumatoloog, hun gevoel van zelfvertrouwen in de communicatie met zorgverleners, hun perceptie van de ziekte en de behandeling, en hun medicatietrouw. De nameting bevatte, naast dezelfde vragen uit de voormeting, ook vragen over het gebruik van het patiëntenportaal, de tevredenheid ermee en de ervaren impact die het portaal heeft op de betrokkenheid van patiënten bij de behandeling. De resultaten van deze vragenlijsten lieten zien dat het gebruik van het portaal goed was, $70 \%$ van de respondenten met toegang tot het internet hadden het portaal bezocht, en $54 \%$ had ingelogd om hun persoonlijke gegevens te bekijken. De respondenten waren erg tevreden met de gebruiksvriendelijkheid van het portaal en ze konden alle informatie goed begrijpen. Het bleek verder dat leeftijd en de mate van internetgebruik voorspellend waren voor het gebruik van het patiëntenportaal. Respondenten die jonger waren en respondenten die meer ervaren waren met het internet maakten significant vaker gebruik van het portaal. Wat betreft de impact van het portaal konden we geen verschillen vinden tussen de voor- en nameting op de gestandaardiseerde meetinstrumenten. Een verklaring hiervoor kan zijn dat de respondenten vooraf al erg positief waren over hun (rol in de) zorg, waardoor er weinig ruimte was om nog hoger te scoren op de instrumenten. Wel gaf een behoorlijk deel van de respondenten in de nameting aan dat ze een verschil ervaarden in hun rol in de behandeling; ze voelden zich meer betrokken bij de zorg en ze hadden het gevoel meer kennis te hebben doordat ze konden inloggen in hun persoonlijke medische dossier. We kunnen daarom concluderen dat het portaal wel degelijk iets heeft toegevoegd aan de zorg die de patiënten ontvangen.

Hoofdstuk 10 biedt een algehele discussie en conclusie van de gevonden resultaten van de onderzoeken in dit proefschrift. Ten eerste hebben onze studies laten zien dat onderzoek naar behoeftes en vaardigheden van de eindgebruikers belangrijk is bij het ontwikkelen van een online (gezondheids)applicatie. Zowel patiënten als zorgverleners moeten betrokken worden in het gehele proces om te zorgen dat de applicatie een aanvullende rol krijgt in de behandeling van patiënten en zodat het gebruik, de 
tevredenheid en de betrokkenheid bij de applicatie verhoogd worden. Daarnaast is het van belang dat de impact van de applicatie zorgvuldig wordt onderzocht. Wij raden aan om dit niet alleen onder patiënten te doen, maar ook onder zorgverleners. Daarbij is onderzoek naar het effect op de werkprocessen in de zorg ook interessant, om te bestuderen in hoeverre een online applicatie in praktisch opzicht verschil maakt. Als laatste spelen digitale gezondheidsvaardigheden een essentiële rol in het gebruik van online informatie en applicaties. Omdat een geschikt meetinstrument voor deze vaardigheden nog niet voor handen is zou vervolgonderzoek zich hierop moeten richten. Een nieuw instrument zou de online zoek- en beoordelingsvaardigheden van patiënten moeten meten en ook het gebruik van interactieve applicaties mee moeten nemen, bij voorkeur met behulp van een praktijktest. De combinatie van al onze studies geeft nieuwe inzichten in hoe webtechnologie op een waardevolle manier kan worden ingezet in de gezondheidszorg. Vervolgonderzoek zou zich kunnen richten op het uitbreiden van de rol van webtechonologie in de zorg, zodat fysieke consulten en online ondersteuning optimaal gecombineerd kunnen worden om de rol en de kracht van de patiënt in de behandeling te blijven vergroten. 


\section{Dankwoord \\ (Acknowledgements in Dutch)}


De afgelopen jaren heb ik als enorm leerzaam ervaren en ik heb met veel plezier aan mijn onderzoek gewerkt. Voor een groot deel heb ik dat te danken aan alle fijne mensen in mijn omgeving die me hebben bijgestaan op professioneel en persoonlijk vlak. Op deze laatste pagina's wil ik graag de gelegenheid nemen om een aantal mensen persoonlijk te bedanken.

Stans, zonder jou zou dit proefschrift niet zijn geworden wat het nu is. Ik bewonder je visie en je wetenschappelijk inzicht enorm. Ik heb veel van je geleerd de afgelopen jaren en ben je erg dankbaar voor al je toegewijde begeleiding. Ook persoonlijk konden we het goed vinden en ik vond het erg fijn dat ik altijd even bij je binnen kon lopen om iets te vragen of iets te delen. Het laatste jaar heb ik zelfs allerlei ochtendrituelen van je mogen leren kennen, in de trein. Ik ben blij dat we elkaar daar de komende tijd in ieder geval nog blijven zien. Bedankt voor alles.

Erik, je objectieve blik en oog voor detail waren enorm waardevol voor de inhoud van dit proefschrift. Je statistische kennis heeft me erg geholpen bij het analyseren van de data en je vond altijd nog wel ergens een foutje in één van de tabellen. Bedankt voor je begeleiding en betrokkenheid.

Mart, door jou kon dit project ontstaan en je gaf me de kans om er aan te beginnen, bedankt voor je vertrouwen in mij. Door de nauwe samenwerking met het MST heb ik ook een inkijkje gekregen in het reilen en zeilen van een polikliniek, ik heb daar veel van geleerd en ben daar erg dankbaar voor.

Leden van de commissie, hartelijk bedankt voor de tijd en moeite die jullie hebben genomen om mijn proefschrift te lezen. Prof. dr. Stanton Newman, thank you for your time and effort to read and evaluate my thesis. Prof. dr. Karlein Schreurs, prof. dr. Robbert Sanderman, prof. dr. Jan Kremer, prof. dr. Marjolijn Sorbi en dr. Lisette van Gemert-Pijnen bedankt voor het zitting nemen in mijn promotiecommissie. Marjolijn, jij hebt me als pas afgestudeerde kennis laten maken met de wetenschappelijke wereld, bedankt daarvoor! Lisette, door jou kon ik dit jaar als post-doc aan de slag en heb ik weer een nieuwe uitdaging in het onderzoek, dankjewel!

Wiepke en Harald, zonder jullie betrokkenheid vanuit het MST was het portaal er misschien nooit gekomen, of in ieder geval nooit op tijd voor mij, om het onderzoek uit te kunnen voeren. Bedankt voor al jullie inzet en voor de fijne samenwerking. Nancy en Mirjam, jullie bedankt voor de ondersteuning tijdens de ontwikkeling van het portaal en tijdens het uitvoeren van de evaluatiestudie.

Alle andere reumatologen, verpleegkundigen en secretaresses van het ReumaCentrumTwente, bedankt voor jullie betrokkenheid en jullie enthousiasme over het portaal. Alle deelnemende patiënten van het ReumaCentrumTwente, enorm bedankt voor jullie deelname aan mijn onderzoek. Zonder jullie was het uiteraard niet mogelijk om dit onderzoek uit te voeren en was het portaal niet geworden zoals het nu is. 
Jan Wijnand Hoek, Willem Smith, Wouter Bouvy, Danny ter Avest en Menno van der Werff, jullie wil ik graag bedanken voor je bijdrage in de ontwerp- en ontwikkelfase van het portaal.

Alle co-auteurs van mijn artikelen, hartelijk bedankt voor jullie bijdrage en samenwerking. Tijdens het opzetten, uitvoeren en opschrijven van mijn onderzoek zijn een aantal collega's en studenten in het bijzonder betrokken geweest die ik graag persoonlijk wil bedanken. Han Repping-Wuts, Alexander van Deursen en Peter ten Klooster, bedankt voor jullie expertise en de fijne samenwerking. Miriam de Heus, Ellen Meenhuis en Jurrie Eijhuisen, bedankt voor jullie bijdrage aan mijn onderzoek, jullie inzet was onmisbaar in het uitvoeren van mijn (e)health literacy studies!

Beste collega's van de afdeling Psychologie, Gezondheid en Technologie, de sfeer en collegialiteit op de afdeling waardeer ik enorm. Bedankt voor alle ondersteuning, advies en gezellige praatjes de afgelopen jaren.

Met een aantal collega's heb ik een speciale band opgebouwd. Lieve meiden van 'de gang', Marloes, Martine, Laurien, Rilana, Maria, Pia, Stephy, Sanne, Ingrid, Saskia en Jojanneke, wat ben ik blij dat ik jullie heb leren kennen. Door jullie ben ik me thuis gaan voelen in Enschede en aan alle leuke etentjes, uitjes en feestjes van de afgelopen jaren heb ik veel mooie herinneringen. Ik ben erg blij dat we onze traditie zo goed volhouden en regelmatig samen gaan eten. Ook alle andere aio's en nieuwe kamergenootjes van de afdeling wil ik graag bedanken voor de gezellige lunchwandelingen en leuke momenten: Hester, Roos, Petra, Jobke, Laura, Anne Marie, Nienke, Nadine, Martijn, Liseth, Nienke, Maarten, Floor, Lex en Olga. Ik kan niet wachten om straks met jullie allemaal mijn feestje te vieren!

Mijn paranimfen, ik vind het super fijn dat jullie me bijstaan tijdens mijn verdediging en jullie verdienen een speciaal woord van dank. Marloes, mijn kamergenootje in de Citadel, wat was het fijn om zoveel met je te kunnen delen. Op maandag kon ik altijd bij iemand mijn weekend uit de doeken doen en door de jaren hebben we samen veel kunnen lachen en soms ook samen kunnen huilen (iets met weinig inspiratie en veel transpiratie..). Bedankt voor alles! Martine, we ontmoetten elkaar voor het eerst op een cursus in de bossen van Amersfoort en hadden toen nooit gedacht dat we elkaar jaren later heel goed zouden leren kennen in diezelfde bossen, tijdens onze vele woensdag-thuiswerkdagwandelingetjes, maar dan als collega's, buurvrouwen en trein-maatjes! Bedankt dat je er zo veel voor me bent de laatste tijd.

Hard werken gaat bij mij hand in hand met 'hard' ontspannen en daar heb ik vooral mijn familie en vriendinnen voor. Daarom wil ik hen op deze plaats ook graag bedanken.

Lieve vriendinnen uit Ermelo, Utrecht en omgeving, bedankt voor al jullie interesse in mijn werk. Maar, vooral bedankt voor alle momenten dat ik even niet aan werk hoef te denken tijdens onze vele gezellige momenten. Ik weet dat ik altijd bij jullie terecht kan voor alles wat me bezig houdt, jullie zijn me erg dierbaar! 
Lieve Marja en Jannes, bedankt voor al jullie oprechte interesse in mijn onderzoek en alle goede zorgen. Ik ben heel blij dat ik me zo thuis mag voelen bij jullie en kan me geen fijnere schoonfamilie wensen.

Lieve Renate, mijn zussie, nu zijn we toch nog bijna tegelijk 'afgestudeerd'! Ik ben blij dat we zoveel kunnen delen en dat ik je grote zus mag zijn. Niels, ontzettend bedankt voor de prachtige omslag van mijn proefschrift, ik heb heel veel bewondering voor je creativiteit en ben erg blij met zo'n leuke zwager.

Lieve pap en mam, bedankt voor alles wat jullie me altijd gegeven hebben en bedankt voor jullie grote vertrouwen in mij. Door de combinatie van paps' kritische kijk op zaken en mams' grote doorzettingsvermogen ben ik waar ik nu ben. Ik ben blij dat ik tegenwoordig weer wat dichter bij Ermelo woon en gemakkelijker bij jullie langs kan komen. Het is altijd fijn om thuis te komen.

Lieve Jason, mijn persoonlijke native speaker, mijn steun en toeverlaat, mijn homeboy, bedankt dat je er altijd voor me bent. 


\section{List of publications}

Van der Vaart R, Drossaert CHC, De Heus M, Taal E, Van de Laar MAFJ. Measuring actual eHealth literacy among patients with rheumatic diseases: a qualitative analysis of problems encountered using Health 1.0 and Health 2.0 applications. J Med Internet Res 2013; 15(2): e27.

Van der Vaart R, Repping-Wuts H, Drossaert CHC, Taal E, Knaapen-Hans HKA, Van de Laar MAFJ. Needs for online information and support of patients with Systemic Sclerosis. Arthrit Care Res 2013; 65(4): 594-600.

Van der Vaart R, Drossaert CHC, Taal E, Ten Klooster PM, Hilderink-Koertshuis RTE, Klaasse JM, Van de Laar MAFJ. Validation of the Dutch functional, communicative and critical health literacy scales. Patient Educ Couns 2012; 89(1): 82-8.

Van der Vaart R, Drossaert CHC, Taal E, Van de Laar MAFJ. Giving rheumatology patients online home access to their electronic medical record (EMR): advantages, drawbacks and preconditions according to care providers. Rheumatol Int 2012; Epub ahead of print.

Van der Vaart R, Van Deursen AJAM, Drossaert CHC, Taal E, Van Dijk JAMG, Van de Laar MAFJ. Does the eHealth Literacy Scale (eHEALS) Measure What it Intends to Measure? Validation of a Dutch Version of the eHEALS in Two Adult Populations. J Med Internet Res 2011; 13(4): e86.

Van der Vaart R, Drossaert CHC, Taal E, Van de Laar MAFJ. Patient preferences for a hospital-based rheumatology Interactive Health Communication Application and factors associated with these preferences. Rheumatology 2011; 50(9): 1618-26.

Van der Vaart R, Drossaert CHC, Taal E. Van de Laar MAFJ. Experiences and preferences of patients with rheumatic diseases regarding an Interactive Health Communication Application. Int J Adv Life Sci 2010; 3(3\&4): 143-53.

Sorbi MJ, Van der Vaart R. User acceptance of an Internet training aid for migraine selfmanagement. J Telemed Telecare 2010; 16(1): 20-4. 